\section{OAK RIDGE \\ NATIONAL \\ LAEORATORY}

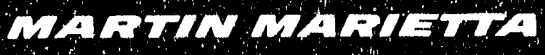

\title{
A Shared Data Environment for the Military Traffic Management Command Directorate of International Traffic
}

\author{
D. L. Russell \\ L. F. Truett \\ V. V. Wheeler
}


This report has been reproduced directly from the best available copy.

Available to DOE and DOE contractors from the Office of Scientific and Technical Information, P.O. Box 62, Oak Ridge, TN 37831; prices available from (615) 576-8401, FTS 626-8401.

Avallable to the public from the National Technical Information Service, U.S. Department of Commerce, 5285 Port Royal Rd., Springfield, VA 22161.

This report was prepared as an account of work sponsored by an agency of the United States Government. Neither the United States Government nor any agency thereof, nor any of their employees, makes any warranty, express or implied, or assumes any legal liability or responsibllity for the accuracy, completeness, or usefulness of any information, apparatus, product, or process disclosed, or represents that its use would not infringe privately owned rights. Reference herein to any specific comrnercial product, process, or service by trade name, trademark, manufacturer, or otherwise, does not necessarily constitute or imply its endorsernent, recommendation, or favoring by the United States Government or any agency thereot. The views and opinions of authors expressed herein do not necessarily state or reflect those of the United States Governinent or any agency thereof. 
Energy Division

A SHARED DATA ENVIRONMENT FOR THE MILITARY TRAFFIC MANAGEMENT COMMAND DIRECTORATE OF INTERNATIONAL TRAFFIC
D. L. Russell*
L. F. Truett
V. V. Wheeler*

January 1992

* University of Tennessee, Knoxville

Prepared for the

MIIITARY TRAFFIC MANAGEMENT COMMAND

DIRECTORATE OF INTERNATIONAL TRAFFIC

Falls Church, Virginia 22041-5050

under

Interagency Agreement DOE No. 1405-1351.A1

Prepared by the

OAK RIDGE NATIONAL LABORATORY

Oak Ridge, Tennessee 37831

managed by

MARTIN MARIETTA ENERGY SYSTEMS, INC.

for the

U.S. DEPARTMENT OF ENERGY

under contract DE-AC05-84OR21400 


\section{CONTENTS}

LIST OF FIGURES AND TABLES $\ldots \ldots \ldots \ldots \ldots$

EXECUTTVE SUMMARY $\ldots \ldots \ldots \ldots \ldots \ldots \ldots \ldots \ldots \ldots \ldots \ldots \ldots$

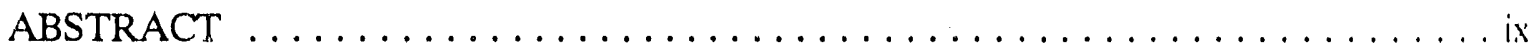

1. OVERVIEW $\ldots \ldots \ldots \ldots \ldots \ldots \ldots \ldots \ldots \ldots \ldots \ldots \ldots \ldots \ldots \ldots$

1.1 PURPOSE OF THIS ANALYSIS $\ldots \ldots \ldots \ldots \ldots \ldots \ldots \ldots \ldots$

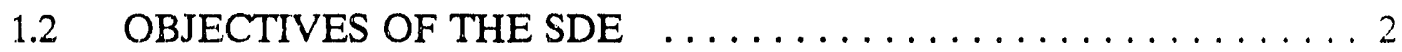

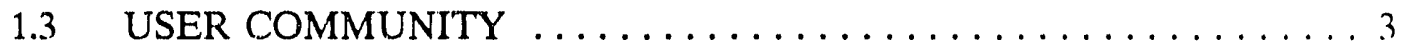

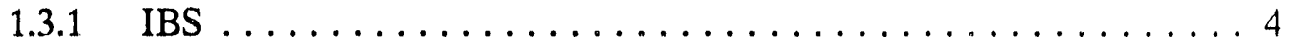

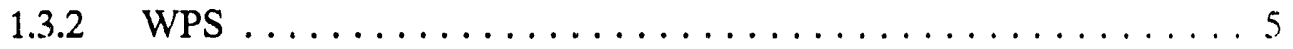

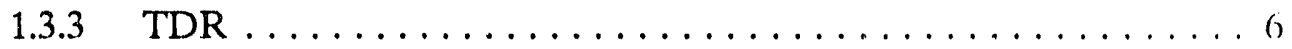

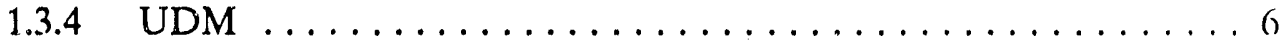

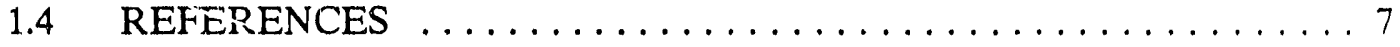

1.5 TERMS AND ABBREVIATIONS ...............

2. GENERAL REQUIREMENTS OF THE SDE $\ldots \ldots \ldots \ldots \ldots \ldots \ldots \ldots \ldots 11$

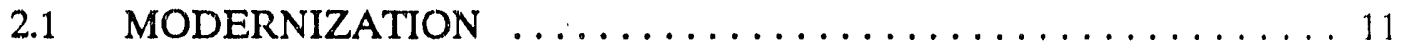

2.2 COMPLIANCE WTTH STANDARDS $\ldots \ldots \ldots \ldots \ldots \ldots \ldots \ldots$

2.3 FUNCTIONAL REQUIREMENTS $\ldots \ldots \ldots \ldots \ldots \ldots \ldots \ldots \ldots$

2.3.1 Database Inquiries and Reports . . . . . . . . . . . 13

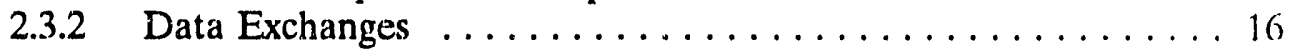

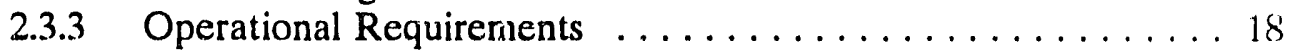

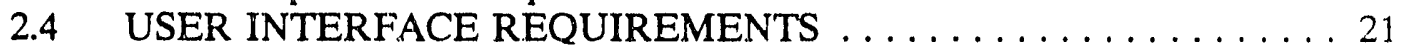

2.5 ADDITIONAL ASSUMPTIONS ................. 21

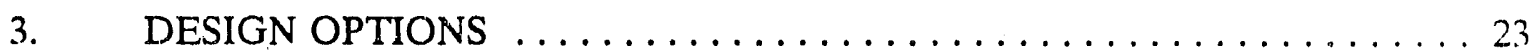

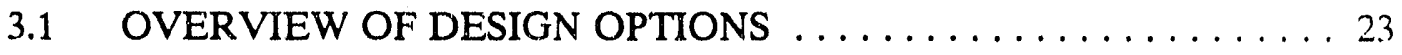

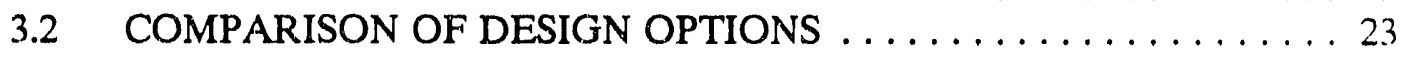

3.2.1 Option 1: Inclusion of the SDE within IBS or WPS . . . . . . 24

3.2.2 Option 2: The SDE as a Separate System ............. 27

3.2.3 Option 3: The SDE as a Distributed Database .......... 28

3.3 EXAMPLE: CREATING, DISTRIBUTING, AND

MODIFYING THE SHIP MANIFEST $\ldots \ldots \ldots \ldots \ldots \ldots \ldots \ldots . \ldots \ldots$

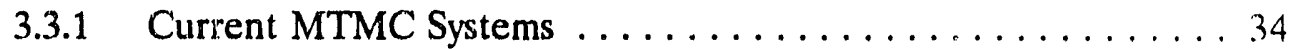

3.3.2 Proposed MTMC Systems .................... 36

3.3.3 Problems with Existing/Proposed Systems . . . . . . . . . . 37

3.3.4 Discussion of Design Options . . . . . . . . . . . . . 39

3.4. ADDITIONAL DATABASE DESIGN ISSUES . . . . . . . . . 41

3.4.1 Logical Data Model and Data Dictionary . . . . . . . . . . 41

3.4.2 Database Integrity and Data Quality ............... 42 


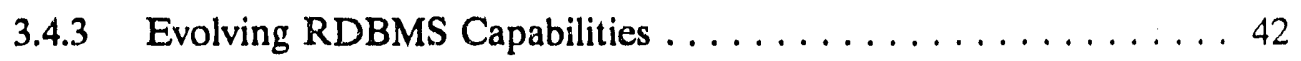

4. PROTOTYPE DATA DICTIONARY $\ldots \ldots \ldots \ldots \ldots \ldots \ldots \ldots \ldots$

4.1 GENERAL DESCRIPTION OF THE SOFTWARE TOOL . . . . . . 45

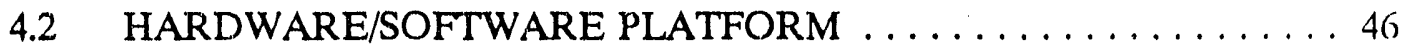

4.3 DATABASE ORGANIZATION ................. 47

4.4 RETRIEVAL AND MAINTENANCE APPLICATIONS . . . . . . . . 47

4.5 POSSIBLE FURTHER DEVELOPMENT . . . . . . . . . . . . 48

5. SUMMARY AND RECOMMENDATIONS $\ldots \ldots \ldots \ldots \ldots \ldots \ldots \ldots$

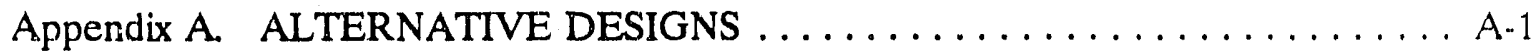

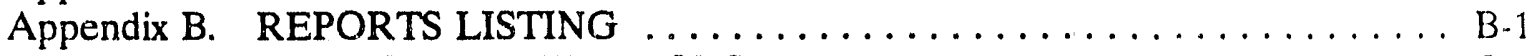

Appendix C. SDE FIELD DEFINITIONS $\ldots \ldots \ldots \ldots \ldots \ldots \ldots \ldots \ldots \ldots \ldots \ldots \ldots \ldots$

Appendix D. SDE FIELD CROSS REFERENCE $\ldots \ldots \ldots \ldots \ldots \ldots \ldots \ldots \ldots$ D-1

Appendix E. SYSTEM FIELD CROSS REFERENCE $\ldots \ldots \ldots \ldots \ldots \ldots \ldots \ldots$ E-1

Appendix F. IBS PROTOTYPE SCHEMA $\ldots \ldots \ldots \ldots \ldots \ldots \ldots \ldots \ldots \ldots \ldots$

Appendix G. WPS PROTOTYPE SCHEMA $\ldots \ldots \ldots \ldots \ldots \ldots \ldots \ldots \ldots$ G-1

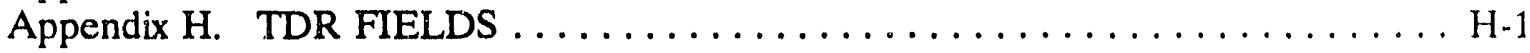

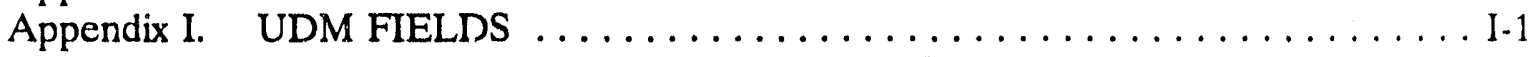

Appendix J. PROTOTYPE DATA DICTIONARY SCHEMA $\ldots \ldots \ldots \ldots \ldots \ldots . .$.

Appendix K. PROTOTYPE DATA DICTIONARY SCRIPTS . . . . . . . . . K-1

Appendix L. EXAMPLES OF SCRIPT USAGE AND OUTPUT . . . . . . . . . L L-1 


\section{LIST OF FIGURES AND TABLES}

Figure

3.1 Inclusion of the SDE Within IBS or WPS (Option 1) $\ldots \ldots \ldots \ldots \ldots \ldots$

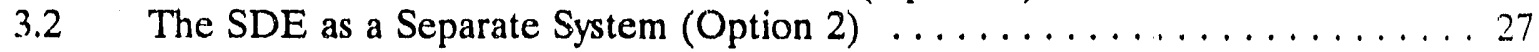

3.3 The SDE as a Distributed Database (Option 3) . . . . . . . . . . . . 29

Table

2.1 Principal Fields for SDE Query Formulation $\ldots \ldots \ldots \ldots \ldots \ldots \ldots \ldots$

2.2 Quality Factors to Be Tested During SDE Software Development . . . . . . . 20 


\section{EXECUTTVE SUMMARY}

The Military Traffic Management Command (MTMC) Directorate of International Traflic (MTIT) requested the assistance of Oak Ridge National Laboratory (ORNL) in the analysis of a potential Shared Data Environment (SDE) for MTIT automated systems. This report describes ORNL's understanding of this SDE at the end of September 1991. The SDE envisioned by ORNL is not merely a repository of information required by users of MTIT systems; it is a full-fledged system that provides MTMC high-level access to and control over international cargo traffic processes. SDE objectives are to provide global visibility for international cargo traffic, support data exchanges, maintain historical data for analysis, automate the processing of shared data, conform to standards for data elements, and provide a consistent set of standard MTIT cargo management data elements.

The primary MTIT systems to be participating in the SDE [the Integrated Booking System (IBS) and the Worldwide Port System (WPS)] are currently under development. ORNL analyzed the information that is available from prototypes of these systems and examined three design options: (1) inclusion of the SDE within IBS or WPS, (2) the SDE as a separate system, and (3) the SDE as a distributed database.

One of the requirements of the SDE is to assist with ship manifest production and distribution. ORNL examined manifest requirements and discussed manifesting in relation to each of the three design options. Based on a general analysis of MTIT objectives for the SDE and a specific analysis of manifest production and distribution, ORNL recommends the development of an SDE architecture that includes the following aspects:

- a loosely coupled, replicated database that encompasses (initially) all IBS and WPS sites,

- high-speed communications among all SDE sites,

- remote access capabilities for SDE users at non-SDE sites,

- a distributed relational database management system (DBMS) that is capable of supporting a single-system perception of data that is physically partitioned among DBMSs from various vendors,

- identification of the data requirements and generation of the physical schema for supporting high-value transactions,

- agreement on message formats and transfer procedures for low-value transactions, and 
- a reevaluation of computing resources (particularly memory and disk space) for IBS and WPS.

ORNL developed a software tool to aid in comparing the data elements of participating systems. This tool, based on Unix shell scripts that access Ingres database management software, was implemented on an Intel 486-based personal computer. ORNL analyzed information that is available from prototypes of IBS and WPS as well as information available from two other systems which are potential users of the SDE: the Transportation Discrepancy Report (TDR) and the Unit Deployment Manifest (UDM) ship tracking system used in the Headquarters MTMC Emergency Operations Center. The software tool used for this data analysis can be adapted by MTTT for future comparison of databases that were not analyzed by ORNL. This prototype data dictionary tool and some of its results are described in this document. 


\begin{abstract}
In September 1991, Oak Ridge National Laboratory (ORNL) completed tasking to assist the Military Traffic Management Command Directorate of International Traffic (M'TIT) in the analysis of a potential Shared Data Environment (SDE) for MTIT automated cargo tralfic systems. This analysis was a preliminary effort with emphasis on documentation of requirements, examination of design alternatives, and identification of specific MTIT systems' diata sharing problems. This report records the results of the ORNL analysis.

The SDE envisioned by ORNL at this point in the analysis is not merely a repository of information; it is a also a system that allows processing of distributed data. To provide highlevel access to and control cuer international cargo processes, ORNL recommends a loosely coupled, replicated database design with high-speed communications among all sites.
\end{abstract}




\section{OVERVIEW}

\subsection{PURPCSE OF THIS ANALYSIS}

This analysis was conducted by Oak Ridge National Laboratory (ORNL) for the Department of Defense (DOD) Military Traffic Management Command (MTMC) Directorate of International Traffic (MTIT). ORNL studied the possibilities of and problems in developing a shared data environment (SDE) ${ }^{1}$ for MTIT. This report describes the general requirements of the SDE, possible architectural designs, and technical istues. It also includes a description of a software tool developed by ORNL for MTIT which aids in comparing the data elements of participating systems and producing reports. Reports from this rudimentary data dictionary tool, running under UNIX on a personal computer (PC), include a preliminary draft SDE data dictionary and a mapping of data elements in the proposed corporate database to those in each contributing system.

It must be noted that this report is based on incomplete information concerning the nature of the SDE envisioned by MTIT and on an initial understanding of the systems and data elements involved. It contains the results of the ORNL requirements analysis as of the end of September 1991, a recommendation for the proposed corporate database design, and output products from the software tool. The primary audience for this document is the group of MTMC personnel who must determine the research and system development path for a corporate database. Additional tasking to be performed by ORNL will extend the results presented in this report.

\footnotetext{
"Throughout this report, the terms "shared data environment" and "corporate database" are used interchangeably to describe the proposed integration of MTIT processes that support worldwide traffic management of surface cargo.
} 


\subsection{OBJECTIVES OF THE SDE}

MTTT systems support traffic management of surface cargo worldwide. From initial booking to final delivery of the cargo at the Port of Debarkation (POD), MTIT needs to have continuous access to information about international cargo movement. Currently data is contained in several systems operated by various organizations within MTMC, by shippers and carrie ${ }_{\iota}$ s, and by MTIT individual sites. In addition, much of the tracking of cargo movement is handled manually. Data sharing among these organizations is eithe nonexistent or primitive and slow. The objectives of the SDE, at this time, are as follows:

- To provide "global visibility" (status, from booking through manifesting) for international surface cargo movement and support for automated tracking mechanisms.

- To support communications to and from participating organizations and systems and to facilitate data exchanges.

- To provide a limited (two years) source of historical data for analysis.

- To provide certain operational processing capabilities, including forms access for reading from and writing to the shared database, report generation, and graphical displays of information.

- To conform, insofar as practical, to DOD, Department of the Army, MTMC, and American National Standards Institute (ANSI) standards for data elements.

- To provide a consistent set of standard data elements used by all MTIT cargo management systems.

MTMC may see fit to expand the scope of these objectives to include the participation of other MTMC Directorates [e.g., rating/routing (MTMC Directorate of Inland Traffic) and finance/payment systems (MTMC Directorate of Resource Management)] in the SDE. However, for the tasking being conducted by ORNL, these systems are not being examined. 


\subsection{USER COMMUNITY}

The two major MTIT systems that would participate in the SDE are the Integrated Booking System (IBS) and the Worldwide Port System (WPS). These two systems, currently under development, will supersede the many separate systems within MTIT for traffic management of international surface cargo. IBS is planned for implementation at the Eastern and Western Area Commands (ACs) by late 1994, and a prototype of WPS is currently being tested at the Western AC.

Two other MTMC systems are generally considered as prime candidates for participation in the SDE. The Transportation Discrepancy Report (TDR), which is MTMC's form for collecting data on transportation problems, could benefit immediately from the use of data in the SDE. The TDR supplies Headquarters MTMC (HQMTMC) with incoming data for the Loss and Damage Reporting and Analysis System. The SDE could facilitate this data transfer for those discrepancies with records in the SDE. The data elements of the Unit Deployment Manifest (UDM) Ship Tracking System, developed for use in Operation Desert Storm by the HQMTMC Emergency Operation Center (EOC), would also benefit from incorporation in the SDE. It must be noted, however, that the UDM contains classified data and would not interface directly with the SDE.

Additional systems have been identified that could potentially be included in the SDE. These include the following:

- Automated Carrier Interface (ACI). It is possible that an interface with the ACI is desirable; however, because design plans call for ACI interfaces with both WPS and IBS, this link may not be necessary, depending on the final design of the SDE.

- Financial Management System (FMS). FMS is the finance/payment system operated by MTMC's Directorate of Resource Management. According to MTIT staff, FMS should interface with the corporate database in the future.

- Continental United States (CONUS) Freight Management (CFM). It is possible that the MTMC Directorate of Inland Traffic's system might interface with the corporate database to provide inland rating and routing information for booking purposes. 
- The Global Transportation Network (GTN). GTN interfaces are currently being analyzed by the United States Transportation Command (USTRANSCOM). Data received by GTN from MTTT systems will provide capability for command and control, planning, and in-transit visibility. This interface will be via automatic electronic file transfer and will consist only of unclassified data.

- Various other classified systems. The current perception is that the SDE will not contain classified data; however, there may be a future requirement to exchange data with classified systems (e.g., the UDM, as described above). The Strategic Deployment System (STRADS) may provide a link (if needed) between the SDE and USTRANSCOM's Joint Operation Planning and Execution System (JOPES). Anothe: ciassified system with a potential need to interface is the Military Sealift Command's Crisis Management System (CMS). Because these systems operate in a classified environment, procedures would need to be established for downloading and uploading data, perhaps through removable electronic media. Thus, these systems would not be "true" participants in the SDE, unless at some future time (when the technology becomes available), the SDE becomes a multi-level secure system.

At a bare minimum, the initial SDE should support the database and communications domains of IBS and WPS. Data elements used in these two systems are the primary ones considered in this requirements analysis, although data elements from the TDR and UDM were also reviewed. ${ }^{2}$ Other than assimilating the appropriate TDR data elements and transmitting them to HQMTMC, no actual TDR processing would be conducted within the SDE. IBS, WPS, and the TDR are unclassified; the UDM is classified. A more detailed discussion of each follows.

\subsubsection{IBS}

The main objective of IBS is to provide a consistent worldwide booking system for both unit and nonunit moves. IBS will be an unclassified system and will replace current automated and manual systems. Development is expected to begin during 1992 and be completed in CONUS late in 1994.

\footnotetext{
${ }^{2}$ Data elements and definitions (where available) from IBS, WPS, TDR, and UDM were collected for ana!lysis. See Appendixes F-I.
} 
The final platform for IBS development has not been determined at this time, although it is expected that an open system architecture including a client/server Relational Database Management System (RDBMS) and Fourth-Generation Language (4GL) will be used. Because IBS will be used at the ACs for booking cargo, the largest sizing load requirement is at the Eastern AC. It is expected that 84 concurrent users and at least 400 user identifiers (IDs) must be supported. Data storage requirements at Eastern $\mathrm{AC}$ are estimated to be at least 705 megabytes (MB) of hard disk space (including program files). IBS must also function at smaller sites. [Western AC performs only about half as many booking operations as Eastern $\mathrm{AC}$, and the sizing requirements for Outside CONUS (OCONUS) sites are unknown, though it is suspected that they would be even smaller than for Western AC.] Telecommunications will include the use of the Defense Data Network (DDN), direct distance dialing (DDD) via remote login, possibly wide-area networks (WANs), and gateways to other RDBMSs. Removable electronic media will also bridge the data-transfer gap between classified systems and IBS.

\subsubsection{WPS}

The purpose of WPS is to provide a standard terminal documentation and cargo accountability system. WPS will replace multiple systems that are currently in operation throughout the world.

MTTT is using the Oracle RDBMS and its associated 4GL tools for development of WPS. WPS is currently being developed on AT\&T 3B2/600G minicomputers and on microcomputers from the Desktop III contract in a fileserver workstation architecture. WPS will operate at the shipping terminals (71 port sites worldwide). Its database at each port site will be small in comparison with IBS sizing requirements. It has been estimated that WPS requires about $154 \mathrm{MB}$ of storage space on the file server located at each terminal site. In addition to WPS residing at the shipping terminals, regional databases are also currently in the design for WPS. These regional sites were initially described as repositories of duplicate copies of data contained in the active databases located at the 
shipping terminals. The current concept for the WPS regional database includes functional processes and system requirements far beyond the scope of this initial concept. Plans call for WPS communications to be handled through DDN, DDD, and the Automatic Digital Network (AUTODIN).

\subsubsection{TDR}

The TDR is a request for information submitted on Standard Form (SF) 361 to MTMC reporting worldwide cargo loss and damage. SF 361 provides basic information needed for initial entry of data into the Loss and Damage Reporting and Analysis System. HQMTMC (MTTT, Inland Traffic, and Safety Security and Intelligence/Provost Marshal) and MTMC ACs [International Traffic, Inland Traffic, and terminals, outports, and transportation terminal units (TTUs)] all participate in the resolution of these problems. The information submitted on the SF 361 form is input into the HQMTMC automated database. Discrepancy reporting using the TDR does not always involve international cargo problems. Thus, TDR entries into the HQMTMC loss and damage system will originate from sources other than MTIT, and the SDE will not be the sole repository of TDR data.

\subsubsection{UDM}

The Ship Tracking System is one of several UDM components developed for the HQMTMC EOC during Desert Storm. The classified system currently operates on a local area network (LAN) of 386/486 clients, using the Advanced Revelation DBMS. The tables analyzed in this report support deployment and redeployment of ships. There are also various reference tables as well as components for redeployment of rail and water. 


\subsection{REFERENCES}

Date, C. J. An Introduction to Database Systems. 4th Ed., Vol. 1, Addison-Wesley. Reading, MA. 1986.

Department of the Army, Headquarters, Military Traffic Management Command. Loss and Damage Reporting and Analysis System and Transportation Discrepancy Report (TDR) Input Instructions. MTMCR 55-38. UNCLASSIFIED. April 1990.

Directorate of International Traffic, Military Traffic Management Command. Integrated Booking System: Mission Element Needs Statement. UNCLASSIFIED. July 1989.

Giordano, Robert, and Barbara Von Halle. "The Heart of the Matter." Database Programming \& Design. 4(5): 15-18 (May 1991).

Giordano, Robert, and Barbara Von Halle. "Remember the Standards." Database Programming \& Design. 4(6): 11-13 (June 1991).

Headquarters, Department of the Army. Army Life Cycle Management of Information Systems. Army Regulation 25-3. UNCLASSIFIED. November 1989.

Oak Ridge National Laboratory. Functional Description for the Integrated Booking System (IBS). UNCLASSIFIED. July 1991.

Oak Ridge National Laboratory. Database Specifications for the Integrated Booking System Prototype (IBS-P). UNCLASSIFIED. June 1991.

USAISC. Management Plan: AUTOSTRAD Modernization Program (A-2000). UNCLASSIFIED. January 1989.

U.S. Department of Defense, Office of Assistant Secretary of Defense. Department of Defense Logistics Data Element Dictionary/Directory (DOD/D). UNCLASSIFIED. DoD 4000.25-13-S1. January 1990.

U.S. Department of Defense. DoD Manual for Standard Data Elements. UNCLASSIFIED. DOD 5000.12-M. July 1989.

U.S. Department of Defense. Military Standard Transportation and Movement Procedures (MILSTAMP). UNCLASSIFIED. October 1988.

U.S. Department of Defense. Military Standard: DOD Automated Information Systems (AIS) Documentation Standards. UNCLASSIFIED. DOD-STD-7935A. October 1988. 
United States Transportaticn Command, GTN Development Division (TCJ6-G). "Global Transportation Network (GTN) DASPS-E Interface Requirements Specification." UNCLASSIFIED. 10 June 1991.

United States Transportation Command, GTN Development Division (TCJ6-G). "Global Transportation Network (GTN) METS II Interface Requirements Specification." UNCLASSIFIED. 10 June 1991.

United States Transportation Command, GTN Development Division (TCJ6-G). "Global Transportation Network (GTN) TSM Interface Requirements Specification." UNCLASSIFIED. 10 June 1991.

United States Transportation Command, GTN Development Division (TCJ6-G). "Global Transportation Network (GTN) TERMS Interrace Requirements Specification." UNCLASSIFIED. 10 June 1991.

WIS Division, GTE Government Systems. Worldwide Military Command and Control System (WWMCCS) Information System (WIS). UNCLASSIFIED. WIS-STD-010. 1988.

Worldwide Port System DRAFT Documentation. Worldwide Port System (WPS) Terminal Level Prototype System Concept and Functional Requirements Document. UNCLASSIFIED. March 1989. Prototype Worldwide Port System Regional Processing Center Functional Requirements Document. UNCLASSIFIED. April 1989.

\subsection{TERMS AND ABBREVIATIONS}

$\begin{array}{ll}\text { A-2000 } & \text { AUTOSTRAD 2000 } \\ \text { AC } & \text { Area Command } \\ \text { ACI } & \text { Automated Carrier Interface } \\ \text { ANSI } & \text { American National Standards Institute } \\ \text { ASCII } & \text { American Standard Code for Information Interchange } \\ \text { ATCMD } & \text { Advanced Transportation Control and Movement Documents } \\ \text { AUEL } & \text { Automated Unit Equipment List } \\ \text { AUTODIN } & \text { Automatic Digital Network } \\ \text { CASE } & \text { Computer-Aided Software Engineering } \\ \text { CFM } & \text { CONUS Freight Management } \\ \text { CMS } & \text { Crisis Management System } \\ \text { COMPASS } & \text { Computerized Movement Planning and Status System } \\ \text { CONUS } & \text { Continental United States } \\ \text { CPU } & \text { Central Processing Unit }\end{array}$




\begin{tabular}{|c|c|}
\hline DA & Data Administrator/Data Administration \\
\hline DAAS & Defense Automated Address System \\
\hline DBA & Database Administrator/Database Administration \\
\hline DBMS & Database Management System \\
\hline DDD & Direct Distance Dialing \\
\hline DDN & Defense Data Network \\
\hline DLSS & Defense Logistics Standard System \\
\hline DOD & Department of Defense \\
\hline DODAAC & DOD Activity Address Code \\
\hline DOE & Department of Energy \\
\hline DOS & Disk Operating System \\
\hline ETR & Export Traffic Release \\
\hline ETRR & Export Traffic Release Request \\
\hline EOC & Emergency Operation Center \\
\hline FMS & Financial Management System \\
\hline FORSCOM & U.S. Forces Command \\
\hline GB & Gigabyte \\
\hline GBL & Government Bill of Lading \\
\hline GSA & General Services Administration \\
\hline GTN & Global Transportation Network \\
\hline GUI & Graphical User Interface \\
\hline HQMTMC & MTMC Headquarters in Washington D.C. \\
\hline IBS & Integrated Booking System \\
\hline ID & Identifier \\
\hline IEEE & Institute of Electrical and Electronic Engineers \\
\hline ITO & Installation Transportation Office \\
\hline $\mathrm{JCCO}$ & Joint Container Control Office \\
\hline JOPES & Joint Operation Planning and Execution System \\
\hline LAN & Local Area Network \\
\hline LDD & Logical Data Dictionary \\
\hline LDM & Logical Data Model \\
\hline LOGDRMS & Logistics Data Resource Management System \\
\hline LOGMARS & $\begin{array}{l}\text { Logistics Application of Automated Marking and Reading } \\
\text { Symbols }\end{array}$ \\
\hline $\mathrm{MB}$ & Megabyte \\
\hline MILSTAMP & Military Standard Transportation and Movement Procedures \\
\hline MILSTRIP & Military Standard Requisitioning and Issue Procedures \\
\hline MSC & Military Sealift Command \\
\hline MTTT & MTMC, Directorate of International Traffic \\
\hline MTMC & Military Traffic Management Command \\
\hline OCONUS & Outside the Continental United States \\
\hline ODT & Open Desktop \\
\hline $\mathrm{OO}$ & Object-Oriented \\
\hline OODB & Object-Oriented Database \\
\hline ORNL & Oak Ridge National Laboratory \\
\hline $\mathrm{PC}$ & Personal Computer \\
\hline
\end{tabular}




$\begin{array}{ll}\text { PDD } & \text { Prototype Data Dictionary } \\ \text { POD } & \text { Port of Debarkation } \\ \text { POE } & \text { Port of Embarkation } \\ \text { POSIX } & \text { Portable Operating System Interface for Computing } \\ & \text { Environments } \\ \text { POV } & \text { Privately Owned Vehicle } \\ \text { QA } & \text { Quality Assurance } \\ \text { QBF } & \text { Query-By-Forms } \\ \text { RAM } & \text { Random Access Memory } \\ \text { RBF } & \text { Report-By-forms } \\ \text { RDBMS } & \text { Relational Database Management System } \\ \text { SCAC } & \text { Standard Carrier Alpha Code } \\ \text { SDE } & \text { Shared Data Environment } \\ \text { SF } & \text { Standard Form } \\ \text { SITREP } & \text { Situation Report } \\ \text { SOCO } & \text { Shipping Order/Clearance Order } \\ \text { SPLC } & \text { Standard Point Location Code } \\ \text { SQL } & \text { Structured Query Language } \\ \text { STRADS } & \text { Strategic Deployment System } \\ \text { TAC } & \text { Transaction Account Code } \\ \text { TC ACCIS } & \text { Transportation Coordinator's Automated Command and } \\ \text { TCMD } & \text { Control Information System } \\ \text { TCN } & \text { Transportation Control and Movement Document } \\ \text { TCP/IP } & \text { Transportation Control Number } \\ \text { TDR } & \text { Transportation Control Protocol/Internet Protocol } \\ \text { TTU } & \text { Transportation Discrepancy Report } \\ \text { UCR } & \text { Transportation Terminal Unit } \\ \text { UDM } & \text { Unit Cargo Release } \\ \text { UIC } & \text { Unit Deployment Manifest } \\ \text { UMD } & \text { Unit Identification Code } \\ \text { USMTF } & \text { Unit Movement Data } \\ \text { USTRANSCOM } & \text { United States Message Text Formatting } \\ \text { VCC } & \text { Vessel Completed Card } \\ \text { WAN } & \text { Wide Area Network } \\ \text { WIN } & \text { WWMCCS Intercomputer Network } \\ \text { WPS } & \text { Worldwide Port System } \\ \text { WWMCCS } & \text { Woridwide Military Command and Control System } \\ \text { 4GL } & \text { Fourth-Generation Language } \\ & \end{array}$




\section{GENERAL REQUIREMENTS OF THE SDE}

\subsection{MODERNIZATION}

MTMC's AUTOSTRAD Modernization Program (A-2000) consists of a plan to support the MTMC DOD-wide mission through modernization of data processing and communications systems. The A-2000 plan encourages use of advanced technology and requires that the hardware and software platform be expandable in order to satisfy future requirements without major redesign. A-2000 encourages flexibility, transportability, and compatibility. The open-architecture approach is a requirement.

To accomplish open-architecture interface requirements, the following generic software, hardware, and communications capabilities are proposed: (1) a POSIX-compatible operating system (probably UNIX or a UNIX clone); (2) IEEE 802.3 and TCP/IP Ethernet communication protocols for LANs, DDN access (one gateway for each site) with X.25 protocol, and dial-in capability for remote PC access over IEEE 802.3 protocol; and (3) an RDBMS with access through Structured Query Language (SQL).

\subsection{COMPLIANCE WITH STANDARDS}

Data sharing requires conformance by all participating systems to certain policies and rules to ensure that:

- data, when entered into the database, is of acceptable quality, and

- data is not degraded while residing in the database. 
A set of policies which must be developed for the SDE will include procedures for user access, data entry (naming conventions, formatting, etc.), maintenance, archiving, and other data administration issues.

As soon as the SDE standards are developed, all participating systems should begin the process of conforming. Incorporating changes will obviously be easier for systems still in development, but the effort (and final cost) will be reduced even more by prioritizing the standardization efforts.

The following standards must be examined in detail to determine which is most applicable for the shared data environment. The WISDIM passive data dictionary includes a set of transportation data elements. The Defense Logistics Standard System (DLSS) Division is responsible for the Department of Defense Logistics Data Resource Management System (DOD LOGDRMS). This dictionary, which includes dial-in access, must be referenced for use of standardized data elements, whenever applicable. The DOD Manual for Standard Data Elements (DOD 5000.12-M, July 1989) lists standard data elements and codes for all DOD data elements. This voluminous manual covers far more than just logistics data. During development of the Logical Data Model (LDM), these data standards should be examined further and ranked for which standard takes precedence when there is disagreement. Also, ANSI standards should be examined to determine how they differ from the DOD standards.

In general terms, ${ }^{3}$ the following guidelines should be followed for naming and describing data elements in the SDE.

- The data element should have one and only one meaning.

- A data element should be uniform in domain. Uniformity constraints include data type, length, and actual values.

${ }^{3}$ These "standard" rules are derived from two articles by Robert Giordano and Barbara von Halle in recent issues of Database Programming \& Design (see references in Sect. 1.4). 
- The domains of data elements should be mutually exclusive. This rule applies especially to codes (e.g., those that are defined primarily to save space on a hard-copy report or a computer screen).

- The data element should be constructed so that it cannot be decomposed into smaller pieces without a loss of meaning. (Some data elements are truly composites; zip codes, for example, should be maintained in standard zip code format, even though each digit has a "meaning," because they are always used in that form.)

- A data element should be uniquely named. Using data element naming policies and understanding the full scope of a data element prior to naming it will help maintain this rule.

- Names and descriptions of business-oriented data elements should be meaningful to the end users. In the SDE, the business definition should be commonly understood across organizational boundaries.

- If derived data elements are included in the data model, they should also conform (o) the rules defined above.

\section{FUNCTIONAL REQUTREMENTS}

The general objectives of the SDE are given in Sect. 1.2. The following sections list specific functional requirements for the SDE.

\subsection{Database Inquiries and Reports}

This section describes requirements for the querying function of the SDE.

All phases of both export and import cargo must be trackable within a region and between regions. A typical user session might include queries concerning booking information, cargo movement milestones, and current status details.

The system must provide two types of query capability. First, frequently used queries will be programmed as integral parts of the applications. These queries should be presented to 
the user as normal menu and form options within the SDE. The database administrator (DBA) should manage access to fields based on the user's login profile. In addition, a more flexible capability should be provided to sophisticated users via the DBMS mechanisms (e.g., Query-By-Forms).

The total number of user IDs has not yet been determined, but it is estimated to be on the order of 2600 for a worldwide user base. This estimate is based on (1) the IBS lowerbound estimate of 400 user IDs at the Eastern AC and a similar number for WPS at a hypothetical WPS Eastern AC regional database and (2) an assumption that approximately 1800 user IDs would be required for all other regional sites worldwide (possibly located at Western AC, Europe, Pacific, and Far East). Most database access should be handled by local database servers; the maximum number of concurrent SDE processes at each server is expected to be on the order of 200. Most responses to simple queries that are handled by the local database server should be instantaneous (i.e., less than 3 seconds). For queries that require more than 3 seconds to complete (i.e., complex queries or those that involve remote servers), the display should include a "working" message.

To enhance response time, the database will be partitioned into active records and history records. A record will be transferred to the history file according to a schedule based on receipt and payment dates. Most cargo records will be maintained in the active area for 90) days after receipt of the cargo at the final destination. Archiving and subsequent retrieval will be transparent to the user making the inquiry. The system application handling the query will determine the required tables (active or history) and access the appropriate data on the basis of the user's entry of values for one or more of the fields listed in Table 2.1. 
Table 2.1. Principle fields for SDE query formulation

Transportation Control Number (TCN), by first $14,15,16$, or 17 positions

Van owner and/or container number

Social security number

Personal property name of owner

Commodity, model, or national stock number

Consignee or Unit Identification Code

Consignor

Voyage number

Port of Embarkation (POE)

Port of Debarkation (POD)

Measurement information (e.g., shipment weight, shipment cube)

Dates (e.g., container spot date, POE receipt, transfer, lift, sail, POD receipt, POD discharge, consignee delivery)

It must be noted that information requested from the SDE will range from very specific (e.g., a cargo description for an individual TCN, a detailed listing of all cargo in a single shipment) to very broad (e.g., a summary listing of all cargo shipped from all ports on the East Coast for the past six months). Thus, in order to clearly delimit the query, the application screen for constructing the query must allow the user to fill in one or more of the fields listed in Table 2.1 and to enter one or more data values (or a range) for each field. The user should be able to enter the appropriate data from the keyboard or, whenever reasonable, to select (by mouse or keyboard) the desired data from a "pick list" of choices generated from the database.

The user will be able to retrieve the results of the query to the screen, to a file, to a DDN mailbox, or to a printer. An output menu screen will provide options from which the user will make choices. The output can be a listing of the contents of individual data fields, an aggregation of data, or a statistical analysis of the data. The numerical output can be either tabular or graphical. 
Certain preformatted reports should be available. A menu screen will list all available preformatted reports and allow the user to choose the desired report and select appropriate delimiters for the data that will be included in the report. Options for appropriately sorting and summarizing the data in each report will be provided.

In the past, various operational and management reports were produced on a routine basis (daily, weekly, monthly). The routine reports that will be required of the SDE are yet to be determined; however, it is assumed that users with a need to know can access these reports and download them to the screen or to a printer as desired. A preliminary list, notably incomplete, of management reports the SDE should provide to support AC activities is given in Appendix C.

\subsection{Data Exchanges}

This section describes interfacing systems that will exchange data with the SDE. In addition, individual users with update privileges will be able to enter and/or update data in the SDE.

Data exchanges with IBS and the ACI should be on a real-time basis as much as possible. These exchanges include skeletal Advanced Transportation Control and Movement Documents (ATCMDs), vessel records, and cargo status updates. Procedures for handling message traffic and database synchronization are discussed in Sect. 3, Design Options.

Data exchanges with WPS (i.e., the WPS terminals) should be as close to "real-time" as possible within the constraints of cost and technical feasibility. These exchanges include ATCMDs, bookings, and cargo status updates. Automated verification retransmittal procedures must be established. Procedures for handling message traffic and database synchronization are discussed in Sect. 3, Design Options. 
Although an interface with FMS is not being analyzed in this report, a brief description ol' this interface is in order. The long-term objective is an efficient automated system interface between MTIT and MTMC's Directorate of Resource Management. Ideally, the contractor payrun should be prepared and produced at the WPS shipping terminal with transmittal of the record to the SDE for distribution to FMS. An interim design option (in case WPS at the shipping terminals cannot support the contractor payrun) is to process the contractor payrun at the SDE and transmit this information to the terminals as well as to FMS. It is assumed that, in the future, FMS personnel should have the ability to update the rate tables at the SDE, which in turn would automatically update the rate tables used by the WPS terminals.

Rather than requiring multiple interfaces to the GTN (one for each MTIT system), it is logical to assume that the SDE will be the primary MTIT interface point for the GTN. Analyses have been conducted on interfaces between GTN and the following MTMC systems: Terminal Manangement System (TERMS), Terminal Support Module (TSM), Mechanized Export Traffic System (METS II), and Department of the Army Standard Port System - Enhanced (DASPS-E). Because of the existing documentation describing these interfaces (see references in Sect. 1.4), the SDE interface with the GTN is not analyzed further in this report.

The interface with STRADS is also not analyzed in this report. This interface is assumed to be with the STRADS Execution Module and should be analyzed further.

Other interfaces may include the Defense Automated Address System (DAAS) for transmittal of the TK7 report data now provided by TERMS in standard MILSTEP format. The MILSTAMP Tracer Request is currently also supported by TERMS. This capability should be provided in the general query capability of the SDE.

${ }^{4}$ Similar documentation describing the G'TN interfaces with IBS and WPS does nol currently exist. 
Once it is clearly determined which of the above systems can be considered "internal" to the SDE and which are "external," interface design documents must be developed for each of the external interfaces. The recommendations at the conclusion of this report are based on the assumption that the major systems encompassed by the SDE are IBS and WPS.

\subsubsection{Operational Requirements}

The SDE must provide authorization for users to edit/correct records, as appropriate. This authorization must be determined on the basis of each individual user and must be revisable.

The SDE will provide ATCMD processing. For unit moves, IBS will submit ATCMDs to the SDE for processing (see Sect. 3.3.2). ${ }^{5}$ For nonunit moves, the SDE may receive ATCMDs from various sources, in both automated and manual formats. For the SDE to receive ATCMDs directly, an automated interface with ACs and shipping activities, with input screen designs similar to those of IBS, should be provided. The SDE will provide an edit routine (similar to that currently provided by TERMS), which will determine whether the ATCMDs can be released to the terminals or must be rejected and held for up to 5 days awaiting correction via an ATCMD correction screen (an SDE application). If the record is not corrected within 5 days, it will be deleted. A daily error report should be provided to the ACs and HQMTMC. This error report should be sorted; those ATCMDs which originated with shippers should be transnitted to the originating shipper, and those ATCMDs which originated at the terminals (records beginning with a " $\mathrm{V}^{\text {" }}$ in the Document Identifier Code) should be transmitted to HQMTMC. It is important that the terminals have access to any ATCMD in the SDE database. Records with invalid Document Identifier Codes should be checked to see if they should be transferred to another processing module (e.g., booking, tracer, etc.). The multivehicle ATCMD must be

${ }^{5}$ Throughout this report, the acronyms "ATCMD" and "TCMD" are used to designate sets of booking information that are similar for both unit and nonunit moves. 
expandable into multiple TCNs with the last position of the TCN changing from A-Z (except X).

The SDE must support the creation, distribution, and modification of the ship manifest. Because this is a major activity, it will be used in Sect. 3 as the example to describe the SDE options. Generally speaking, the manifest record will be sent by the port to the SDE. Durrently, it is assumed that, if necessary, a copy of the manifest record can be edited in the SDE after transmittal. On the basis of logic residing in the SDE, the SDE will select appropriate recipients for the manifest report as well as the appropriate communications medium (DDN, AUTODIN, hard-copy via mail, ACI, and possibly others) and distribute the manifest. The list of "appropriate recipients" will include PODs, HQMTMC, Military Sealift Command (MSC), and MSC ACs. If it becomes necessary to retransmit a manifest record, this should be a simple procedure.

The SDE must provide the capability to edit the Transaction Account Code (TAC). The SDE will verify the information received on all incoming ATCMDs against TAC tables of valid values and produce a daily error report sorted by TCN. Updating of the TAC tables should be an assigned responsibility of the Data Administrator (DA). This updating must be communicated to all appropriate parties on a real-time basis.

The SDE must provide capability to produce Ocean Government Bills of Lading (GBLs). This includes the ability to produce continuation sheets based on manifested cargo using logic similar to that currently residing in TERMS.

The SDE must provide capability to identify data appropriate for the TDR and transmittal of an automated form of the SF 361 to HQMTMC. The receipt and proper distribution of TDR problem resolution information when received from HQMTMC should be an automated feature of the SDE.

Finally, the SDE must provide standard system reports automatically. These reports include the following: 
- journal events and an audit trail/log,

- quality assessment (QA) and other statistical usage reports, and

- production of error reports.

The SDE will require system administration, database administration, and data administration support.

To fulfill all requirements, the SDE requires a very sophisticated design. Table 2.2 summarizes the software quality factors that must be incorporated into the SDE system development plan to ensure that the programs perform according to specifications.

Table 2.2. Quality factors to be tested during SDE software development

\begin{tabular}{ll}
\hline Factor & Criteria \\
\hline Correctness & Traceability, completeness, consistency \\
Reliability & Consistency, accuracy, simplicity, error tolerance \\
Flexibility & Modularity, generality, expandability, self-descriptiveness \\
Portability & Software system and hardware independence \\
Usability & Training, communicativeness, operability \\
Inter/intra operability & Modularity, data commonality, communication commonality \\
Efficiency & Execution efficiency, storage efficiency \\
Integrity & Access control, access audit \\
Maintainability & Consistency, simplicity, conciseness, modularity, self- \\
& descriptiveness \\
Survivability & Generality, modularity, software/hardware independence, \\
& self-descriptiveness
\end{tabular}

A comprehensive Test Plan and Configuration Management Plan should be produced in the early stages of SDE system development. 


\subsection{USER INTERFACE REQUIREMENTS}

The proposed SDE should be accessible to the organizational units and systems identified in Sects. 1.3 and 2.3.2. In addition, it is anticipated that individual users at other sites will require login access to the SDE to extract information, to correct errors, and to request printed reports. The user interface for these interactions must conform to high-quality user interface architectural designs and to Worldwide Military Command and Control Systems (WWMCCS) guidelines. The IBS prototype was designed under these guidelines and could be used as a model for screen layout, display colors, etc.

The SDE should be a menu-based system that allows fast-key access for sophisticated users. A graphical user interface (GUI) windowing system with mouse input (probably based on X Windows) should be supported.

It is assumed that primary access to the SDE will be through high-resolution monitors capable of bit-mapped graphics. Capability of graphical representation of statistical analysis of data is required. However, some remote access may also require the SDE to be downward compatible with character-based terminals or PCs, depending on the user's login profile.

A programmer's toolkit that takes full advantage of the architecture should be employed for system development.

\subsection{ADDITIONAL ASSUMPTIONS}

Because the system must be accessible from a worldwide user base, it is assumed that the SDE would be accessible for 24 hours per day.

Depending on the design, primary SDE database servers will be physically located at aboul four or five sites worldwide. Implementation and operation of the SDE will require, at a 
minimum, support staff (at multiple sites) for maintaining the operating system, SDE applications, network, database, and data quality. These individuals must be thoroughly trained in the technologies employed.

Current schedules (as of the end of September 1991) indicate that WPS will be implemented in CONUS in January 1993. Thus, if the SDE is to replace the WPS regional database concept, ${ }^{6}$ it must be operational by this date.

The DOD mandate to eliminate the use of AUTODIN should be factored into the system design. Although DDN is not fully operational in the Far East, it is assumed that DDN will be implemented worldwide by the time the SDE is implemented in the Far East.

${ }^{6}$ Because the WPS regional database and the SDE concepts are still evolving, it is impossible to say at this time whether or not they are mutually exclusive. If the SDE serves as the basis for a corporate MTIT database, it may include some or all of the functionality planned for the WPS regional database. 


\section{DESIGN OPTIONS}

This section discusses three SDE architectural design options that fulfill, with varying degrees of efficiency, the system requirements described in Sect. 2. Additional design options, which were examined and discarded fairly early in the analysis, are briefly discussed in Appendix A.

\subsection{OVERVIEW OF DESIGN OPTIONS}

The three options can be described briefly as follows:

- Inclusion of the SDE within IBS or WPS. The SDE would be a subsystem belonging to one of the two major participating systems. Communications would be necessary only for the external systems involved (including the other of the two major systems, i.e., either IBS or WPS) and for any remote users. Figure 3.1 illustrates this architecture.

- The SDE as a separate system. The SDE would be located on its own hardware at sites that might not correspond to IBS or WPS sites. Communications would be required for all participating systems. Figure 3.2 illustrates this architecture.

- The SDE as a distributed database. There are several different possibilities corresponding to the various degrees of data distribution, but the focus in this report is on what can be termed a loosely coupled, replicated database. Figure 3.3 illustrates this architecture.

\subsection{COMPARISON OF DESIGN OPTIONS}

A more detailed comparison of each of the three design options follows. 


\subsubsection{Option 1: Inclusion of the SDE within IBS or WPS}

This option (see Figure 3.1) presupposes that the system requirements could be met if the SDE were a component of either IBS or WPS. We will assume, for purposes of discussion, that the SDE is a subsystem of WPS. ${ }^{7}$

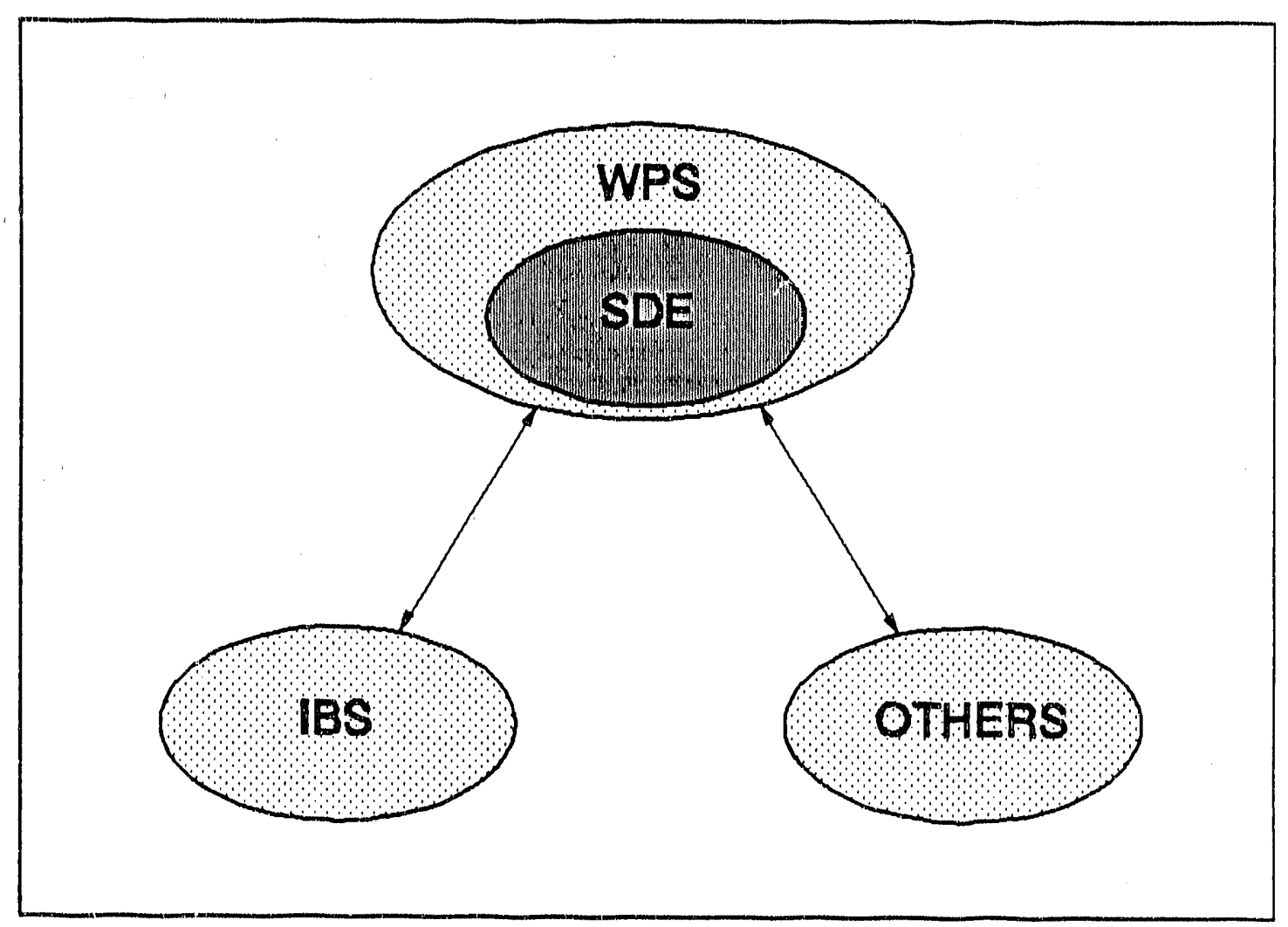

Figure 3.1. Inclusion of the SDE within IBS or WPS (Option 1).

The means of exchanging data with the SDE would be by standardized messages between WPS and each participating system. A common set of rules [e.g., United States Message

"Throughout this paper, Option 1 discussions will refer to the SDE being a component of WPS. The examples would be similar if the SDE were a part of IBS instead. Where specific problems would result from one association as opposed to the other, the text is explicit. 
Text Formatting (USMTF)] should be adopted by MTIT and established as the official messaging standard for all systems that talk to the SDE. This standard should be inclusive enough to support a variety of individualized message formats. Since each system deals with different collections of data, there will undoubtedly be a number of actual message formats (within the constraints of the standard) for each system.

Message parsers, necessary to trap errors and to translate messages to databases and vice versa, would be written to handle both ends of each messaging pipeline. As a general rule, there would be two parsers for each message exchange, since (1) the data would have to be mapped to the particular database involved, and (2) each system would have its own method for handling errors. The message formats (and, therefore, the parsers) would have to be amended whenever the information flows changed. Procedures for handling bad messages (data transmission errors) and bad data (unacceptable key values) would be incorporated into each parser or written as separate code that is tightly coupled to the parser. Each message exchange would also involve data transfer rules concerning unsuccessful events. These rules would have to be procedurally coordinated between each pair of systems.

Certain data that was originally generated by processes in IBS (and other systems) would be replicated in the SDE. There would, therefore, be a set of procedures for detecting and resolving data discrepancies. Some differences might turn out to be tolerable; others would not. It is essential that key fields, especially identifiers of common entities (e.g., carriers, ships, geolocation codes), conform to an inter-system standard (which currently does not exist). Identifier mismatches (especially the formats of key fields) are disastrous for RDBMS-based systems. Inconsistency detection would also involve periodic execution of procedures to determine if data that was transferred successfully had become corrupted since the original transfer.

An important consideration is the ability of WPS computing facilities to handle the additional requirements generated by the SDE. If the current server platform (AT\&T $3 \mathrm{~B} 2$ ) is found to be only marginally capable of supporting the operational WPS, as 
suspected by MTIT, it will certainly prove to be insufficient for WPS plus the SDE. (Similarly, if the SDE were to become an IBS component, further consideration and possible expansion of the IBS platform would be mandated.) Additional provisions (e.g., dedicated lines) would be required to equip WPS for handling remote access by the full SDE user community.

Most of the difficulties in Option 1 stem from the fact that application code must be written to handle data sharing. By itself, the technology of message transfers and parsers is not especially complex. The complications arise when developers from various systems must coordinate message design and database synchronization procedures. Relegating all such inter-system adjustments to application code within disparate systems makes this option labor-intensive to design, implement, and maintain. Although most systems now deal with data sharing in this way, it is a short-range solution with inherent difficulties for the inevitable modifications to message design and synchronization procedures.

Because both IBS and WPS are in the early stages of development, an encompassing strategy to standardize critical system elements might still succeed in minimizing architectural and database design disparities between the two major systems. Even if both systems used the same DBMS and operating system, however, the discussion above is still germane.

The success of an SDE based on the Option 1 architecture depends on the following factors:

- a high level of agreement (among the designers of the interfaces) on message design and synchronization procedures,

- the overall management of message traffic and data format issues by MTIT, and

- the volume of SDE data, which must not overtax the containing system. 


\subsubsection{Option 2: The SDE as a Separate System}

With the Option 2 design (see Figure 3.2), the SDE is an independent system that communicates with other systems (including IBS and WPS) as required.

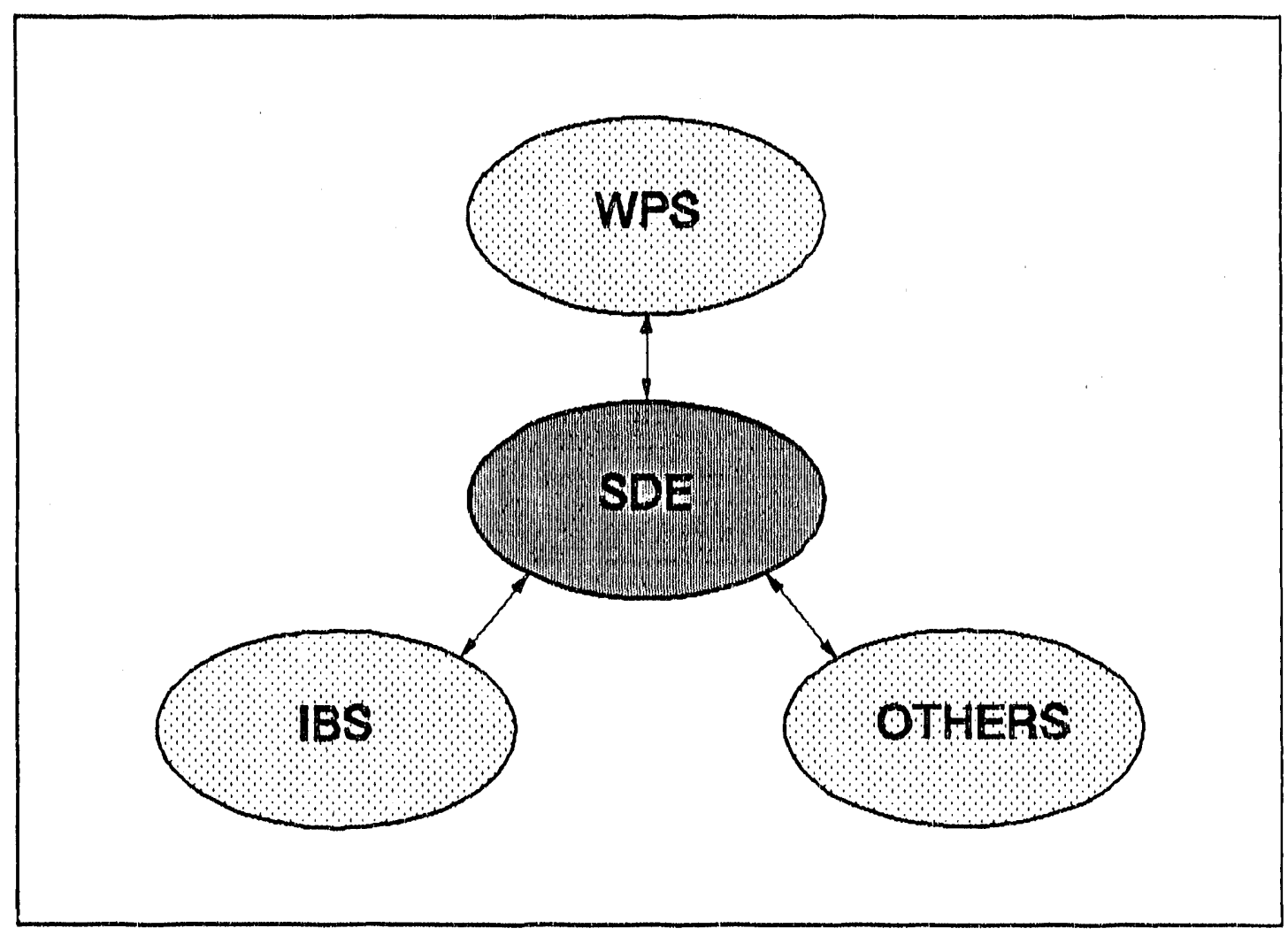

Figure 3.2. The SDE as a separate system (Option 2).

This architecture is more flexible than that of Option 1 , by virtue of the fact that implementation details can be handled independently. Otherwise, most of the comments concerning Option 1 are applicable to this design as well, except that in Option 2, virtually all SDE data is a replica of data in other systems. Obviously, the messaging is even more complex here, because of the additional transfers between WPS and the SDE.

Again, the success of Option 2 depends on the following factors: 
- a high level of agreement (among the designers of the interfaces) on message design and synchronization procedures,

- the ovorall management of message traffic and data format issues by MTIT, and

- the volume of SDE data, which must not ovurtax the communications lines between the SDE and each participating system.

\subsubsection{Option 3: The SDE as a Distributed Database}

If, as in Option 3 (see Figure 3.3), the SDE employs a distributed database ${ }^{8}$ design, MTIT users would perceive IBS and WPS (and other participating systems) as portions of a single, integrated system. The determination of the sites throughout the system where data is actually stored would be based on performance factors associated with the use of the data.

Sharing of common data elements is rapidly becoming a business requirement. Corporations are searching for ways to integrate multiple existing stovepipe systems that use a variety of technologies. Several software tools companies now offer products that "solve" these disparate database problems. Their solution is to roll up the data and present it to the user as if it came from a single database. Companies using this technique generally claim that their products are "open" and that they facilitate full communication between databases of any type. In fact, these tools are appropriate only for read-only, decision-support applications. It should be noted that even the first generation of distributed DBMS products are much more comprehensive than this type of product.

There are many different ways to implement distributed databases and/or cooperative processing of distributed data. To avoid confusion, this report focuses on two of the major

${ }^{8}$ Distributed database, until recently, was an esoteric and primarily academic abstraction, but many major RDBMS vendors are now supplying or developing distributed database features. 


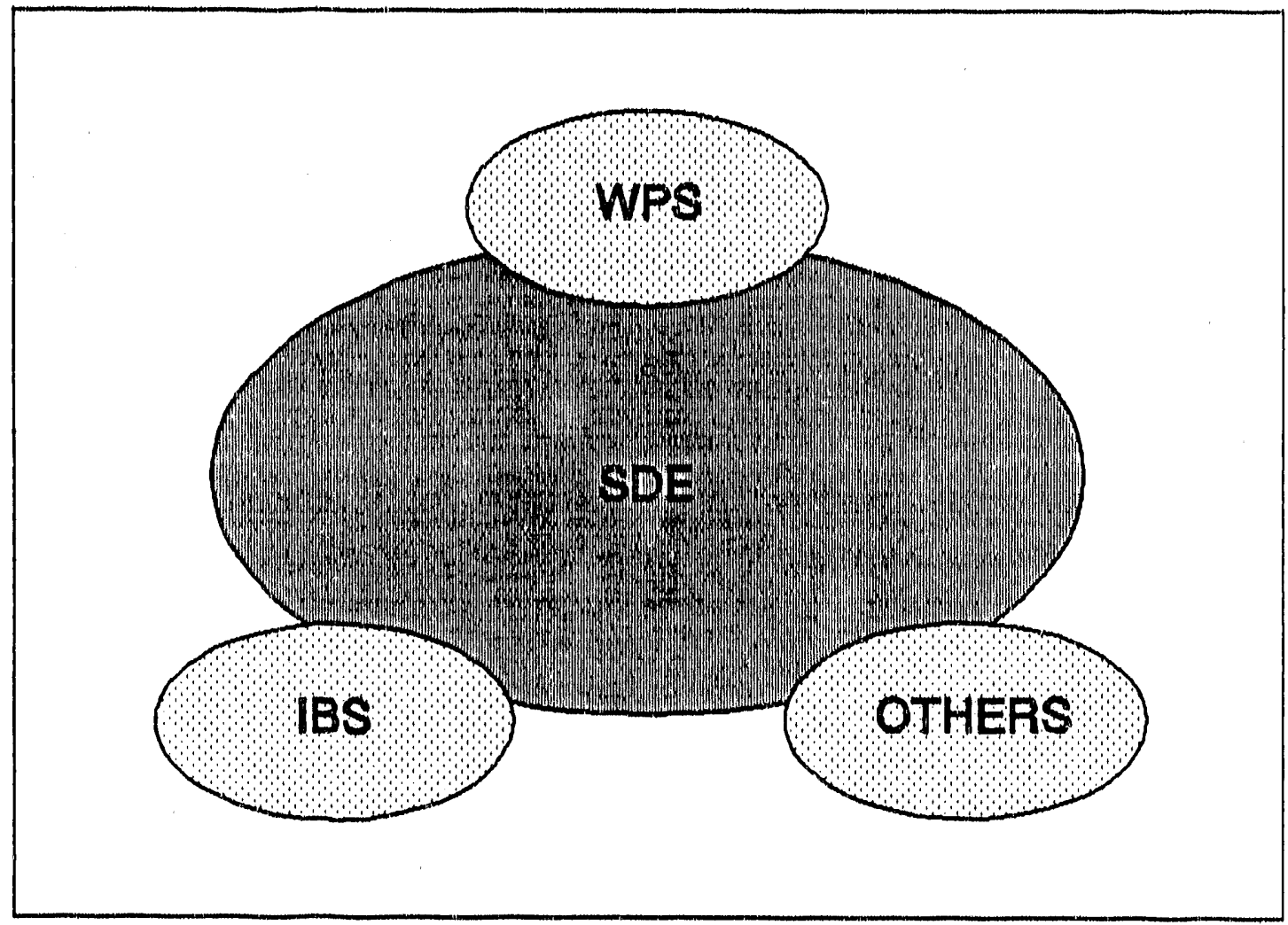

Figure 3.3. The SDE as a distibuted database (Option 3).

concepts: a tightly coupled, distributed database and a loosely coupled, replicated databasc. Distributed and replicated databases are employed in real-world processing by 24 -hour bank tellers and airline reservation systems, among others.

\section{Tightly coupled, distributed database}

The primary goal of distributed database systems is to provide users with a "single-system image," even when the data itself is widely dispersed at various physical sites. In a tightly coupled, distributed database, the single-system image holds true for application programmers as well as end users; that is, database code would not specify where the data is actually stored. Only the database administration (DBA) team would be aware of the physical details of data location. Throughout system development and maintenance, the 
DBA would continue to modify the physical design in response to changing requitements of the SDE and the participating systems.

A tightly coupled, distributed database necessitates a common database schema (i.e., full agreement of database table structures) among all participating systems (and a DBA function that spans all sites). While there might be advantages to this approach, the current and evolving MTIT systems that would benefit from participation in an SDE are autonomous. Adoption of a common database schema among all these systems is unrealistic, as only a small percentage of data elements are actually shared among the existing autonomous systems. Thus a tightly coupled, distributed database is not considerer. further in this report.

Loosely coupled, replicated database

A rule of thumb for most databases is that $20 \%$ of the data is used $80 \%$ of the time. While a full analysis of SDE data has not yet been undertaken, it may be true that only a small number of data elements are actually involved in high-value transactions. In this report, a high-value transaction is considered to be any database update that

- is crucial to the overall business of tracking worldwide cargo movement,

- involves data that is of interest to a wide spectrum of users, not just users at a single site or users of a single component of a participating system, and

- needs to be propagated immediately throughout the SDE user community.

Examples of high-value transactions include:

- cargo cancellations after the release has been approved and sent, and

- carrier notification of ship unavailability. 
For purposes of discussion, a low-value transaction is a database update that either:

- involves data that is of interest only to users at a single site or within a single component of a participating system,

- involves data that can be propagated throughout the SDE user community periodically at a predefined frequency, or

- is available as required, though access is not as rapid as it is for replicated data used in the high-value transactions.

In an SDE that is based on a loosely coupled, replicated database, the high-value transactions would be coordinated among all the participating sites. Although the data would actually exist at various sites, all users would have a single-system image of this crucial information; in other words, widely separated users would see the same data changes occurring at roughly the same moment. They would also have write access to the data that supports their participation in the high-value transaction. All sites would either "agree" (through distributed RDBMS control) to commit each transaction at roughly the same moment or they would all roll back to the previous state.

The results of low-value transactions would also be propagated throughout the system, but according to less stringent timing requirements. Low-value transactions would still be processed locally (as they are now designed) in portions of the database that are autonomously designed and managed. Periodic transfers would be required to support SDE processes (e.g., reports) as well as normal system-to-system communications. Those sites that have a clear need to see certain information would receive periodic updates as part of the overall SDE communications procedures or as part of the normal message traffic initiated by each participating system. Similar message trafficking rules and procedures as described under Option 1 would apply to SDE handling of low-value transactions. The quantity and criticality of the transfers would be diminished because distributed database processing would be employed for high-value transactions. 
The loosely coupled, replicated database design may be viewed as a hybrid of Option 1 and a tightly coupled, distributed database. Containing features of both designs, it applies these features as appropriate to data of differing criticality. A portion of each system's database would be specialized to support the high-value transactions that must be accessible by all sites. One way, although certainly not the only way, to implement the distributed design would be for each system to address the shared data as a physically distinct database. Several DBMS products allow the addressing of database fields as a dotdelimited full name (parts of which default to the local objects if they are omitted) as follows:

\section{SiteName.DatabaseName.OwnerName.TableOrViewName.FieldName}

Full name addressing makes the local use of several databases straightforward and efficient.

The Option 3 design requires high-speed network connections, a distributed RDBMS, and standardization among participating systems of that portion of the database schemas that supports the high-value transactions. ${ }^{9}$

DBMS necessities include the use of "intelligent," distributed server software, since database synchronization cannot be left up to the applications. To allow for multi-site updating by the distributed DBMS, a two-phase commit facility ${ }^{10}$ is required. Global and local data dictionaries are also system requirements. The distributed DBMS must be able to use the global data dictionary to intervene in situations that might otherwise lead to

The hardware platform, especially memory and disk space, of each participating system will undoubtedly require augmentation of current capabilities. The full extent will depend on a thorough analysis of the data volumes present in the high-value transactions.

${ }^{10} \mathrm{~A}$ good discussion of two-phase commit is found in C. J. Date's An Introduction to Database Systems. See Sect. 1.4 for full reference. 
deadlock. ${ }^{11}$ Another desirable feature is open database server technology that allows a server to appear as a client to another server, while still maintaining its identity as a server to its own regular clients.

The distributed system must be able to survive the loss of any number of sites due to Central Processing Unit (CPU), disk, or network failures. A proven recoverability strategy that minimizes or eliminates offline time is essential. The goal is to keep all other sites running, while gracefully bringing the broken site back into synchronization.

The Option 3 design strategy involves a high degree of replicated data worldwide. It does not guarantee synchronization of all data (e.g., the information involved in low-value transactions) within a short time frame (i.e., seconds). It does, however, provide for a single system image and tighter coupling where synchronization is essential. Transparent data replication is done at the database level while at the same time preserving a large share of the autonomy of participating systems.

The success of the Option 3 design depends on the following factors:

- the adoption of a proven distributed DBMS,

- the identification of a database design that supports high-value transactions (i.e., the replicating of critical data elements),

- thorough preliminary analysis of data usage to minimize hardware and communications costs associated with readjusting the physical storage strategy,

- the volume of high-value transaction replicated data, which must not overtax the network that supports the distributed RDBMS, and

- the development of a support staff for designing, coding, and maintaining the integration of local autonomous systems with the global SDE.

${ }^{11}$ A good discussion of deadlock is found in C. J. Date's An Introduction to Databasc Systems. See Sect. 1.4 for full reference. 


\subsection{EXAMPLE: CREATING, DISTRIBUTING, AND MODIFYING THE SHTP MANIFEST}

Manifest documentation for unit equipment shipments was chosen as an example because both IBS and WPS will participate in development and communication of the manifests. The booking system creates the ATCMD, which evolves into the TCMD and becomes the basis for the manifest. ${ }^{12}$ The booking system then feeds this data (i.e., the ATCMD) into the terminal support system which completes the manifest documentation. (Sections 3.3.1 and 3.3.2, respectively, describe current and proposed booking/terminal support systems.)

Per MILSTAMP, TCMDs provide the basis for preparing manifests. Within CONUS, MTMC prepares the manifests; otherwise, the POE is responsible for the preparation of the manifests. The terminal operator adds the necessary loading detail to the TCMDs. Manifests are used to verify delivery of cargo, support billing services, and justify claims. Documents related to the manifest include the manifest recapitulation, manifest summary, and the cargo traffic message.

\subsubsection{Current MTMC Systems}

ASPUR is supplied an Automated Unit Equipment List (AUEL) from the U.S. Forces Command (FORSCOM) Computerized Movement Planning and Status System (COMPASS) as the basis for the ASPUR database. The Installation Transportation Officc (ITO) submits Unit Movement Data (UMD) via the Transportation Coordinator's Automated Command and Control Information System (TC ACCIS) to provide the most up-to-date detail information to be used by ASPUR. The listing which contains records common to both of these two systems constitutes the expected cargo at the port. ASPUR creates skeletal ATCMDs from the detail data in its own database.

\footnotetext{
${ }^{12}$ The acronyms "ATCMD" and "TCMD" are used to designate the set of data elements transferred from ASPUR to TERMS (eventually, from IBS to WPS).
} 
These ATCMDs are then loaded into the TERMS On-Line System (TOLS) at the AC to become the basis of the manifest document. Prior to creating the master file, TOLS validates the data fields and produces error listings for erroneous data. Records with fatal errors are rejected. Other records may produce warnings to the operator that certain fields need modifications.

When the unit equipment arrives at the terminal, the Logistics Application of Automated Marking and Reading Symbols (LOGMARS) system is used to read the TCN off each item. The LOGMARS data is loaded into TOLS to update the enroute records with actual cargo received at the port. TOLS is updated again when the equipment is loaded onto the vessel. A load list modifies the status of the enroute records as cargo is actually lifted onto the vessel.

A vessel completed card (VCC) is submitted to TOLS when the ship sails. The VCC notifies TOLS to change all records with a "load" status for the given voyage number and ship name to "sail" status. Also included on the VCC is the POE, POD, julian date sailed, and time ship sailed. The manifest is created when the VCC is added to the enroute records.

An automated message of the manifest must be released from the POE to the POD within 72 hours of sailing if the transit time is 7 days or less; it is required within 5 days, if transit time is 8 days or greater. The POD and MSC receive automated messages. Paper copies of the manifest are released to the "world" - any organizations interested in the ship's cargo and/or itinerary. Recipients of the manifest include the POE and its clearance authority, local agent of carrier, sponsoring service, and MTIT ACs. After 90 days from sailing, the manifest record is retired to history. 
Problems with a manifest are generally discrepancies between expected cargo and actual cargo. ${ }^{13}$ Per MILSTAMP, true adjustments to a manifest are considered errors or omissions in already dispatched manifests. These modifications are sent to the same addressees as the original manifest via the original method. Under the current operations, sometimes these adjustments are successfully implemented and sometimes they are not.

\subsubsection{Proposed MTMC Systems ${ }^{14}$}

FORSCOM will supply AUEL data to IBS to form the basis of the IBS unit moves database. Since TC ACCIS maintains the most up-to-date unit equipment listings, TC ACCIS will submit UMDs to IBS which update the AUEL data. From its unit equipment detail data, IBS will create skeletal ATCMDs for input to the regional WPS. These ATCMDs provide WPS with listings of cargo expected at the port.

Once the ATCMDs are received by the regional WPS, they will form the basis for the manifest. Error checking and validation will be performed. The regional WPS will then distribute ATCMDs electronically to WPS terminal mailboxes for retrieval by the terminal. These notifications provide the terminals with a "heads-up" of what to expect at the ports. Via the regional database, a port will have the ability to download ATCMDs for other terminals.

As equipment arrives at the port, TCNs will be scanned with LOGMARS and the data uploaded into WPS. This new data is added to the enroute records (ATCMDs) to create

\footnotetext{
${ }^{13}$ For example, if ATCMDs project 25 tanks are to arrive at the port of Charleston on Wednesday and only 20 arrive, then TOLS must be updated to confirm receipt of only 20 tanks. However, if two more tanks arrive the following Monday, TOLS must be updated again to show two additional tanks.

${ }^{14}$ These paragraphs describe one potential path for ATCMD data exchanges between IBS and WPS. Because these systems are still in the conceptual stage, this description is preliminary and subject to revision.
} 
the manifest with the details of the cargo that is actually received at the port. When the cargo is lifted onto a vessel, records within WPS are updated to reflect a loaded status. When the vessel finally sails, WPS will again be updated.

Although the regional WPS will not always replicate data in the WPS terminal systems, the regional WPS will try to maintain updates that are as close to "real-time" as possible with frequent uploads from the terminals. The frequency will be determined based on cost and technical feasibilities.

Once WPS at a POE updates the regional database for the POD with a vessel's final manifest, the manifest will be transmitted to the appropriate recipients via the predetermined communications medium. The necessary addresses and media selection criteria will be maintained at the regional level. The 72-hour and 5-day deadlines for release of manifests should be easily met for the majority of the PODs. Manifests will still be kept active for up to 90 days within the regional database.

One goal of the regional database is to make manifest adjustments available in a more timely manner than by redispatching updates from the terminals.

\subsubsection{Problems with Existing/Proposed Systems}

The central shortcoming of the evolving MTIT systems and procedures regarding manifest creation and distribution is that a "global" view of the entire cargo movement is impossible to achieve because no single system contains a complete information store. IBS loses visibility after the skeletal ATCMD is passed to WPS, and WPS cannot view the original data used to create the ATCMD. Thus, at different times information about the cargo movement is processed in various forms:

- AUEL and UMD

- $\quad$ ATCMD (expected cargo) 
- enroute records

- actual cargo received at the port

- load list

- VCC

- manifest

- manifest adjustment

These stages in manifest production can be seen as milestones in the data-driven processes, but they are not necessarily sequential. It is desirable that detailed information at each of these steps be immediately available to those users with a need to know.

It may be possible to force global visibility onto the framework of the emerging architecture by allowing users of one system (e.g., IBS shippers) to have access to WPS in order to determine the status of their cargo. Allowing "outside" users to have authorized WPS accounts may constitute a threat to the integrity of the WPS database unless this access is meticulously controlled (i.e., by individual user accounts, not by a general purpose group account).

The speed at which requests are processed is also crucial. In the absence of a corporate SDE, the data updates will be periodically "frozen" and sent to other sites. The recipients will rely only on the final version of the message, which may not be transmitted efficiently, especially if the user is talking to a remote site on the phone. The latter alternative -. establishing contacts via telephone with users who are authorized to query WPS -establishes a time-consuming and personnel-intensive procedure.

Additional problems exist with the present means of updating manifests. Rather than forwarding entire manifests, some adjustments result in messages that consist of line item updates. This requires the recipient to maintain a previous version of the manifest which is then manually updated with the line item change. A replicated database offers a completc, up-to-date manifest that is available to all authorized users in a near real-time environment. 


\subsubsection{Discussion of Design Options}

This section addresses the three proposed SDE design options as they are related to the manifest example.

\section{Option 1: Inclusion of the SDE within IBS or WPS}

How much IBS data should be replicated in the WPS-contained SDE? Since the SDE will not replicate all IBS data, visibility over cargo data prior to creation of the ATCMD will be limited to IBS users. At a minimum, the skeletal ATCMDs will result in messages $t o$ WPS. But if the expected cargo changes, through some agent reporting to IBS, that information must also be sent to WPS.

Will the entire IBS community be authorized to login to the SDE through WPS? If so, WPS must be designed to handle the extra user burden (including non-IBS users). It not, provisions must be made to refresh all non-WPS users with messages whenever important manifest information is changed in WPS. If the processing of enroute records and the loacl list is of continual interest to users other than those at the terminals, it must be decided how often this information is to be disseminated.

It is not clear whether the WPS regional databases will each contain a complete set of cargo status information or whether the data will be geographically partitioned, that is, with each database managing data only for its immediate region. If the latter, WPS may need to support transparent access to all the information required by SDE users.

\section{Option 2: The SDE as a separate system}

All important manifest messages must be parsed by WPS and sent to the SDE parser. This option relieves WPS of the burden of processing message traffic from all other systems 
involved (the SDE will handle it separately), but the Immediate availability of the shared data to WPS users is diminished.

Is it feasible to replace regional WPS processing with the SDE? IBS would provide constant booking information to the SDE from the time requests are recelved. The SDE would be dependent on IBS to maintain the status of the booking records and to submit ATCMDs at the appropriate ilme. If the SDE replaced the regional WPS database, the ATCMDs would then be processed in the SDE instead of at the regional WPS database. After the ATCMDs were made available to the WPS terminal systems, the ports would then exchange data with the SDE rather than the regional WPS.

If manifest adjustments are sent by WPS to the SDE, they will in turn be sent by the SDE to all who received the original manifest. The recipients of these messages cannot be assured that additional adjustments are not already in the pipeline (which might take morc than a few seconds to transmit). In addition, if the adjustment is a line item change, it is the responsibility of each recipient to match it up to the original manifest. Mismatches duc to faulty transmission or WPS error will reverberate among all users until a correct transmission succeeds. Each user will require a method of backing out the incorrect adjustment and replacing it with the correct one.

\section{Option 3: The SDE as a distributed database}

In addition to fulfilling the needs of a regional WPS, this option also offers the most attainable "real-time" environment. Based on their login profiles, users would be able to access manifest data in IBS, WPS, and other databases. Queries would be constructed in a user-friendly SDE interface, not requiring the user to have knowledge of the physical location of the data. This strategy also protects data integrity.

The major difficulty is in determining which data is to be replicated and which data is to be messaged. If it is determined that the high-value transactions include, for example, 
AUEL/UMD processing status and manifest creation, these portions will be avallable to all SDE users as if they existed within a single system. But the continual traffic on the network to support this single systern image may prove to be excessive. An alternative design, such as requiring message traffic for expected cargo data visibility, might be a morc workable strategy, Resorting to alternatives such as this re-introduces the messaging problems described above.

\subsection{ADDITIONAL DATABASE DESIGN ISSUES}

There are certain aspects of SDE database development that apply to all of the design options described above. These are discussed briefly below.

\subsubsection{Logical Data Model and Data Dictionary}

The development of an LDM is highly recommended for the SDE. An SDE LDM is especially crucial because of the nonexistence of LDMs for IBS and WPS. This shortcoming will make the creation of an SDE LDM, which requires the participation of both IBS and WPS systems developers, more difficult and time-consuming.

All of the information entities (and their attributes) associated with the corporate databasc support for MTIT should be detailed in a Logical Data Dictionary (LDD). The LDD should also include mappings between the SDE and the data in each participating system. ${ }^{15}$ The LDM and its supporting LDD should be maintained throughout system development, long after they have been translated to their physical equivaleats. The final SDE Data Dictionary should maintain information about data and processes that form the operational SDE.

\footnotetext{
${ }^{15}$ Preliminary data element mappings to the IBS and WPS prototypes were developed. Examples may be seen in Appendixes $D$ and $E$.
} 


\subsubsection{Database Integrity and Data Quality}

Database integrity is of primary importance to maintaining data-driven systems that rely (1) RDBMS technology. Because RDBMSs address data by its values, not by its locations, tho management of key fleld correctness is crucial to internal synchronization. A database thai is not in a state of integrity, due to key field value corruption, is difficult, if not impossible, to correct.

Modern RDBMS products supply features that support database integrity and data quality at the database level, for example:

- triggers -. a trigger is a collection of SQL code that will automatically execute wher some action (e.g., insertion, deletion) is performed on a table;

- rules ... a rule is a detailed definition of the allowed values or range of values that arc appropriate for a field; and

- defaults -- a default supplies a value for a field if the application fails to supply one when it inserts a row into the containing table.

These features are obviously a superior means of achieving integrity and quality goals than by programming such issues at the application level. RDBMS triggers, rules, and default: allow the database designers to incorporate integrity constraints as part of the schema shared by all applications. If these aspects of the design change, they need only be changed once, at the database level. The alternative -- tracking down all the applications that affect the tables and fields in question -- is time-consuming and error-prone.

\subsubsection{Evolving RDBMS Capabilities}

The principal DBMS vendors are currently struggling to provide the most intelligent database server for the low-end workstation/high-end PC market. This will undoubtedly 
remain a major item on their agendas throughout the next decade. Closely related Indlustry developments are the growing number of distributed RDBMS features and multi-level socure systems.

Another technological trend in the database area is the growing importanec of object oriented (OO) techniques. Thesc techniquas allow the specification of data/code "packages" that behave in predictable ways and aro described by the messages to which they respond. A particular objoct can be used to pertorm a similar action lor a wide variety of requestors. The development of Object Orlented Database (OODB) products has influenced some traditional RDBMS vendors to incorporate hooks to established $O O$ products (e,g., $\mathrm{C}++$, Ada), Incorporating OO techniques within UNIX RDBMS products has been facilitated by the development of X-Windows. Some RDBMS vendors have expanded their application development tools and user interfaces to include X. Window toolset (e.g., Motif) features. Others have added a software layer above the cllent/sorver interface that is adaptable to a varlety of local windowing environments.

Suggestion of a particular RDBMS and related software (e.g., 4GL application development tools that allow both GUI and character-mode access) cannot be made until the SDE design is more fully established. It should be clear that agreement among all participating systems on a single, widely used DBMS product that supports distributed features (e.g., Ingres, Sybase, Oracle) is preferable to reconciling databases implemented in DBMSs from different vendors. The choice of software tools that make use of evolving technologies should be based on the identified needs of the SDE. 


\section{PROTOTYYPE DATA DICTIONARY}

To identlfy and describe potential data eloments in the SDE, a Prototypo Data Dlctionary (PDD) was constructed and populated with the avallable information from several MTT'T systems. Analysis (fucilitated by the PDD) of data olements from these systems was undertaken to support the recommendations in Sect. 5.

\subsection{GENERAL DESCRIPITON OF THE SOFTWARE TOOL}

The PDD is a Unix PC-based DBMS tool that facilitates analysis of data requirements related to the SDE. In its initial implementation, it is a stand-alone tool; it is not currently connected to the data catalog of any participating system. Section 4.2 describes the PDD hardware and software platform.

The primary purposes of the PDD are:

- to report on similar data elements in the participating systems,

- to propose standardized formats for certain data elements that are perceived as belonging to the SDE, and

- to identify problems that might arise if certain shared data elements in the participating systems are not standardized.

Certain critical data elements (but not all data elements) from the following systems are contained in the PDD:

- IBS,

- WPS,

- TDR, and

- UDM. 
A listing of all data elements currently perceived as part of the SDE is contained in Appendix C.

Listings of SDE fields cross referenced to fields in participating systems and vice versa are contained in Appendixes D and $\mathrm{E}$.

Listings of data element definitions (where available) in the participating systems are contained in Appendixes F-I.

It should be noted that because of the preliminary nature and the lack of documentation of the above systems, the PDD is by no means a final product. The outstanding logical data modeling tasks associated with the PDD are discussed in Sect. 4.5.

The PDD is not designed as a user-friendly application, but rather as a tool to be used only by database designers and database administrator/data administrator (DBA/DA) teams. For example, metadata from participating systems must be entered and maintained manually, either through SQL_-based DBMS utilities (e.g., bulk copy from Unix files) or through the standard data entry features of the DBMS. PDD scripts (e.g., reports) are readily accessible from the Unix command line, and the shell routines that initiate them are self-documenting. Section 4.4 and Appendix $\mathrm{K}$ present a more detailed discussion and listing, respectively, of these information retrieval and maintenance applications.

\subsection{HARDWARE/SOFTWARE PLATFORM}

The PDD is currently implemented on an Intel 486-based PC running Santa Cruz Operation's (SCO) Open Desktop (ODT) software. ODT (release 1.1) supports SCO Unix System V/386 (release 3.2.2) and disk operating system (DOS; version 3.3) in a fully integrated filesystem. Bundled with ODT is Ingres, a relational DBMS that supports forms-based access to the database as well as standard report generation facilities. Neither 
of the tools, Query-By-Forms (QBF) and Report-By-Forms (RBF), is required for use of the PDD scripts. ODT provides C, Bourne, and Korn shells.

The PDD scripts are Korn shell routines that insert, retrieve, and/or update database information (by using the Ingres sql utility). In most cases output is filtered with various Unix tools (e.g., awk). Standard output is to the screen but may be redirected to a file. [Note: Script usage is also available to users whose default shell is not the Korn shell.]

ODT (release 1.1) requires a 386 or 486 computer based on ISA, EISA, or MCA, a graphics display system such as EGA or VGA (for X Windows), a mouse, and, for the basic single-user system, $6 \mathrm{MB}$ RAM (8 MB is recommended), and $100 \mathrm{MB}$ disk space. For the "Development System," 140 MB disk space is required, and for the "Server Upgrade," $180 \mathrm{MB}$ disk space is required for the system, with .5 MB for each user.

\subsection{DATABASE ORGANIZATION}

The PDD currently consists of five permanent tables that store information pertaining to the SDE and participating systems. Documentation of the PDD database structure is available by running the sdetabfld script at the Unix prompt. The output of sdetabfld all (for all PDD tables) is given in Appendix $\mathrm{J}$.

\subsection{RETRIEVAL AND MAINTENANCE APPLICATIONS}

Each of the PDD scripts is self-documenting; if the name of the script is entered at the Unix prompt, the screen output shows the usage and definition of the script. In addition, documentation on how to use all PDD scripts is available by running the sdehelp script at the Unix prompt. The results of sdehelp are given in Appendix $\mathrm{K}$; examples of some of the PDD scripts are given in Appendix L. 


\subsection{POSSIBLE FURTHER DEVELOPMENT}

Various tasks remain for data modeling associated with the SDE. This section discusses several possible enhancements to the PDD that would facilitate overall SDE development.

It should be noted that the PDD is currently a limited tool. Its major benefit will be to identify those data elements that pose risks to the effective sharing of information (either through the SDE or elsewhere). These risks arise primarily because data formats and/or domains are not standardized.

Currently the PDD maintenance is a manual DBMS procedure that is facilitated by the PDD reports. To make the PDD a dynamic tool (even before the SDE is initiated), it should be connected to the working catalog of a principal participating system such as WPS. This would obviate the need for manually updating the PDD (e.g., when the associated structures and definitions change, when SDE field names are standardized). Once the SDE database development is sufficiently underway, the PDD could be reconnected to the SDE catalog.

If a computer-aided software engineering (CASE) tool is employed in the development of the SDE, connections between the PDD and the CASE tool should be explored. The use of a CASE tool that interfaces to a standard DBMS (i.e., Ingres) would be preferable to ASCII file transfers, but either implementation is workable. Of vital importance to continuing benefits from the PDD-CASE tool connection is the ability to manage data and processes in an integrated way (i.e., a "where used" facility).

Additional PDD tables, alterations of existing PDD tables, and augmentation of the scripts to include new reports and/or updates are all readily achievable by database designers familiar with Unix. Some possibilities include:

- a cross reference of SDE field names to a standard set of data element names from the yet-to-be-chosen MTMC data administration standard, 
- automated entry (including temporary "best guess" cross reference to existing SDE field names) of data elements from "new" participating systems or from new portions of current participating systems,

- a field to capture the conversion rules that need to be applied to data in each of the SDE-system interfaces, and

- error-checking routines in the scripts could be made more comprehensive, thus making the PDD more robust.

It should also be noted that the definitions of data elements that comprise the initial SDE are preliminary in nature. Fuller and more accurate information on the meaning and use of each data element, its datatype (including size and precision), domain (allowed values) and units of measurement are required before database design can succeed in organizing data elements into tables. In addition, a more complete analysis of which system fields should be replicated is crucial to the success of the SDE. 


\section{SUMMARY AND RECOMMENDATIONS}

MTMC is in the process of designing and implementing several new automated systems to replace antiquated data management procedures (both manual and automated). This rapict modernization could result in costly redesign and long-term maintenance problems if a "quick fix" approach is chosen over thorough analysis and design. Rapid prototyping -while efficient if managed competently -- tends to create a momentum of systems development that is unable to respond to crucial improvements, even when all involved parties agree the improvements are essential.

MTIT is currently studying the concept of an SDE for global visibility of surface transportation cargo movement data. This report has briefly explored SDE system requirements and three specific design options.

MTIT should analyze its data-related problems and arrive at a strategy for maintaining accurate and complete information among all automated systems. This strategy, which should establish a basic information architecture that will survive into the foreseeable future, should include an SDE based on distributed database principles and technologies.

A distributed database approach is recommended because of the need for information availability and synchronization throughout the globally distributed SDE user community. Worldwide transportation systems, by their very nature, are forging the real-world use of distributed database tools. Other means of providing read and write access to information at widely separated sites are proving to be inefficient and unmaintainable.

The distributed database, to be effective immediately, should restrict its scope to coordinating only high-value updates at multiple sites. Distributed RDBMS features that are essential for this approach are: 
- intelligent database servers,

- a two-phase commit facility, and

- both global and local data dictionaries.

A loosely coupled, replicated database will provide for continued autonomy of participating systems as well as SDE-wide propagation of high-value transactions.

No inatter what architecture the SDE eventually adopts, the transfer of information around the world will require the highest-speed networking facilities available. Fortunately, dramatic bandwidth improvements within the next few years are expected by most industry analysts. Similarly, raw computing power (also expected to increase dramatically) will need to be utilized by intelligent database servers. If a computing platform other than those currently envisioned for IBS and WPS is employed, it should be based on a scalable, upwardly-compatible family of computers that would allow for re-hosting with minimal impact as improved machines in the family appear.

As previously stated, these recommendations are based on the assumption that the major systems encompassed by the SDE are IBS and WPS. The conclusions are not significantly altered (except in terms of the power of the computing platform) by the incorporation of additional systems.

In summary, the design a:- the MTTT SDE should fit within an overall MTMC information architecture. In the recommended design, the key issue to be resolved is how to communicate high-value transactions rapidly in a loosely coupled, replicated database that is integrated with the variety of local databases. The major organizational impact will be the development of distributed RDBMS expertise. However, the cost of developing DBA and DA proficiency will be more than offset by the value of global availability of crucial information to the user community.

ORNL thus recommends the development of an SDE architecture that includes the following aspects: 
- a loosely coupled, replicated database that encompasses (initially) all IBS and WPS sites,

- high-speed communications among all SDE sites,

- remote access capabilities for SDE users at non-SDE sites,

- a distributed RDBMS that is capable of supporting a single-system perception of dati that is physically partitioned among DBMSs from various vendors,

- identification of the data reriuirements and generation of the physical schema for supporting high-value transactions,

- agreement on message formats and transfer procedures for low-value transactions, and

- a reevaluation of computing resources (particularly memory and disk space) for IBS and WPS. 


\section{Appendix A ALTERNATIVE DESIGNS}

Preliminary ORNL research on the SDE examined various design options other than those described in Sect. 3. Three ideas that were briefly considered before being rejected are discussed in this appendix.

1. Since both IBS and WPS are still in the early stages of development, one design approach is to allow each system to address the problem domain previously reserved for the other. In other words, the scope of both system development plans would expand so that WPS would replicate the functionality of IBS and vice versa. Since this design is not a part of the charter of either system (nor in the general mode of MTIT systems development) and because it would entail "duplicated" costs and might lead to long-term system redundancy, it was not considered further.

2. A simple means of accumulating data to support the majority of MTIT cargo movement traffic management processes is to batch load information from IBS into WPS. In this design, the concerns of the two systems are viewed as separated by timing. For example, IBS would complete all booking procedures and then transmit the export request and booking information to the appropriate WPS terminal site. The two systems would remain disconnected, except for this simple data transfer.

This design is fundamentally flawed by fts failure to provide a single system to support retrieval of international cargo movement information. The main shortcoming lies in the simplistic assumption that IBS and WPS (and other systems) are temporally separated. It is unrealistic to think that IBS data would be "frozen" at a point early enough to be useful for WPS processing. There would have to be an active two-way data transfer for effective utilization of both systems. Furthermore, write access to shared information by a global 
user community is not even addressed. Because this architecture does not fullill the requirements of a corporate SDE, it was not considered further. ${ }^{16}$

3. Another design option includes a windowing environment that would allow users to access each participating system in a window of lis own. The systems would still be separated, as far as data was concerned, but information would be visible in the various windows, and cutting and pasting from one window to another might be facilitated.

Because this design option does fulfill the requirements of the SDE, it received additional consideration.

Technical questions posed by this alternative include:

- Does each system have an architecture that would allow it to be executed in a windowing environment?

- Is it possible to run each system remotely or would they need to be co-located at each site?

- Are security levels compatible? If not, technologies such as compartmented-mode workstations (to prevent information flow between windows) might be necessary.

Advantages of the SDE design option recommended in this report over windows-bound systems include:

- Ease of information retrieval. For example, users inquiring about the status of a particular shipment would query only one system, the SDE.

- Consistency of user interface. Only one set of tools (i.e., menus, forms, commands) would have to be learned to query the SDE. For windows-bound systems, the user would need to be able to navigate successfully through all systems containing the data of interest.

${ }^{16}$ An elaboration of this rudimentary concept that does fulfill the SDE requirements is described as Option 1 in Section 3.2.1. 
- Completeness of information. Data from all appropriate systems would be collected and displayed by the SDE so that its users need not worry about falling to query a particular source.

- Security. The architecture of the SDE would be explicilly controlled so that user's would have access to only that information which they require to perform their jobs. All users of a collection of windows-bound systems would have to have accounts on each of those systems, and the security levels would have to be coordinated to provide access to the appropriate information.

Conceivable advantages of windows-bound systems over an SDE include:

- Up-to-date information. The required information may be in a state of flux due to last-minute changes. If most of the data updates are handled by one site at a time, the most timely data will reside at that site.

- Faster development time. The development will focus on communications issues rather than the building of a new database and user interface to support the SDE. (This assumes that IBS and WPS, as the main participants, would be windows-based systerns; as noted elsewhere, non-windows-based systems may require substantial modifications, thereby increasing the development time.)

The question of SDE expandability is difficult to judge at this stage. If systems other than those currently under consideration need to be incorporated into the SDE at a later date, they could be added transparently to the user. However, this could require modification of the shared database schema and/or processing of high-value transactions, an expense which might be greater than adding a window for the new system (provided its architecture is compatible with the windowing environmeris).

Although this alternative is not completely unreasonable, the advantages of the SDE design represented in this report are clearly superior. The main mitigating factor, up-todate information, may not emerge as a constraint if only a few high-value transactions are identified and these can be expedited by networking, operating system, and/or RDBMS technological advances. 
The critical system consideration that led to the rejection of the above three alternatives is the likely need to manage international traffic from a central location during contingencies. Lessons learned in Operation Desert Storm include the wartime subsuming of certain AC functions by HQMTMC. The rejected designs would not significantly facilitate the dispersal of information from a central location during contingencies. 


\section{Appendix B. REPORTS LISTING}

A tentative list of reports necessary to support $\mathrm{AC}$ activities is glven below. Additional analysis should determine which reports will be produced automatically (i.e., without explicit user requests) and the frequency of production (daily, weekly, etc.). In addition, the data elements required by these reports should be compared with the SDE Data Dictionary to ensure that all data elements for report production are avallable to the SDE.

Two preliminary draft lists follow; the first was supplied by the Eastern $\mathrm{AC}$, and the second by the Western AC.

\section{EASTERN AC REPOR'S}

Report Code Report Title

\begin{tabular}{ll}
\hline 6070210 & Invalid TAC Report \\
6070110 & Batch Input \\
6070180 & Sorted Input Listing \\
6070200 & Daily Error Report \\
6070700 & Manifest Recap MTON by POE \\
$6070620 \mathrm{~A}$ & Manifest Detail \\
$6070620 \mathrm{D}$ & Manifest EDMA/Error List \\
$6070641 \mathrm{E}$ & Daily Manifest Card Transmission Batches \\
$8195710 \mathrm{Q}$ & Communication Center Report \\
$6075960 \mathrm{~A}$ & Manifest Recap Breakdown Surnmarized by POE Area \\
$6075370 \mathrm{~A}$ & Aged over 30 On-Hand Shippage \\
$6070560 \mathrm{~A}$ & Command Tonnage Summary Report \\
$6072190 \mathrm{~A}$ & Weekly Export Personal Property Inventory \\
$6075390 \mathrm{~A}$ & Weekly On-Hand Hold Cargo Inventory \\
6075240 & Container Status Report \\
6130200 & Import Input List \\
6130100 & Import Input Analysis \\
$6130110 \mathrm{E}$ & Input Error Edit \\
6130220 & Import Detail Manifest \\
6130630 & Import Vessel Pending Manifest
\end{tabular}




\section{WESTTERN AC REPORTS}

Report Code Report Title

$\mathrm{W}(5073000)$

W6073220

W6073230

W6073240

W6073550

W6074240

W6074260

W6074270

W6076180

W6076190

W6078040

W6078140

W6078150

W6070110

W6070180

W6070200

W6070210

W6070270

W6070280

W6070291)

W6070350

W6070400

W6070590

W6070600

W6070610

W6070620

W6070640

W607(1660

W6070670

W6070690

W6070700

W6707010

W6070740

W6070770

W6130110

W6130110
Input Analysis Roport

TK 7 XCVR Tapo Header and Traller Long

TK7 Input/output Listing

TK7 Input Listing

Quarterly Cumulative Dispositions

METS TCMD Reship Disc TWX CNV

Match of TM1 with TOL. File

TM1 Tracer Card

TCNs in Load Status Rpt

Export on Hand Inventory Repor!

TK7 Input/Output Listing

Monthly Analysis Cargo Manifest

VSL Sailing and Arrival Report

HA, HB VCC Cards, Surs Input/Reject Listing, AO Cards, Nonfinal VCC

Input Listing

Dally Composite Error Report

Invalid TAC Report

Matched/Unmatched CTM Batch

Matched/Unmatched CTN Batch - Milstamp Classified List

RI/Address Dump to Print - Cargo CTM XCVR

$\mathrm{HA} 1, \mathrm{HB}$ and $\mathrm{HC}$ edit

VCC Error Report

Unmatched VCC Listing

Cumulative Export Disp.

PP Disposition

Manifest Error/Check List

End MA/Error. - Manifest Detail Mats - Attachment to Manifest Summary

Daily Manifest Card XCVR Batch - Manifest XCVR A/M Batch

Manifest Adjustment XCVR Batch List

Manifest Summary

Seavan TCMD Recap on Paper - Manifest Error/Check list Manifest Recap Mats

Manifest Recap M/To by POE

Daily Manifest Distribution List

Manifest Error/Check List

Classified Manifested Cargo List - Import Input Error List

Import Batch Totals

Import Input List 


\begin{tabular}{|c|c|}
\hline Report Codo & Roport Titlo \\
\hline W6130120 & Import T'AC Error Report \\
\hline W6130140 & Import Sort 6130110 \\
\hline W6130170 & Import Ponding Manifest \& Extract \\
\hline W613()2(K) & Import Input List \\
\hline W6130220 & Import Detail Manilest \\
\hline W6130240 & Import Recap Manifest \\
\hline W6130360 & Import Seavan List By Seavan Number \\
\hline W6130410 & Import Dally Composito Error Report \\
\hline W6130450 & Import Cum Gen Cargo Disposition \\
\hline W6130460 & Import PP Disposition Report \\
\hline W6130520 & Import Dally Transaction Report \\
\hline W6133020 & Import Terminal Workload \\
\hline W6132700 & Import Weekly Trano/OH Summary \\
\hline W6134300 & POV Performance Report \\
\hline W6316900 & TML, Cargo MVMT Report \\
\hline W63170000 & Western Area Cargo MVMT Report \\
\hline W6316950 & Regional Cargo MVMT Report \\
\hline W6317050 & Western Area Seavan Commodity Report \\
\hline W6317100 & Alaska Agreement MVT Report \\
\hline W6130620 & Import TCNS Pending Manifest \\
\hline W6130630 & Import VSL Pending Manifest \\
\hline W6130700 & Import TCN Inventory Report \\
\hline W2350350 & Invalid TAC Monthly Rec \\
\hline W8195710 & Autodin T'ransmit Utility Report \\
\hline
\end{tabular}




\section{Appendix C. SDE FIELD DEFINITIONS}

The following preliminary field definitions are for data elements identified in tho SDE,

SDE FIELD NAME: aci_status

DATA TYPE: chär

LENGTH: 1

PRECISION: NA

UNITS: NA

DOMAIN: alphanumeric

DEFINITION: ACI status

SDE FIELD NAME: actual_arrival_pod_date

DATA TYPE: date

LENGTH: 8

PRECISION: NA

UNITS: NA

DOMAIN: datetime

DEFINITION: Date of actual arrival at POD

SDE FIELD NAME: actual_num_lifted_pieces

DATA TYPE: integer

LENGTH: 4

PRECISION: NA

UNITS: NA

DOMAIN: numeric

DEFINITION: Actual number of cargo pieces lifted

SDE FIELD NAME: adjustment_code

DATA TYPE: char

LENGTH: 1

PRECISION: NA

UNITS: NA

DOMAIN: alphanumeric

DEFINITION: Adjustment code 
SDE FIELD NAME: air_wheeled_track_code

DATA TYPE: char

LENGTH: 1

PRECISION: NA

UNITS: NA

DOMAIN: alphanumeric

DEFINITION: Code indicating transit by air, wheel, or track

SDE FIELD NAME: ald

DATA TYPE: date

LENGTH: 8

PRECISION: NA

UNITS: NA

DOMAIN: datetime

DEFINITION: Available to load date

SDE FIELD NAME: ald_cday

DATA TYPE: char

LENGTH: 4

PRECISION: NA

UNITS: NA

DOMAIN: alphanumeric

DEFINITION: ALD in C-days

SDE FIEI.D NAME: ammo_facility_flag

DATA TYPE: char

LENGTH: 1

PRECISION: NA

UNITS: NA

DOMAIN: Y/N

DEFINITION: Flag indicating facility is capable of handling ammunition

SDE FIELD NAME: army_location_code

DATA TYPE: char

LENGTH: 5

PRECISION: NA

UNITS: NA

DOMAIN: alphanumeric

DEFINITION: Code indicating site is an Army location 
SDE FIELD NAME: arrival_code

DATA TYPE: char

LENGTH: 1

PRECISION: NA

UNITS: NA

DOMAIN: alphanumeric

DEFINITION: Code indicating arrival_date is either actual or expected

SDE FIELD NAME: arriva!_date

DATA TYPE: date

LENGTH: 8

PRECISION: NA

UNITS: NA

DOMAIN: datetime

DEFINITION: Datetime of cargo arrival

SDE FIELD NAME: average_cargo_.mtons

DATA TYPE: float

LENGTH: 8

PRECISION: 1

UNITS: mtons

DOMAIN: numeric

DEFINITION: Average amount of cargo in mtons

SDE FIELD NAME: barge_arrival_date

DATA TYPE: date

LENGTH: 8

PRECISION: NA

UNITS: NA

DOMAIN: datetime

DEFINITION: Date of barge arrival

SDE FIELD NAME: barge_id

DATA TYPE: char

LENGTH: 6

PRECISION: NA

UNITS: NA

DOMAIN: alphanumeric

DEFINITION: ID number of barge 
SDE FIELD NAME: barge_name

DATA TYPE: char

LENGTH: 12

PRECISION: NA

UNITS: NA

DOMAIN: alphanumeric

DEFINITION: Name of barge

SDE FIELD NAME: berth_date

DATA TYPE: date

LENGTH: 8

PRECISION: NA

UNITS: NA

DOMAIN: datetime

DEFINITION: Estimated or actual datetime ship is berthed

SDE FIELD NAME: berth_date_flag

DATA TYPE: char

LENGTH: 1

PRECISION: NA

UNITS: NA

DOMAIN: $Y / N$

DEFINITION: Flag indicating berth_date is either estimated or actual

SDE FIELD NAME: booking_description

DATA TYPE: char

LENGTH: 4

PRECISION: NA

UNITS: NA

DOMAIN: alphanumeric

DEFINITION: Booking description

SDE FIELD NAME: booking_id

DATA TYPE: char

LENGTH: 5

PRECISION: NA

UNITS: NA

DOMAIN: alphanumeric

DEFINITION: Booking number 
SDE FIELD NAME: booking_reason_code

DATA TYPE: char

LENGTH: 2

PRECISION: NA

UNITS: NA

DOMAIN: alphanumeric

DEFINITION: Code indicating reason for booking

SDE FIELD NAME: booking_remarks

DATA TYPE: vchar

LENGTH: 240

PRECISION: NA

UNITS: NA

DOMAIN: alphanumeric

DEFINITION: Booking remarks

SDE FIELD NAME: breakbulk_code

DATA TYPE: char

LENGTH: 6

PRECISION: NA

UNITS: NA

DOMAIN: alphanumeric

DEFINI'TION: Breakbulk code

SDE FIELD NAME: cancellation_code

DATA TYPE: char

LENGTH: 1

PRECISION: NA

UNITS: NA

DOMAIN: alphanumeric

DEFINITION: Code indicating type of cancellation

SDE FIELD NAME: cancellation_code_posted_date

DATA TYPE: date

LENGTH: 8

PRECISION: NA

UNITS: NA

DOMAIN: datetime

DEFINITION: Datetime cancellation_code pos $\_d$ 
SDE FIELD NAME: cancellation_date

DATA TYPE: date

LENGTH: 8

PRECISION: NA

UNITS: NA

DOMAIN: datetime

DEFINITION: Date cancelled

SDE FIELD NAME: cancellation_reason

DATA TYPE: vchar

LENGTH: 60

PRECISION: NA

UNITS: NA

DOMAIN: alphanumeric

DEFINITION: Reason request cancelled

SDE FIELD NAME: cargo_allocated_flag

DATA TYPE: char

LENGTH: 1

PRECISION: NA

UNITS: NA

DOMAIN: Y/N

DEFINITION: Flag indicating cargo has been allocated

SDE FIELD NAME: cargo_classification_code

DATA TYPE: char

LENGTH: 3

PRECISION: NA

UNITS: NA

DOMAIN: alphanumeric

DEFINITION: Code indicating classification level of cargo

SDE FIELD NAME: cargo_cube

DATA TYPE: float

LENGTH: 8

PRECISION: 1

UNITS: cubic_feet

DOMAIN: numeric

DEFINITION: Size of cargo in cubic feet 
SDE FIELD NAME: cargo_height_feet

DATA TYPE: integer

LENGTH: 4

PRECISION: NA

UNITS: feet

DOMAIN: numeric

DEFINITION: Height of cargo in feet.

SDE FIELD NAME: cargo_length_feet

DATA TYPE: integer

LENGTH: 4

PRECISION: NA

UNITS: feet

DOMAIN: numeric

DEFINITION: Length of cargo in feet

SDE FIELD NAME: cargo_lifted_mtons

DATA TYPE: float

LENGTH: 8

PRECISION: 1

UNITS: mtons

DOMAIN: numeric

DEFINITION: Amount of cargo lifted in mtons

SDE FIELD NAME: cargo_mtons

DATA TYPE: float

LENGTH: 8

PRECISION: 1

UNITS: mtons

DOMAIN: numeric

DEFINITION: Total amount of cargo in mtons

SDE FIELD NAME: cargo_status_code

DATA TYPE: char

LENGTH: 1

PRECISION: NA

UNITS: NA

DOMAIN: alphanumeric

DEFINITION: Code indicating status of cargo 
SDE FIELD NAME: cargo_type

DATA TYPE: char

LENGTH: 25

PRECISION: NA

UNITS: NA

DOMAIN: alphanumeric

DEFINITION: Description of type of cargo

SDE FIELD NAME: carrier_booked_date

DATA TYPE: date

LENGTH: 8

PRECISION: NA

UNITS: NA

DOMAIN: datetime

DEFINITION: Date cargo booked with carrier

SDE FIELD NAME: carrier_id

DATA TYPE: char

LENGTH: 4

PRECISION: NA

UNITS: NA

DOMAIN: alphanumeric

DEFINITION: ID for cargo carrier

SDE FIELD NAME: carrier_usage_rate_percent

DATA TYPE: float

LENGTH: 8

PRECISION: 1

UNITS: percentages

DOMAIN: $0.0-100.0$

DEFINITION: Carrier's usage rate èpressed as a percentage

SDE FIELD NAME: cas_code

DATA TYPE: char

LENGTH: 1

PRECISION: NA

UNITS: NA

DOMAIN: alphanumeric

DEFINITION: Code indicating controlled atmosphere service 
SDE FIELD NAME: channel_name

DATA TYPE: char

LENGTH: 15

PRECISION: NA

UNITS: NA

DOMAIN: alphanumeric

DEFINITION: Channel name and definition

SDE FIELD NAME: city_name

DATA TYPE: char

LENGTH: 30

PRECISION: NA

UNITS: NA

DOMAIN: alphanumeric

DEFINITION: Name of city

SDE FIELD NAME: classified_protected_code

DATA TYPE: char

LENGTH: 1

PRECISION: NA

UNITS: NA

DOMAIN: alphanumeric

DEFINITION: Code indicating classified or protected cargo

SDE FIELD NAME: commercial_bus

DATA TYPE: integer

LENGTH: 4

PRECISION: NA

UNITS: NA

DOMAIN: numeric

DEFINITION: Commercial bus

SDE FIELD NAME: commercial_voyage_id

DATA TYPE: char

LENGTH: 2

PRECISION: NA

UNITS: NA

DOMAIN: alphanumeric

DEFINITION: Commercial voyage number 
SDE FIELD NAME: commodity_handling_code

DATA TYPE: char

LENGTH: 5

PRECISION: NA

UNITS: NA

DOMAIN: alphanumeric

DEFINITION: Code indicating commodity and speclal handling

SDE FIELD NAME: compatibility_group

DATA TYPE: char

LENGTH: 1

PRECISION: NA

UNITS: NA

DOMAIN: alphanumeric

DEFINITION: Compatibility group

SDE FIELD NAME: consignee_dodaac

DATA TYPE: char

LENGTH: 6

PRECISION: NA

UNITS: NA

DOMAIN: alphanumeric

DEFINITION: Consignee DODAAC

SDE FIELD NAME: consignee_.name

DATA TYPE: char

LENGTH: 20

PRECISION: NA

UNITS: NA

DOMAIN: alphanumeric

DEFINITION: Name of consignee of shipment

SDE FIELD NAME: consignor_name

DATA TYPE: char

LENGTH: 6

PRECISION: NA

UNITS: NA

DOMAIN: alphanumeric

DEFINITION: Name of consignor of shipment 
SDE FIELD NAME: container_releasc_units

DATA TYPE: char

LENGTH: 2

PRECISION: NA

UNITS: NA

DOMAIN: alphanumeric

DEFINITION: Number of container release units

SDE FIELD NAME: container_seal_id

DATA TYPE: char

LENGTH: 8

PRECISION: NA

UNITS: NA

DOMAIN: alphanumeric

DEFINITION: ID number of seal on container

SDE FIELD NAME: country_state_code

DATA TYPE: char

LENGTH: 2

PRECISION: NA

UNITS: NA

DOMAIN: alphanumeric

DEFINITION: Country or state code

SDE FIELD NAME: country_state_long_name

DATA TYPE: char

LENGTH: 15

PRECISION: NA

UNITS: NA

DOMAIN: alphanumeric

DEFINITION: Country or state long name

SDE FIELD NAME: created_date

DATA TYPE: date

LENGTH: 8

PRECISION: NA

UNITS: NA

DOMAIN: datetime

DEFINITION: Date record created 
SDE FIELD NAME: cutoff_date

DATA TYPE: date

LENGTH: 8

PRECISION: NA

UNITS: NA

DOMAIN: datetime

DEFINITION: Cutofl date

SDE FIELD NAME: daily_flow_factor

DATA TYPE: char

LENGTH: 2

PRECISION: NA

UNITS: NA

DOMAIN: alphanumeric

DEFINITION: Daily flow factor

SDE FIELD NAME: delay_code

DATA TYPE: char

LENGTH: 1

PRECISION: NA

UNITS: NA

DOMAIN: alphanumeric

DEFINITION: Code indicating type of delay

SDE FIELD NAME: delay_code_posted_date

DATA TYPE: date

LENGTH: 8

PRECISION: NA

UNITS: NA

DOMAIN: datetime

DEFINITION: Datetime delay_code posted

SDE FIELD NAME: deletion_activity_code

DATA TYPE: char

LENGTH: 4

PRECISION: NA

UNITS: NA

DOMAIN: alphanumeric

DEFINITION: Code indicating activity responsible for deletion 
SDE FIELD NAME: deletion_reason_code

DATA TYPE: char LENGTH: 1

PRECISION: NA UNITS: NA

DOMAIN: alphanumeric

DEFINITION: Code indicating reason for deletion

SDE FIELD NAME: deletion_user_id

DATA TYPE: char

LENGTH: 3

PRECISION: NA UNITS: NA

DOMAIN: alphanumeric

DEFINITION: ID of user responsible for deletion

SDE FIELD NAME: delivered_cargo_cube

DATA TYPE: float

LENGTH: 8

PRECISION: 1

UNITS: cubic_feet

DOMAIN: numeric

DEFINITION: Size of delivered cargo in cubic feet

SDE FIELD NAME: destination_city_name

DATA TYPE: char

LENGTH: 15

PRECISION: NA

UNITS: NA

DOMAIN: alphanumeric

DEFINITION: Name of destination city

SDE FIELD NAME: destination_country_name

DATA TYPE: char

LENGTH: 15

PRECISION: NA

UNITS: NA

DOMAIN: alphanumeric

DEFINITION: Name of destination country 
SDE FIELD NAME: destination_rail_splc

DATA TYPE: char

LENGTH: 9

PRECISION: NA

UNITS: NA

DOMAIN: alphanumeric

DEFINITION: Destination rail SPLC

SDE FIELD NAME: destination_truck_sple

DATA TYPE: char

LENGTH: 9

PRECISION: NA

UNITS: NA

DOMAIN: alphanumeric

DEFINITION: Destination truck SPLC

SDE FIELD NAME: discharged_cargo_activity_code

DATA TYPE: char

LENGTH: 4

PRECISION: NA

UNITS: NA

DOMAIN: alphanumeric

DEFINITION: Code indicating activity responsible for discharging cargo

SDE FIELD NAME: discharged_cargo_cube

DATA TYPE: float

LENGTH: 8

PRECISION: 1

UNITS: cubic_feet

DOMAIN: numeric

DEFINITION: Size of discharged cargo in cubic feet

SDE FIELD NAME: discharged_cargo_pod

DATA TYPE: char

LENGTH: 3

PRECISION: NA

UNITS: NA

DOMAIN: alphanumeric

DEFINITION: Water port where cargo is discharged 
SDE FIELD NAME: discharged_cargo_stons

DATA TYPE: lloat

LENCTH: 8

PRECISION: 1

UNITS: stons

DOMAIN: numeric

DEFINITION: Welght of discharged cargo in stons

SDE FIELD NAME: discharged_cargo_user_id

D.ATA TYPE: char

LENGTH: 3

PRECISION: NA

UNITS: NA

DOMAIN: alphanumeric

DEFINITION: ID of user entering discharged cargo data

SDE FIELD NAME: discharged_completion_date

DATA TYPE: date

LENGTH: 8

PRECISION: NA

UNITS: NA

DOMAIN: datetime

DEFINITION: Date cargo discharge completed

SDE FIELD NAME: discharged_start_date

DATA TYPE: date

LENGTH: 8

PRECISION: NA

UNITS: NA

DOMAIN: datetime

DEFINITION: Date cargo discharge started

SDE FIELD NAME: discrepancy_cargo_stons

DATA TYPE: float

LENGTH: 8

PRECISION: 1

UNITS: stons

DOMAIN: numeric

DEFINITION: Weight (stons) of cargo in discrepancy report 
SDE FIELD NAME: discrepancy_code

DATA TYPE: char

LENGTH: 2

PRECISION: NA

UNITS: NA

DOMAIN: alphanumeric

DEFINITION: Code indicating type and cause of discrepancy

SDE FIELD NAME: diverted_cargo_cube

DATA TYPE: float

LENGTH: 8

PRECISION: 1

UNITS: cubic feet

DOMAIN: numeric

DEFINITION: Size of diverted cargo in cubic feet

SDE FIELD NAME: diverted_cargo_pod

DATA TYPE: char

LENGTH: 3

PRECISION. NA

UNITS: INA

DOMAIN: alphanumeric

DEFINITION: Water port to which cargo is diverted

SDE FIELD NAME: dodaac

DATA TYPE: char

LENGTH: 6

PRECISION: NA

UNITS: NA

DOMAIN: alphanumeric

DEFINITION: DOD reporting activity code

SDE FIELD NAME: dodic

DATA TYPE: char

LENGTH: 4

PRECISION: NA

UNITS: NA

DOMAIN: alphanumeric

DEFINITION: DOD Identification Code 
SDE FIELD NAME: domestic_ucr

DATA TYPE: char

LENGTH: 1

PRECISION: NA

UNITS: NA

DOMAIN: alphanumeric

DEFINITION: Domestic UCR

SDE FIELD NAME: drop_frame

DATA TYPE: integer

LENGTH: 4

PRECISION: NA

UNITS: NA

DOMAIN: numeric

DEFINITION: Drop frame

SDE FIELD NAME: due_at_poe_date

DATA TYPE: date

LENGTH: 8

PRECISION: NA

UNITS: NA

DOMAIN: datetime

DEFINITION: Date cargo due at POE

SDE FIELD NAME: ead

DATA TYPE: date

LENGTH: 8

PRECISION: NA

UNITS: NA

DOMAIN: datetime

DEFINITION: Earliest arrival date

SDE FIELD NAME: ead_cảay

DATA TYPE: char

LENGTH: 4

PRECISION: NA

UNITS: NA

DOMAIN: alphanumeric

DEFINITION: EAD in C-days 
SDE FIELD NAME: effective_date

DATA TYPE: date

LENGTH: 8

PRECISION: NA

UNITS: NA

DOMAIN: datetime

DEFINITION: Effective date

SDE FIELD NAME: entry_date

DATA TYPE: date

LENGTH: 8

PRECISION: NA

UNITS: NA

DOMAIN: datetime

DEFINITION: Entry date

SDE FIELD NAME: equipment_length_feet

DATA TYPE: integer

LENGTH: 4

PRECISION: NA

UNITS: feet

DOMAIN: numeric

DEFINITION: Length of equipment in feet

SDE FIELD NAME: estimated_completion_date

DATA TYPE: date

LENGTH: 8

PRECISION: NA

UNITS: NA

DOMAIN: datetime

DEFINITION: Estimated date of completion

SDE FIELD NAME: eta

DATA TYPE: date

LENGTH: 8

PRECISION: NA

UNITS: NA

DOMAIN: datetime

DEFINITION: Estimated time of arrival 
SDE FIELD NAME: etr_release_date

DATA TYPE: date

LENGTH: 8

PRECISION: NA

UNITS: NA

DOMAIN: datetime

DEFINITION: Date ETR reicased

SDE FIELD NAME: etr_release_poe

DATA TYPE: char

LENGTH: 3

PRECISION: NA

UNITS: NA

DOMAIN: alphanumeric

DEFINITION: POE to which ETR is released

SDE FIELD NAME: etrr_received_date

DATA TYPE: date

LENGTH: 8

PRECISION: NA

UNITS: NA

DOMAIN: datetime

DEFINITION: Date ETRR received

SDE FIELD NAME: export_import_flag

DATA TYPE: char

LENGTH: 1

PRECISION: NA

UNITS: NA

DOMAIN: Y/N

DEFINITION: Flag indicating export or import

SDE FIELD NAME: export_ucr_flag

DATA TYPE: char

LENGTH: 1

PRECISION: NA

UNITS: NA

DOMAIN: $\mathrm{Y} / \mathrm{N}$

DEFINITION: Flag indicating export UCR 
SDE FIELD NAME: flash_point

DATA TYPE: char

LENGTH: 4

PRECISION: NA

UNITS: NA

DOMAIN: alphanumeric

DEFINITION: Flash point

SDE FIELD NAME: freight_classification_code

DATA TYPE: char

LENGTH: 6

PRECISION: NA

UNITS: NA

DOMAIN: alphanumeric

DEFINITION: Freight classification number

SDE FIELD NAME: freight_classification_index

DATA TYPE: char

LENGTH: 2

PRECISION: NA

UNITS: NA

DOMAIN: alphanumeric

DEFINITION: Freight classification index

SDE FIELD NAME: funding_ageacy_code

DATA TYPE: char

LENGTH: 1

PRECISION: NA

UNITS: NA

DOMAIN: alphanumeric

DEFINITION: Funding agency code

SDE FIELD NAME: $g$ bl

DATA TYPE: char

LENGTH: 8

PRECISION: NA

UNITS: NA

DOMAIN: alphanumeric

DEFINITION: Government Bill of Lading 
SDE FIELD NAME: gbl_office_code

DATA TYPE: char

LENGTH: 4

PRECISION: NA UNITS: NA

DOMAIN: alphanumeric

DEFINITION: Code indicating GBL office

SDE FIELD NAME: generic_port_location

DATA TYPE: char

LENGTH: 2

PRECISION: NA

UNITS: NA

DOMAIN: alphanumeric

DEFINITION: Code indicating generic location of port

SDE FIELD NAME: geolocation_code

DATA TYPE: char

LENGTH: 4

PRECISION: NA

UNITS: NA

DOMAIN: alphanumeric

DEFINITION: Geolocation code as specified in quarterly GEOFILE from JDSSC

SDE FIELD NAME: gsa_-_city_code

DATA TYPE: char

LENGTH: 4

PRECISION: NA

UNITS: NA

DOMAIN: alphanumeric

DEFINITION: GSA city code

SDE FIELD NAME: gsa_country_code

DATA TYPE: char

LENGTH: 3

PRECISION: NA

UNITS: NA

DOMAIN: alphanumeric

DEFINITION: GSA country code 
SDE FIELD NAME: gsa_state_code

DATA TYPE: char

LENGTH: 2

PRECISION: NA

UNITS: NA

DOMAIN: alphanumeric

DEFINITION: GSA state code

SDE FIELD NAME: hazardous_cargo_flag

DATA TYPE: char

LENGTH: 1

PRECISION: NA

UNITS: NA

DOMAIN: Y/N

DEFINITION: Flag indicating that cargo is hazardous

SDE FIELD NAME: heavy_lift_dimension_code

DATA TYPE: char

LENGTH: 1

PRECISION: NA

UNITS: NA

DOMAIN: alphanumeric

DEFINITION: Heavy lift/dimension code

SDE FIELD NAME: icao_code

DATA TYPE: char

LENGTH: 4

PRECISION: NA

UNITS: NA

DOMAIN: alphanumeric

DEFINITION: Standard International Civil Aviation Organization identifier of an airport

SDE FIELD NAME: installation_type_code

DATA TYPE: char

LENGTH: 3

PRECISION: NA

UNITS: NA

DOMAIN: alphanumeric

DEFINITION: Installation type code 
SDE FIELD NAME: julian_date

DATA TYPE: char LENGTH: 3

PRECISION: NA UNITS: NA

DOMAIN: alphanumeric

DEFINITION: Julian date

SDE FIELD NAME: lad

DATA TYPE: date

LENGTH: 8

PRECISION: NA

UNITS: NA

DOMAIN: datetime

DEFINITION: Latest arrival date

SDE FIELD NAME: lad_cday

DATA TYPE: char

LENGTH: 4

PRECISION: NA

UNITS: NA

DOMAIN: alphanumeric

DEFINITION: LAD in C-days

SDE FIELD NAME: lading_term_code

DATA TYPE: char

LENGTH: 1

PRECISION: NA

UNITS: NA

DOMAIN: alphanumeric

DEFINITION: Code indicating lading term

SDE FIELD NAME: lift_activity_code

DATA TYPE: chär

LENGTH: 4

PRECISION: NA

UNITS: NA

DOMAIN: alphanumeric

DEFINITION: Code indicating activity responsible for lifting cargo onto vessel 
SDE FIELD NAME: lift_capability_sq_ft

DATA TYPE: integer

LENGTH: 4

PRECISION: NA

UNITS: square feet

DOMAIN: numeric

DEFINITION: Lift capability of ship in square feet

SDE FIELD NAME: lift_cargo_sq_ft

DATA TYPE: integer

LENGTH: 4

PRECISION: NA

UNITS: square feet

DOMAIN: numeric

DEFINITION: Amount of cargo lifted in square feet

SDE FIELD NAME: lift_date

DATA TYPE: date

LENGTH: 8

PRECISION: NA

UNITS: NA

DOMAIN: datetime

DEFINITION: Date cargo lifted

SDE FIELD NAME: lift_user_id

DATA TYPE: char

LENGTH: 3

PRECISION: NA

UNITS: NA

DOMAIN: alphanumeric

DEFINITION: ID of user entering lifted data

SDE FIELD NAME: line_item_id

DATA TYPE: char

LENGTH: 6

PRECISION: NA

UNITS: NA.

DOMAIN: alphanumeric

DEFINITION: Line item number 
SDE FIELD NAME: load_completion_date

DATA TYPE: date

LENGTH: 8

PRECISION: NA

UNITS: NA

DOMAIN: datetime

DEFINITION: Date loading of ship is completed

SDE FIELD NAME: logistics_planning_report_code

DATA TYPE: char

LENG'TH: 2

PRECISION: NA

UNITS: NA

DOMAIN: alphanumeric

DEFINITION: Logistics planning and reporting code

SDE FIELD NAME: long_tons

DATA TYPE: integer

LENGTH: 4

PRECISION: NA

UNITS: NA

DOMAIN: numeric

DEFINITION: Long tonnage of cargo

SDE FIELD NAME: lot_id

DATA TYPE: chär

LENGTH: 14

PRECISION: NA

UNITS: NA

DOMAIN: alphanumeric

DEFINITION: Lot number

SDE FIELD NAME: lowboy

DATA TYPE: integer

LENGTH: 4

PRECISION: NA

UNITS: NA

DOMAIN: numeric

DEFINITION: Commercial lowboy 
SDE FIELD NAME: majority_unit_loaded_name

DATA TYPE: char

LENGTH: 15

PRECISION: NA

UNITS: NA

DOMAIN: alphanumeric

DEFINITION: In-the-clear name of "biggest" unit loaded

SDE FIELD NAME: manifest_actual_arrival_date

DATA TYPE: date

LENGTH: 8

PRECISION: NA

UNITS: NA

DOMAIN: datetime

DEFINITION: Actual datetime of cargo arrival on manifest

SDE FIELD NAME: manifest_cargo_cube

DATA TYPE: float

LENGTH: 8

PRECISION: 1

UNITS: cubic_feet

DOMAIN: numeric

DEFINITION: Size (cu ft) of shipment on manifest

SDE FIELD NAME: manifest_cargo_stons

DATA TYPE: float

LENGTH: 8

PRECISION: 1

UNITS: stons

DOMAIN: numeric

DEFINITION: Weight (stons) of cargo on manifest

SDE FIELD NAME: manifest_carrier_name

DATA TYPE: char

LENGTH: 20

PRECISION: NA

UNITS: NA

DOMAIN: alphanumeric

DEFINITION: Name of cargo carrier on manifest 
SDE FIELD NAME: manifest_date

DATA TYPE: date

LENGTH: 8

PRECISION: NA

UNITS: NA

DOMAIN: datetime

DEFINITION: Date of shipment on manifest

SDE FIELD NAME: manifest_flag

DATA TYPE: char

LENGTH: 1

PRECISION: NA

UNITS: NA

DOMAIN: $Y / N$

DEFINITION: Flag indicating if manifest exists

SDE FIELD NAME: manifest_loading_date

DATA TYPE: date

LENGTH: 8

PRECISION: NA

UNITS: NA

DOMAIN: datetime

DEFINITION: Date of loading on manifest

SDE FIELD NAME: manifest_sent_date

DATA TYPE: date

LENGTH: 8

PRECISION: NA

UNITS: NA

DOMAIN: datetime

DEFINITION: Datetime manifest sent to SPOE

SDE FIELD NAME: manifest shipment id

DATA TYPE: char

LENGTH: 17

PRECISION: NA

UNITS: NA

DOMAIN: alphanumeric

DEFINITION: ID of shipment on manifest 
SDE FIELD NAME: manifest_type__cargo_code

DATA TYPE: char

LENGTH: 5

PRECISION: NA

UNITS: NA

DOMAIN: alphanumeric

DEFINITION: Code indicating type of cargo on manifest

SDE FIELD NAME: message_id

DATA TYPE: char

LENGTH: 15

PRECISION: NA

UNITS: NA

DOMAIN: alphanumeric

DEFINITION: Message identifier

SDE FIELD NAME: milstrip_project_code

DATA TYPE: char

LENG'TH: 3

PRECISION: NA

UNITS: NA

DOMAIN: alphanumeric

DEFINITION: Code indicating MILSTRIP project

SDE FIELD NAME: mton_factor

DATA TYPE: float

LENGTH: 8

PRECISION: 1

UNITS: NA

DOMAIN: numeric

DEFINITION: MTON factor

SDE FIELD NAME: navy_ocean_area_code

DATA TYPE: char

LENGTH: 2

PRECISION: NA

UNITS: NA

DOMAIN: alphanumeric

DEFINITION: Code indicating navy ocean area 
SDE FIELD NAME: not_explosive_welght_.stons

DATA TYPE: float

LENGTH: 8

PRECISION: 1

UNITS: stons

DOMAIN: numeric

DEFINITION: Net weight of explosive cargo in stons

SDE FIELD NAME: num_actual__oading_minutes

DATA TYPE: integer

LENGTH: 4

PRECISION: NA

UNITS: minutes

DOMAIN: numeric

DEFINITION: Time it actually took to load ship in minutes

SDE FIELD NAME: num_barges_at_port

DATA TYPE: integer

LENGTH: 4

PRECISION: NA

UNITS: NA

DOMAIN: numeric

DEFINITION: Number of barges at the associated port

SDE FIELD NAME: nurn_barges_loaded

DATA TXPE: integer

LENGTH: 4

PRECISION: NA

UNITS: NA.

DOMAIN: numeric

DEFINITION: Number of barges loaded on the ship at the associated port

SDE FIELD NAME: num_barges_stuffed

DATA TYPE: integer

LENGTH: 4

PRECISION: NA

UNITS: NA

DOMAIN: numeric

DEFINITION: Number of barges that have been stuffed at the associated port 
SDE FIELD NAME: num_containers

DATA TYPE: integer

LENGTH: 4

PRECISION: NA

UNITS: NA

DOMAIN: numeric

DEFINITION: Total number of containers

SDE FIELD NAME: num_containers_delivered

DATA TYPE: integer

LENGTH: 4

PRECISION: NA

UNITS: NA

DOMAIN: numeric

DEFINITION: Number of containers delivered

SDE FIELD NAME: num_containers_discharged

DATA TYPE: integer

LENGTH: 4

PRECISION: NA

UNITS: NA

DOMAIN: numeric

DEFINITION: Number of containers of discharged cargo

SDE FIELD NAME: num_containers_diverted

DATA TYPE: integer

LENGTH: 4

PRECISION: NA

UNITS: NA

DOMAIN: numeric

DEFINITION: Number of containers diverted

SDE FIELD NAME: num_discrepancy_pieces

DATA TYPE: integer

LENGTH: 4

PRECISION: NA

UNITS: NA

DOMAIN: numeric

DEFINITION: Number of cargo pieces in discrepancy report 
SDE FIELD NAME: num_manifest_pieces

DATA TYPE: integer

LENGTH: 4

PRECISION: NA

UNITS: NA

DOMAIN: numeric

DEFINITION: Number of cargo pieces on manifest

SDE FIELD NAME: num_manifest_shipment_units

DATA TYPE: integer

LENGTH: 4

PRECISION: NA

UNITS: NA

DOMAIN: numeric

DEFINITION: Number of shipment units loaded on manifest

SDE FIELD NAME: num_persons_shipped

DATA TYPE: integer

LENGTH: 4

PRECISION: NA

UNITS: NA

DOMAIN: numeric

DEFINITION: Number of persons shipped with cargo

SDE FIELD NAME: num_pieces

DATA TYPE: integer

LENGTH: 4

PRECISION: NA

UNITS: NA

DOMAIN: numeric

DEFINITION: Total number of pieces of cargo

SDE FIELD NAME: num_pieces_discharged

DATA TYPE: integer

LENGTH: 4

PRECISION: NA

UNITS: NA

DOMAIN: numeric

DEFINITION: Number of pieces of discharged cargo 
SDE FIELD NAME: num_rail_transit_days

DATA TYPE: integer

LENGTH: 4

PRECISION: NA

UNITS: days

DOMAIN: numeric

DEFINITION: Number of days required for rail transit

SDE FIELD NAME: num_shipment_units

DATA TYPE: integer

LENGTH: 4

PRECISION: NA

UNITS: NA

DOMAIN: numeric

DEFINITION: Number of shipment units

SDE FIELD NAME: num_standard_loading_minutes

DATA TYPE: integer

LENGTH: 4

PRECISION: NA

UNITS: minutes

DOMAIN: numeric

DEFINITION: Standard time for loading ship in minutes

SDE FIELD NAME: num_tcn_adn_errors

DATA TYPE: integer

LENGTH: 4

PRECISION: NA

UNITS: NA

DOMAIN: numeric

DEFINITION: Number of TCN or ADN errors requiring entry of Type 3 records

SDE FIELD NAME: num_transit_hours

DATA TYPE: integer

LENGTH: 4

PRECISION: NA

UNITS: hours

DOMAIN: numeric

DEFINITION: Transit time in hours 
SDE FIELD NAME: num_unstuffed_cargo_pieces

DATA TYPE: integer

LENGTH: 4

PRECISION: NA

UNITS: NA

DOMAIN: numeric

DEFINITION: Number of pieces of unstuffed cargo

SDE FIELD NAME: num_vans_released

DATA TYPE: integer

LENGTH: 4

PRECISION: NA

UNITS: NA

DOMAIN: numeric

DEFINITION: Number of vans released

SDE FIELD NAME: num_vans_required

DATA TYPE: integer

LENGTH: 4

PRECISION: NA

UNITS: NA

DOMAIN: numeric

DEFINITION: Number of vans required

SDE FIELD NAME: ocean_commodity_code

DATA TYPE: char

LENGTH: 1

PRECISION: NA

UNITS: NA

DOMAIN: alphanumeric

DEFINITION: Code indicating ocean commodity

SDE FIELD NAME: ocean_cost

DATA TYPE: money

LENGTH: 8

PRECISION: NA

UNITS: NA

DOMAIN: numeric

DEFINITION: Overocean cost from POE to POD 
SDE FIELD NAME: offered_to_carrier_date

DATA TYPE: date

LENGTH: 8

PRECISION: NA

UNITS: NA

DOMAIN: datetime

DEFINITION: Date booking offered to carrier

SDE FIELD NAME: offering_type_code

DATA TYPE: char

LENGTH: 1

PRECISION: NA

UNITS: NA

DOMAIN: alphanumeric

DEFINITION: Code indicating type of booking offer

SDE FIELD NAME: operation_code

DATA TYPE: char

LENGTH: 2

PRECISION: NA

UNITS: NA

DOMAIN: alphanumeric

DEFINITION: Operation code

SDE FIELD NAME: operation_phase_code

DATA TYPE: char

LENGTH: 2

PRECISION: NA

UNITS: NA

DOMAIN: alphanumeric

DEFINITION: Code indicating the phase of the voyage's operation

SDE FIELD NAME: origin_city_name

DATA TYPE: char

LENGTH: 15

PRECISION: NA

UNITS: NA

DOMAIN: alphanumeric

DEFINITION: Name of the city associated with the origin of the cargo movement 
SDE FIELD NAME: origin_geolocation_code

DATA TYPE: char

LENGTH: 4

PRECISION: NA

UNITS: NA

DOMAIN: alphanumeric

DEFINITION: Geolocation code of origin of cargo movement

SDE FIELD NAME: origin_name

DATA TYPE: char

LENGTH: 28

PRECISION: NA

UNITS: NA

DOMAIN: alphanumeric

DEFINITION: Name of origin of cargo movement

SDE FIELD NAME: origin_poe_drayage_cost

DATA TYPE: money

LENGTH: 8

PRECISION: NA

UNITS: NA

DOMAIN: numeric

DEFINITION: Drayage cost from origin to POE

SDE FIELD NAME: origin_rail_splc

DATA TYPE: char

LENGTH: 9

PRECISION: NA

UNITS: NA

DOMAIN: alphanumeric

DEFINITION: Origin rail SPLC

SDE FIELD NAME: origin_state_name

DATA TYPE: char

LENGTH: 2

PRECISION: NA

UNITS: NA

DOMAIN: alphanumeric

DEFINITION: Name of state of origin on cargo movement 
SDE FIELD NAME: origin_truck_spic

DATA TYPE: char

LENGTH: 9

PRECISION: NA

UNITS: NA

DOMAIN: alphanumeric

DEFINITION: Origin truck SPLC

SDE FIELD NAME: poc_at_poe_name

DATA TYPE: char

LENGTH: 20

PRECISION: NA

UNITS: NA

DOMAIN: alphanumeric

DEFINITION: Name of point of contact at POE

SDE FIELD NAME: poc_at_poe_phone

DATA TYPE: char

LENGTH: 10

PRECISION: NA

UNITS: NA

DOMAIN: alphanumeric

DEFINITION: Telephone number of point of contact at POE

SDE FIELD NAME: pod

DATA TYPE: char

LENGTH: 3

PRECISION: NA

UNITS: NA

DOMAIN: alphanumeric

DEFINITION: Port of debarkation

SDE FIELD NAME: pod_destination_drayage_cost

DATA TYPE: money

LENGTH: 8

PRECISION: NA

UNITS: NA

DOMAIN: numeric

DEFINITION: Drayage cost from POD to destination 
SDE FIELD NAME: pod_zone

DATA TYPE: char

LENGTH: 2

PRIECISION: NA

UNITS: NA

DOOMAIN: alphanumeric

DEFINITION: Major POD zone

SDE FIELD NAME: poe

DATA TYPE: char

LENGTH: 3

PRECISION: NA

UNITS: NA

DOMAIN: alphanumeric

DEFINITION: Port of embarkation

SDE FIELD NAME: poe_geolocation_code

DATA TYPE: char

LENGTH: 4

PRECISION: NA

UNITS: NA

DOMAIN: alphanumeric

DEFINITION: Geolocation code of POE

SDE FIELD NAME: poe_handling_cost

DATA TYPE: money

LENGTH: 8

PRECISION: NA

UNITS: NA

DOMAIN: numeric

DEFINITION: Port handling cost at POE

SDE FIELD NAME: poe_mode

DATA TYPE: char

LENGTH: 5

PRECISION: NA

UNITS: NA

DOMAIN: alphanumeric

DEFINITION: POE mode 
SDE FIELD NAME: port_area_name

DATA TYPE: char

LENGTH: 25

PRECISION: NA

UNITS: NA

DOMAIN: alphanumeric

DEFINITION: In-the-clear port area name

SDE FIELD NAME: port_call_file_id

DATA TYPE: char

LENGTH: 6

PRECISION: NA

UNITS: NA

DOMAIN: alphanumeric

DEFINITION: Port call file number

SDE FIELD NAME: port_commander_name

DATA TYPE: char

LENGTH: 20

PRECISION: NA

UNITS: NA

DOMAIN: alphanumeric

DEFINITION: Port Commander's name

SDE FIELD NAME: port_name

DATA TYPE: vchar

LENGTH: 80

PRECISION: NA

UNITS: NA

DOMAIN: alphanumeric

DEFINITION: Full name of port

SDE FIELD NAME: port_sequence_id

DATA TYPE: char

LENGTH: 4

PRECISION: NA

UNITS: NA

DOMAIN: alphanumeric

DEFINITION: Port sequence number 
SDE FIELD NAME: port_short_name

DATA 7YYPE: char

LENGTH: 20

PRECISION: NA

UNITS: NA

DOMAIN: alphanumeric

DEFINITION: Short name of port

SDE FIELD NAME: portcall_id

DATA TYPE: char

LEIVGTH: 5

PRECISION: NA

UNITS: NA

DOMAIN: alphanumeric

DEFINITION: Portcall number

SDE FIELD NAME: pov_color_code

DATA TYPE: char

LENGTH: 3

PRECISION: NA

UNITS: NA

DOMAIN: alphanumeric

DEFINITION: Code indicating POV color

SDE FIELD NAME: pov_license_tag

DATA TYPE: char

LENGTH: 5

PRECISION: NA

UNITS: NA

DOMAIN: alphanumeric

DEFINITION: POV license tag number

SDE FIELD NAME: pov_license_tag_state_code

DATA TYPE: char

LENGTH: 2

PRECISION: NA

UNITS: NA

DOMAIN: alphanumeric

DEFINITION: POV state of license tag 
SDE FIELD NAME: pov_make_model_code

DATA TYPE: char

LENGTH: 4

PRECISION: NA UNITS: NA

DOMAIN: alphanumeric

DEFINITION: POV make and model

SDE FIELD NAME: pov_manufacture year

DATA TYPE: char

LENGTH: 4

PRECISION: NA

UNITS: NA

DOMAIN: alphanumeric

DEFINITION: POV year manufactured

SDE FIELD NAME: primary_destination_rail_scac

DATA TYPE: char

LENGTH: 4

PRECISION: NA

UNITS: NA

DOMAIN: alphanumeric

DEFINITION: Primary destination rail SCAC

SDE FIELD NAME: primary_origin_rail_scac

DATA TYPE: char

LENGTH: 4

PRECISION: NA

UNITS: NA

DOMAIN: alphanumeric

DEFINITION: Primary origin rail SCAC

SDE FIELD NAME: prime_geolocation_code

DATA TYPE: char

LENGTH: 4

PRECISION: NA

UNITS: NA

DOMAIN: alphanumeric

DEFINITION: Prime geolocation code 
SDE FIELD NAME: private_siding_flag

DATA TYPE: char

LENGTH: 1

PRECISION: NA

UNITS: NA

DOMAIN: $\mathrm{Y} / \mathrm{N}$

DEFINITION: Flag indicating private siding

SDE FIELD NAME: projected_release_date

DATA TYPE: date

LENGTH: 8

PRECISION: NA

UNITS: NA

DOMAIN: datetime

DEFINITION: Projected release date

SDE FIELD NAME: providence_code

DATA TYPE: char

LENGTH: 3

PRECISION: NA

UNITS: NA

DOMAIN: alphanumeric

DEFINITION: Providence code

SDE FIELD NAME: providence_name

DATA TYPE: char

LENGTH: 14

PRECISION: NA

UNITS: NA

DOMAIN: alphanumeric

DEFINITION: Providence name

SDE FIELD NAME: record id

DATA TYPE: integer

LENGTH: 4

PRECISION: NA

UNITS: NA

DOMAIN: numeric

DEFINITION: Record number 
SDE FIELD NAME: record_type_code

DATA TYPE: char

LENGTH: 1

PRECISION: NA

UNITS: NA

DOMAIN: alphanumeric

DEFINITION: Code indicating type of header record

SDE FiELD NAME: region_code

DATA TYPE: char

LENGT:A: 3

PRECISION: NA

UNITS: NA

DOMAIN: alphan smeric

DEFINITION: Region code

SDE FIELD NAME: release_id

DATA TYPE: char

LENGTH: 14

PRECISION: NA

UNITS: NA

DOMAIN: alphanumeric

DEFINITION: Release number

SDE FIELD NAME: release_routing_id

DATA TYPE: char

LENGTH: 7

PRECISION: NA

UNITS: NA

DOMAIN: alphanumeric

DEFINITION: Release's routing ID

SDE FIELD NAME: reoffer_poe

DATA TYPE: char

LENGTH: 3

PRECISION: NA

UNITS: NA

DOMAIN: alphanumeric

DEFINITION: POE to which request is reoffered 
SDE FIELD NAME: reoffer_posted_date

DATA TYPE: date

LENGTH: 8

PRECISION: NA

UNITS: NA

DOMAIN: datetime

DEFINITION: Date reoffer posted

SDE FIELD NAME: repair_port_etui

DATA TYPE: date

LENGTH: 8

PRECISION: NA

UNITS: NA

DOMAIN: datetime

DEFINITION: Estimated datetime of arrival at port of repair

SDE FIELD NAME: repair_replacement_cost

DATA TYPE: money

LENGTH: 8

PRECISION: NA

UNITS: NA

DOMAIN: numeric

DEFINITION: Total cost of repair or replacement

SDE FIELD NAME: reponsible_org_code

DATA TYPE: char

LENGTH: 1

PRECISION: NA

UNITS: NA

DOMAIN: alphanumeric

DEFINITION: Code indicating organization type responsible for discrepancy

SDE FIELD NAME: reporting_activity_area_code

DATA TYPE: char

LENGTH: 1

PRECISION: NA

UNITS: NA

DOMAIN: alphanumeric

DEFINITION: Code indicating reporting activity area of operation 
SDE FIELD NAME: requestor_dodaac

DATA TYPE: char

LENGTH: 6

PRECISION: NA

UNITS: NA

DOMAIN: alphanumeric

DEFINITION: Requestor DODAAC

SDE FIELD NAME: requestor_id

DATA TYPE: char

LEIJGTH: 8

PRECISION: NA

UNITS: NA

DOMAIN: alphanumeric

DEFINITION: ID of requestor

SDE FIELD NAME: requestor_name

DATA TYPE: char

LENGTH: 20

PRECISION: NA

UNITS: NA

DOMAIN: alphanumeric

DEFINITION: Name of requestor

SDE FIELD NAME: requestor_phone

DATA TYPE: char

LENGTH: 10

PRECISION: NA

UNITS: NA

DOMAIN: alphanumeric

DEFINITION: Telephone number of requestor

SDE FIELD NAME: requestor_routing_id

DATA TYPE: char

LENGTH: 7

PRECISION: NA

UNITS: NA

DOMAIN: alphanumeric

DEFINITION: Requestor's routing ID 
SDE FIELD NAME: required_delivery_date

DATA TYPE: date

LENGTH: 8

PRECISION: NA

UNITS: NA

DOMAIN: datetime

DEFINITION: Date by which cargo delivery is required

SDE FIELD NAME: reserve_unit_code

DATA TYPE: char

LENGTH: 4

PRECISION: NA

UNITS: NA

DOMAIN: alphanumeric

DEFINITION: Code for reserve unit(s) that manage the port

SDE FIELD NAME: responsible_uic

DATA TYPE: char

LENGTH: 6

PRECISION: NA

UNITS: NA

DOMAIN: alphanumeric

DEFINITION: UIC of responsible organization

SDE FIELD NAME: sail_date

DATA TYPE: daté

LENGTH: 8

PRECISION: NA

UNITS: NA

DOMAIN: datetime

DEFINITION: Date ship begins voyage

SDE FIELD NAME: second_destination_rail_scac

DATA TYPE: char

LENGTH: 4

PRECISION: NA

UNITS: NA

DOMAIN: alphanumeric

DEFINITION: Secondary destination rail SCAC 
SDE FIELD NAME: second_origin_rail_scac

DATA TYPE: char LENGTH: 4

PRECISION: NA

UNITS: NA

DOMAIN: alphanumeric

DEFINITION: Secondary origin rail SCAC

SDE FIELD NAME: self_sustaining_flag

DATA TYPE: char

LENGTH: 1

PRECISION: NA

UNITS: NA

DOMAIN: $\mathrm{Y} / \mathrm{N}$

DEFINITION: Flag indicating self-sustaining mode

SDE FIELD NAME: service_type_code

DATA TYPE: integer

LENGTH: 4

PRECISION: NA

UNITS: NA

DOMAIN: numeric

DEFINITION: Code indicating type of service

SDE FIELD NAME: ship_agent_code

DATA TYPE: char

LENGTH: 2

PRECISION: NA UNITS: NA

DOMAIN: alphanumeric

DEFINITION: Code indicating Ship agent

SDE FIELD NAME: ship_barge_capacity

DATA TYPE: char

LENGTH: 5

PRECISION: NA

UNITS: NA

DOMAIN: alphanumeric

DEFINITION: Ship's barge capacity 
SDE FIELD NAME: ship_call_sign

DATA TYPE: char

LENGTH: 8

PRECISION: NA

UNITS: NA

DOMAIN: alphanumeric

DEFINITION: Ship's call sign

SDE FIELD NAME: ship_id

DATA TYPE: char

LENGTH: 50

PRECISION: NA

UNITS: NA

DOMAIN: alphanumeric

DEFINITION: Ship number

SDE FIELD NAME: ship_inactive_date

DATA TYPE: date

LENGTH: 8

PRECISION: NA

UNITS: NA

DOMAIN: datetime

DEFINITION: Date vessel becomes inactive

SDE FIELD NAME: ship_loading_percent

DATA TYPE: float

LENGTH: 8

PRECISION: 1

UNITS: percentages

DOMAIN: $0.0-100.0$

DEFINITION: Percentage of the ship loaded with cargo

SDE FIELD NAME: ship_name

DATA TYPE: char

LENGTH: 20

PRECISION: NA

UNITS: NA

DOMAIN: alphanumeric

DEFINITION: Name of ship 
SDE FIELD NAME: ship_nationality_code

DATA TYPE: char

LENGTH: 2

PRECISION: NA

UNITS: NA

DOMAIN: alphanumeric

DEFINITION: Code indicating the flag under which the ship is sailing

SDE FIELD NAME: ship_speed_knots

DATA TYPE: float

LENGTH: 8

PRECISION: 1

UNITS: knots

DOMAIN: numeric

DEFINITION: Ship speed in nautical miles per hour

SDE FIELD NAME: ship_status_code

DATA TYPE: char

LENGTH: 3

PRECISION: NA

UNITS: NA

DOMAIN: alphanumeric

DEFINITION: Code indicating condition of ship

SDE FIELD NAME: ship_subtype_code

DATA TYPE: char

LENGTH: 15

PRECISION: NA

UNITS: NA

DOMAIN: alphanumeric

DEFINITION: Code indicating subtype of ship

SDE FIELD NAME: ship_type_code

DATA TYPE: char

LENGTH: 3

PRECISION: NA

UNITS: NA

DOMAIN: alphanumeric

DEFINITION: Code indicating type of ship 
SDE FIELD NAME: shipment_correction_date

DATA TYPE: date

LENGTH: 8

PRECISION: NA

UNITS: NA

DOMAIN: datetime

DEFINITION: Date of correction of shipment record

SDE FIELD NAME: shipment_correction_user_id

DATA TYPE: char

LENGTH: 3

PRECISION: NA

UNITS: NA

DOMAIN: alphanumeric

DEFINITION: ID of user responsible for correction

SDE FIELD NAME: shipment_method_code

DATA TYPE: char

LENGTH: 1

PRECISION: NA

UNITS: NA

DOMAIN: alphanumeric

DEFINITION: Cride indicating method used for initial shipment from origin

SDE FIELD NAME: shipper_dodaac

DATA TYPE: char

LENGTH: 6

PRECISION: NA

UNITS: NA

DOMAIN: alphanumeric

DEFINITION: Shipper DODAAC

SDE FIELD NAME: shipping_document_id

DATA TYPE: char

LENGTH: 10

PRECISION: NA

UNITS: NA

DOMAIN: alphanumeric

DEFINITION: Shipping document number 
SDE FIELD NAME: shipping_document_type_code

DATA TYPE: char

LENGTH: 2

PRECISION: NA

UNITS: NA

DOMAIN: alphanumeric

DEFINITION: Code indicating type of shipping document

SDE FIELD NAME: shipping_name

DATA TYPE: vchar

LENGTH: 50

PRECISION: NA

UNITS: NA

DOMAIN: alphanumeric

DEFINITION: Shipping name

SDE FIELD NAME: sitrep_listing_flag

DATA TYPE: char

LENGTH: 1

PRECISION: NA

UNITS: NA

DOMAIN: $\mathrm{Y} / \mathrm{N}$

DEFINITION: Flag indicating ship's final listing on SITREP

SDE FIELD NAME: soco_carriage_terms

DATA TYPE: char

LENGTH: 2

PRECISION: NA

UNITS: NA

DOMAIN: alphanumeric

DEFINITION: Code indicating SOCO terms of carriage

SDE FIELD NAME: soco_routing_index

DATA TYPE: char

LENGTH: 2

PRECISION: NA

UNITS: NA

DOMAIN: alphanumeric

DEFINITION: SOCO routing index 
SDE FIELD NAME: soco_vessel_id

DATA TYPE: char

LENGTH: 4

PRECISION: NA

UNITS: NA

DOMAIN: alphanumeric

DEFINITION: SOCO vessel number

SDE FIELD NAME: splc

DATA TYPE: char

LENGTH: 6

PRECISION: NA

UNITS: NA

DOMAIN: alphanumeric

DEFINITION: SPLC

SDE FIELD NAME: spoe_name

DATA TYPE: char

LENGTH: 50

PRECISION: NA UNITS: NA

DOMAIN: alphanumeric

DEFINITION: Name of SPOE

SDE FIELD NAME: spot_date

DATA TYPE: date

LENGTH: 8

PRECISION: NA

UNITS: NA

DOMAIN: datetime

DEFINITION: Spot date

SDE FIELD NAME: sro_due_at_pod_date

DATA TYPE: date

LENGTH: 8

PRECISION: NA

UNITS: NA

DOMAIN: datetime

DEFINITION: Date due at POD on SRO 
SDE FIELD NAME: sro_id

DATA TYPE: char

LENGTH: 4

PRECISION: NA

UNITS: NA

DOMAIN: alphanumeric

DEFINITION: ID of Standing Route Order

SDE FIELD NAME: sro_poe

DATA TYPE: char

LENGTH: 3

PRECISION: NA

UNITS: NA

DOMAIN: alphanumeric

DEFINITION: POE on SRO

SDE FIELD NAME: sro_transportation_mode_code

DATA TYPE: char

LENGTH: 1

PRECISION: NA

UNITS: NA

DOMAIN: alphanumeric

DEFINITION: Code indicating SRO transportation mode

SDE FIELD NAME: station_name

DATA TYPE: char

LENGTH: 9

PRECISION: NA

UNITS: NA

DOMAIN: alphanumeric

DEFINITION: Abbreviated station name

SDE FIELD NAME: stow_factor

DATA TYPE: char

LENGTH: 4

PRECISION: NA

UNITS: NA

DOMAIN: alphanumeric

DEFINITION: Stow factor 
SDE FIELD NAME: stowage_capacity

DATA TYPE: integer

LENGTH: 4

PRECISION: NA

UNITS: NA

DOMAIN: numeric

DEFINITION: Ship's stowage capacity

SDE FIELD NAME: stuffing_activity_code

DATA TYPE: char

LENGTH: 4

PRECISION: NA

UNITS: NA

DOMAIN: alphanumeric

DEFINITION: Code indicating activity responsible for stuffing container

SDE FIELD NAME: stuffing_user_id

DATA TYPE: char

LENGTH: 3

PRECISION: NA

UNITS: NA

DOMAIN: alphanumeric

DEFINITION: ID of user entering stuffing data

SDE FIELD NAME: supplement_date

DATA TYPE: date

LENGTH: 8

PRECISION: NA

UNITS: NA

DOMAIN: datetime

DEFINITION: Date of supplement

SDE FIELD NAME: supplement_id

DATA TYPE: char

LENGTH: 2

PRECISION: NA

UNITS: NA

DOMAIN: alphanumeric

DEFINITION: ID number of supplement 
SDE FIELD NAME: tactical_zone

DATA TYPE: char

LENGTH: 2

PRECISION: NA

UNITS: NA

DOMAIN: alphanumeric

DEFINITION: Code indicating tactical zone

SDE FIELD NAME: tcmd_preparation_date

DATA TYPE: date

LENGTH: 8

PRECISION: NA

UNITS: NA

DOMAIN: datetime

DEFINITION: Preparation date of TCMD

SDE FIELD NAME: tcn

DATA TYPE: char

LENGTH: 17

PRECISION: NA

UNITS: NA

DOMAIN: alphanurneric

DEFINITION: Transportation Control Number

SDE FIELD NAME: teu

DATA TYPE: integer

LENGTH: 4

PRECISION: NA

UNITS: NA

DOMAIN: numeric

DEFINITION: Transportation equivalent units

SDE FIELD NAME: total_cargo_movement_cost

DATA TYPE: money

LENGTH: 8

PRECISION: NA

UNITS: NA

DOMAIN: numeric

DEFINITION: Total cost of cargo movement 
SDE FIELD NAME: total_cargo_stons

DATA TYPE: float

LENGTH: 8

PRECISION: 1

UNITS: stons

DOMAIN: numeric

DEFINITION: Total weight of cargo in stons

SDE FIELD NAME: total_num_barges_loaded

DATA TYPE: integer

LENGTH: 4

PRECISION: NA

UNITS: NA

DOMAIN: numeric

DEFINITION: Total number barges loaded on ship from all ports

SDE FIELD NAME: tractor

DATA TYPE: integer

LENGTH: 4

PRECISION: NA

UNITS: NA

DOMAIN: numeric

DEFINITION: Commercial tractor

SDE FIELD NAME: transaction_code

DATA TYPE: char

LENGTH: 1

PRECISION: NA

UNITS: NA

DOMAIN: alphanumeric

DEFINITION: Transaction code

SDE FIEI.D NAME: transmitted_date

DA IA TYPE: date

LENGTH: 8

PRECISION: NA

UNITS: NA

DOMAIN: datetime

DEFINITION: Date transmitted 
SDE FIELD NAME: transportation_mode_code

DATA TYPE: char LENGTH: 1

PRECISION: NA UNITS: NA

DOMAIN: alphanumeric

DEFINITION: Code indicating mode of transportation

SDE FIELD NAME: transportation_priority_code

DATA TYPE: char

LENGTH: 1

PRECISION: NA

UNITS: NA

DOMAIN: alphanumeric

DEFINITION: Code indicating priority of transportation

SDE FIELD NAME: type_packing_code

DATA TYPE: char

LENGTH: 2

PRECISION: NA

UNITS: NA

DOMAIN: alphanumeric

DEFINITION: Code indicating type of packing

SDE FIELD NAME: uic

DATA TYPE: char

LENGTH: 6

PRECISION: NA

UNITS: NA

DOMAIN: alphanumeric

DEFINITION: Unit identification code

SDE FIELD NAME: uln

DATA TYPE: char

LENGTH: 7

PRECISION: NA

UNITS: NA

DOMAIN: alphanumeric

DEFINITION: Unit line number 
SDE FIELD NAME: un_class_division_code

DATA TYPE: char

LENGTH: 2

PRECISION: NA

UNITS: NA

DOMAIN: alphanumeric

DEFINITION: United Nations class and division numbers from the International

Maritime Dangerous Goods Code (IMDGC) 49 CFR 172.102. This cocte

is part of the Unit Movement Data (UMD) detail from TC AIMS.

SDE FIELD NAME: un_na_code

DATA TYPE: char

LENGTH: 2

PRECISION: NA

UNITS: NA

DOMAIN: alphanumeric

DEFINITION: UN/NA indicator

SDE FIELD NAME: un_na_id

DATA TYPE: char

LENGTH: 4

PRECISION: NA

UNITS: NA

DOMAIN: alphanumeric

DEFINITION: UN/NA number

SDE FIELD NAME: unit_move_flag

DATA TYPE: char

LENGTH: 1

PRECISION: NA

UNITS: NA

DOMAIN: $Y / N$

DEFINITION: Flag indicating unit move

SDE FIELD NAME: unit_name

DATA TYPE: char

LENGTH: 30

PRECISION: NA

UNITS: NA

DOMAIN: alphanumeric

DEFINITION: Name of unit 
SDE FIELD NAME: unload_minutes

DATA TYPE: integer

LENGTH: 4

PRECISION: NA

UNITS: minutes

DOMAIN: numeric

DEFINITION: Time it takes to unload ship in minutes

SDE FIELD NAME: unstuffed_activity_code

DATA TYPE: char

LENGTH: 4

PRECISION: NA

UNITS: NA

DOMAIN: alphanumeric

DEFINITION: Code indicating activity responsible for unstuffing container

SDE FIELD NAME: unstuffed_cargo_cube

DATA TYPE: float

LENGTH: 8

PRECISION: 1

UNITS: cubic_feet

DOMAIN: numeric

DEFINITION: Size of unstuffed cargo in cubic feet

SDE FIELD NAME: unstuffed_cargo_stons

DATA TYPE: float

LENGTH: 8

PRECISION: 1

UNITS: stons

DOMAIN: numeric

DEFINITION: Weight of unstuffed cargo in stons

SDE FIELD NAME: unstuffed_user_id

DATA TYPE: char

LENGTH: 3

PRECISION: NA

UNITS: NA

DOMAIN: alphanumeric

DEFINITION: ID of user entering unstuffing data 
SDE FIELD NAME: van_id

DATA TYPE: char

LENGTH: 8

PRECISION: NA

UNITS: NA

DOMAIN: alphanumeric

DEFINITION: Van number

SDE FIELD NAME: van_owner_code

DATA TYPE: char

LENGTH: 4

PRECISION: NA

UNITS: NA

DOMAIN: alphanumeric

DEFINITION: Code indicating van owner

SDE FIELD NAME: van_size

DATA TYPE: float

LENGTH: 8

PRECISION: 1

UNITS: NA

DOMAIN: numeric

DEFINITION: Van size

SDE FIELD NAME: van_type_code

DATA TYPE: char

LENGTH: 1

PRECISION: NA

UNITS: NA

DOMAIN: alphanumeric

DEFINITION: Code indicating van type

SDE FIELD NAME: vehicle_miton_factor

DATA TYPE: float

LENGTH: 8

PRECISION: 2

UNITS: NA

DOMAIN: numeric

DEFINITION: Vehicle MTON factor 
SDE FIELD NAME: voyage_document_id

DATA TYPE: char

LENGTH: 5

PRECISION: NA

UNITS: NA

DOMAIN: alphanumeric

DEFINITION: Voyage Document Number

SDE FIELD NAME: water_commodity_code

DATA TYPE: char

LENGTH: 3

PRECISION: NA

UNITS: NA

DOMAIN: alphanumeric

DEFINITION: Water commodity code

SDE FIELD NAME: zip_code

DATA TYPE: char

LENGTH: 5

PRECISION: NA

UNITS: NA

DOMAIN: alphanumeric

DEFINITION: Zip code 


\section{Appendix D. SDE FIELD CROSS REFERENCE}

The following report contains SDE fields cross referenced to fields in the participating systems.

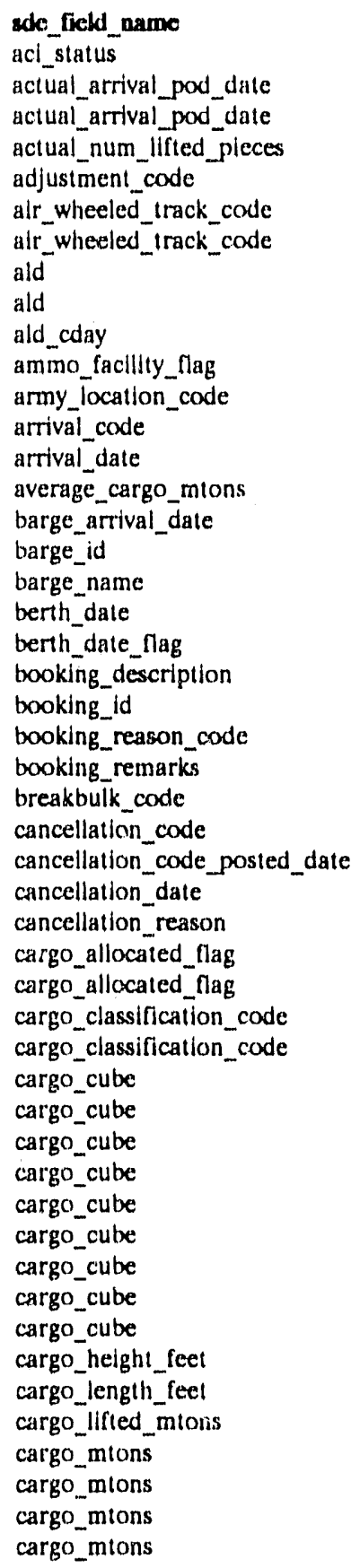

\begin{tabular}{|c|c|c|}
\hline system & table_tume & field_name \\
\hline IES & CMR_RU & ACISTAT \\
\hline WPS & VSNR̄ & ACTIL_DATE_ARV \\
\hline WPS & XVSNR & ACTL,DATE_ARV \\
\hline UDM & $\mathrm{ST}^{\prime}$ & ST.PIECES,LIFTED \\
\hline WPS & SHIPMENT & ADJ_CODE \\
\hline IBS & DETAIL & $A W \bar{T}$ \\
\hline IBS & MSTRDET & AWT \\
\hline IBS & CHANNELS & ALD \\
\hline IBS & JOPESE3 & ALD \\
\hline IBS & JOPESE3 & CALD \\
\hline IBS & PORTTHIRU & $\mathrm{AMMO}_{-} \mathrm{F}$ \\
\hline IBS & GEOFILE & ARMY \\
\hline IBS & VESSCHED & ARRIVE_T \\
\hline IBS & VESSCHED & ARRIVE_D \\
\hline IBS & LOAD'TIME & MTON_AVG \\
\hline WPS & SHIPMENT & BARGE_ARRIVAL_DATE \\
\hline WPS & SHIPMENT & BARGE_NO \\
\hline WPS & SHIPMENT & BARGE NAME \\
\hline UDM & ST & ST.BERTHED.DATE.TIME \\
\hline UDM & ST & ST.BERTHED.EST.OR.ACI' \\
\hline WPS & SHIPMENT & BOOKING DESC \\
\hline WPS & SHIPMENT & BOOKING NR \\
\hline IBS & CMR RU & BOOK RSN̄ \\
\hline IBS & CMR_RU & BOOK REM \\
\hline IBS & MADDD & BBULK $\vec{K} D$ \\
\hline IBS & CMR_RU & CANCEL_C \\
\hline IBS & CMR_RU & $\mathrm{CANC}_{-} \mathrm{D}^{-}$ \\
\hline IBS & GEOF̄ILE & CANCËLLED \\
\hline IBS & CMR_RU & CANC_RSN \\
\hline IBS & CHAÑNELS & ALLOC̄ATED \\
\hline IBS & SHORTFAL & ALLOCATED \\
\hline IDS & DETAIL & $\mathrm{CCC}$ \\
\hline IBS & MSTRDET & $\mathrm{CCC}$ \\
\hline IBS & CHANNELS & CUBE \\
\hline IBS & CMR_OUT & CUBE \\
\hline IBS & CMR_RU & CUBE \\
\hline IBS & CMR_SU & CUBE \\
\hline IBS & DETÄIL & CUBE \\
\hline IBS & MSTRDET & CUBE \\
\hline WPS & EXPLOSIVE & CUBE \\
\hline WPS & OUTSIZE & CUBE \\
\hline WPS & SHIPMENT & CUBE \\
\hline WPS & OUTSIZE & HEIGHT \\
\hline WPS & OUTSIZE & LENG'TH \\
\hline UDM & ST & ST.MTONS.LIFIED \\
\hline IBS & ALLOCATE & MTON \\
\hline IBS & CHANNEISS & MTON \\
\hline IBS & CMR_RU & MTON \\
\hline IBS & PORTTHRU & MTON \\
\hline
\end{tabular}




\begin{tabular}{|c|c|c|c|}
\hline cargo_nutons & IBS & SHIPCHAR & MTON \\
\hline cargo_mtons & IBS & SHORTFAL & MTON \\
\hline cargo_status_code & WPS & SHIPMENT & CARGO_STATUS \\
\hline cargo_type & IBS & STOWFAC'1 & CARG_TYPE \\
\hline cartier_booked_date & IBS & CMR_RU & BOOKED \\
\hline carrier id & IBS & ACHÄRGE & CARR_ID \\
\hline carrier_id & IBS & CMR_RU & CARR_ID \\
\hline carrier_id & IBS & CONTTRATE & CARRID \\
\hline carrier_id & IBS & CONUSDR & CARR ID \\
\hline carrier_ld & IBS & MT_FACT & CARR_ID \\
\hline carrier_id & IBS & OCŌNUSDR & CARR_ID \\
\hline carrier_id & IBS & VESSEL, & CARR_ID \\
\hline carrier_usage_rate_tercent & IBS & CONTRATE & PERCENT \\
\hline cas_code & IBS & ACHARGE & CAS CODE \\
\hline channel name & IBS & ALLOCATE & CHĀNNEL \\
\hline channel_nam': & IBS & CHANNELS & CHANNEL \\
\hline channel_npane & IBS & CHNLEUCR & CHANNEL \\
\hline channel .aume & IBS & SHORTFAL & CHANNEL. \\
\hline city_np.me & IBS & DODAACS & CITY \\
\hline city..name & IBS & MADD & CITY \\
\hline classified_protected_code & TDR & $?$ & CLASS/PRO'T CODES \\
\hline commercial_bus & IBS & MSTRHDR & BUS \\
\hline commercial_voyage_id & IBS & VESSCHED & COMVOYNO \\
\hline compatibility group & IBS & DETAIL & GROUP \\
\hline compatibility_group & IBS & MSTRDET & GROUP \\
\hline consignce_dodaac & IBS & CMR RU & C. DODAAC \\
\hline consignee_dodaac & IBS & CMR_SU & C_DODAAC \\
\hline consignee_name & IBS & HEAD̄ER & CŌNSIGNEE \\
\hline consignee_name & IBS & MSTRHDR & CONSIGNEE \\
\hline consignee_name & WPS & SHIPMENT & CONSIGNEE \\
\hline consignor_name & WPS & SHIPMENT & CONSIGNOR \\
\hline container_release_units & WPS & SHIPMENT & CONTAINER_RELEASE_UNIT'S \\
\hline container_seal_id & WPS & SHIPMENT & SEALNO \\
\hline country_state_code & IBS & DODAACS & STATE \\
\hline country_state_code & IBS & HEADER & STATE \\
\hline country_stale_code & IBS & MSTRHDR & STATE \\
\hline country..state _. code & TDR & $?$ & COUNTRY/STATE CODE \\
\hline country_state_long_name & IBS & GEOFILE & CS_LN \\
\hline country_8tate_long_name & IBS & POR'IS & CS LN \\
\hline created_date & IBS & GEOFILE & CREATED \\
\hline cutoff_date & IBS & VESSCHED & CUTOFF_D \\
\hline dally_flow_factor & IBS & CMR_RU & FLOW FC' \\
\hline delay _codé & IBS & CMR_RU & DELAȲ $C$ \\
\hline delay_code_posted_date & IBS & CMR_RU & DELAYD \\
\hline deletion_activity_code & WPS & SHIPM̄ENT & DELETE_ACIV_CD \\
\hline deletion_reason_code & WPS & SHIPMENT & DELETE_REASÖN \\
\hline deletion_user_id & WPS & SHIPMENT & DELETE_USER_ID \\
\hline delivered_cargo_cube & WPS & VOYDOC & DELIVERED_CÜBE \\
\hline destination_city_.name & IBS & OCONUSDR & DESTCITY \\
\hline destination_country_name & IBS & OCONUSDR & DESTCTRY \\
\hline destination_rail_spic & IBS & HEADER & D_R_SPLC \\
\hline destination_rall_splc & IBS & MSTRHDR & D_R_SPLC \\
\hline destination_truck_spic & IBS & HEADER & D_T_SPLC \\
\hline destination_truck_splc & IBS & MSTRHDR & DTTSPLC \\
\hline discharged_cargo_activity_code & WPS & SHIPMENT & DISC̈HARGE_ACTV_CD \\
\hline discharged_cargo_cube & WPS & SHIPMENT & DISCHARGED_CUBE \\
\hline discharged_cargo_cube & WPS & VOYDOC & DISCHARGED CUBE \\
\hline discharged_cargo_pod & WPS & SHIPMENT & DISCHARGE POD \\
\hline discharged cargo stons & WPS & SHIPMENT & DISCHARGED WEIGHT \\
\hline
\end{tabular}

MTTT Shared Data Environment D-2

January 20,1992 


\begin{tabular}{|c|c|c|c|}
\hline discharged_cargo_user_id & WPS & SHIPMENT & DISCHARGE_USER_ID \\
\hline discharged_completion_date & WPS & VOYDOC & DISCH_COMP_DATE \\
\hline discharged_start_date & WPS & VOYDOC & DISCH_START_DATE \\
\hline discrepancy_cargo_stons & TDR & $?$ & DISCRĒEP. WEIG̈HT \\
\hline discrepancy_code & TDR & $?$ & CAUSE OF DISCREPANCY \\
\hline diverted_cargo_cube & WPS & VOYDOC & DIVERTED_CUBE \\
\hline diverted_cargo_pod & WPS & SHIPMENT & DIVERTED_POD \\
\hline dodaac & IBS & DODAACS & DODAAC \\
\hline dodaac & TDR & $?$ & DODAAC \\
\hline dodic & IBS & DETAIL & DODIC \\
\hline dodic & IBS & MSTRDET & DODIC \\
\hline dodic & WPS & SHIPMENT & DODIC \\
\hline domestic_ucr & IBS & MSTRHDR & DUCR \\
\hline drop..trame & IBS & MSTRHDR & DROP \\
\hline due_at_poe_date & IBS & CMR_RU & D_DUE_POE \\
\hline ead & IBS & CHAN̄NELS & $E \bar{A} D$ \\
\hline ead & IBS & JOPESE3 & $\mathrm{EAD}$ \\
\hline ead_cday & IBS & JOPESE3 & CEAD \\
\hline effective_date & IBS & MADD & EFFECTIVE \\
\hline entry_date & IBS & VESSCHED & ENTRY_D \\
\hline entry_date & IBS & VESSEL & ENTRY_D \\
\hline equipment_length_feet & IBS & ACHARGE & EQUIP_LEN \\
\hline estimated_completion_date & WPS & VSNR & EST_CÖMP_DATE \\
\hline estimated_completion_date & WPS & XVSNR & EST_COMP_DATE \\
\hline eta & WPS & SHIPMENT & ETA \\
\hline eta & WPS & VSNR & ETA \\
\hline eta & WPS & XVSNR & ETA \\
\hline etr_release_date & IBS & CMR_RU & REL_D \\
\hline etr_release_poe & IBS & CMR_RU & REL_POE \\
\hline etrT_received_date & IBS & CMR_RU & RECD_D \\
\hline export_import_flag & WPS & SHIPM̄ENT & EXPORT_IMPORT_IND \\
\hline export_import_flag & WPS & SUPPLEMENT & EXPORT_IMPORT_IND \\
\hline export_import_flag & WPS & VOYDOC & EXPORT_IMPORT_IND \\
\hline export_import_flag & WPS & VSNR & EXPORT_IMPORT_IND \\
\hline export_import_flag & WPS & XVOYDOC & EXPORT_IMPORT_IND \\
\hline export_import_flag & WPS & XVSNR & EXPORT_IMPORT_IND \\
\hline export_ucr_flag & IBS & HEADER & EUCR \\
\hline export_ucr_llag & IBS & MSTRHDR & EUCR \\
\hline flash_point & IBS & DETAIL & FLASHPT \\
\hline flash_point & IBS & MSTRDET & FLASHPT \\
\hline freight_classification_code & IBS & DETAIL & FRGTNO \\
\hline freight_classification_code & IBS & MSTRDET & FRGTNO \\
\hline freight_classification_index & IBS & DETAIL & FRGTNDX \\
\hline freight_classification_Index & IBS & MSTRDET & FRGTNDX \\
\hline funding_agency_code $\bar{e}^{-}$ & IBS & CMR_RU & FUND_AG \\
\hline funding_agency_code & IBS & CMR_SU & FUND_AG \\
\hline$g b \mid$ & WPS & SHIPMENT & $\mathrm{GBL}$ \\
\hline gbl_office_code & IBS & HEADER & GBLOC \\
\hline gbl_office_code & IBS & MSTRHDR & GBLOC \\
\hline generic_port_location & UDM & ST & ST.POR'T.COMMAND \\
\hline geolocation_code & IBS & GEOFILE & GEOCODE \\
\hline geolocalion_code & IBS & PORTS & GEOCODE \\
\hline gsa_cily_code & IBS & GEOFILE & GSACITY \\
\hline gsa_country_code & IBS & GEOFILE & GSACOUNTY \\
\hline gsa_state_code & IBS & GEOFILE & GSASTATE \\
\hline hazardous_cargo_flag & IBS & DETAIL & HAZARD \\
\hline hazardous_cargo_flag & IBS & MSTRDET & HAZARD \\
\hline heavy_lift_dimension_code & IBS & DETAIL & HLDC \\
\hline heavy_lift_dimension_code & IBS & MSTRDET & HLDC \\
\hline
\end{tabular}




\begin{tabular}{|c|c|c|c|}
\hline lcao_code & IBS & GEOFILE & ICAO \\
\hline Installation_type_code & IBS & GEOFILE & ITC \\
\hline Julian_date & TDR & $?$ & DATE \\
\hline lad & IBS & CHANNELS & LAD \\
\hline lad & IBS & JOPESE3 & LAD \\
\hline lad cday & IBS & JOPESE3 & CLAD \\
\hline lading_term_code & IAS & CMR_RU & LTC \\
\hline lifi_activity_code & WPS & SHIPMEN"I & LIFT_ACTV_CD \\
\hline lift_capability_sq_ft & UDM & ST & ST.LIFI:CAP,SQ,FI \\
\hline lift_cargo_sq_ft & UDM & $\mathrm{ST}$ & ST.SQ.FIILIFIEIS \\
\hline lift_date & IBS & CMR_RU & LIFT_D \\
\hline lift_user_id & WPS & SHIPMENT & LIFT_USEIR_ID \\
\hline line $e_{-}$tem_ld & IBS & DETAIL & LIN \\
\hline line_ilem_id & IBS & MSTRDET & LIN \\
\hline load_completion_date & WPS & XVOYDOC & LOAD_COMP_DATE \\
\hline load_completion_date & WPS & XVSNR & LOAD_COMP_DATE \\
\hline logistics planning_report code & IBS & GEOFILE & LPRC \\
\hline long_tons & IBS & CMR RU & LTON \\
\hline lot id & WPS & EXPLOSIVE & LOT \\
\hline lowboy & IBS & MSTRHDR & LOWBOY \\
\hline majority unit loaded_name & UDM & ST & ST,MAJORITYUNITILOADISI) \\
\hline manifest actual arrival date & UDM & ST & ST.MFST.ARIV.SPOD.DATIE \\
\hline manifest cargo cube & WPS & SHIPMENT & MANIFEST_CUBE \\
\hline manifest_cargo_stons & WPS & SHIPMENT & MANIFEST_WEIGHT \\
\hline manifest carrier name & UDM & ST & ST.MNFST,C̄ARRIER \\
\hline manifest_date & WPS & SHIPMENT' & MANIFEST_DATE \\
\hline manifesi_flag & WPS & SHIPMENT & MANIFEST_IND \\
\hline manifest_loading_date & WPS & VOYDOC & MNFST_LOADED_DATE \\
\hline manifest_loading_date & WPS & XVOYDOC & MNFST_LOADED_DATE \\
\hline manifest_sent_date & UDM & ST & ST.MNFST.SENT.DATE.TIME \\
\hline manifest shipment id & UDM & ST & ST.MNFST,SHHIPENT,ID \\
\hline manifest_type_cargo_code & UDM & ST & ST.MNFST.TYPE.CARGO \\
\hline message_id & IBS & PCALLMSO & MSGID \\
\hline milstrip_project_code & WPS & SHIPMENT & PROJECT_CODE \\
\hline mton factor & IBS & $\mathrm{MT}$ _FACT & MTFACTOR \\
\hline navy_ocean_area_code & IBS & GEÖFILE & NAVY \\
\hline net_explosive_weight_stons & WPS & EXPLOSIVE & NET_EXPLOSIVE_WT \\
\hline num_actual loading minutes & UDM & ST & ST.HOURS.WORKED \\
\hline num_barges at port & UDM & ST & ST.PORT.TOTAL.BARGES \\
\hline num barges loaded & UDM & ST & ST.POR'T,BARGES,LOADED \\
\hline num barges stuffed & UDM & ST & ST.PORT.BARGES.STUFFED \\
\hline num_containers & IBS & VESSEL & NO CONT \\
\hline num_containers delivered & WPS & VOYDOC & DELIVERED_CONTAINERS \\
\hline num containers discharged & WPS & VOYDOC & DISCHARGED CONTAINERS \\
\hline num containers diverted & WPS & VOYDOC & DIVERTED CONTAINERSS \\
\hline num_discrepancy_pieces & TDR & $?$ & DISCREP, PIECES \\
\hline num_manlfest_pleces & WPS & SHIPMENT & MANIFEST_PIECES \\
\hline num_manifest_shipment_units & WPS & XVOYDOC & MNNST_LOADED_SU \\
\hline num_persons_shipped & UDM & ST & ST.SUPER.CARGŌ \\
\hline num_pleces & IBS & CMR_OUT & PCS \\
\hline num_pieces & IBS & CMR_RU & PCS \\
\hline num_pieces & IBS & CMR_SU & PCS \\
\hline num pieces & WPS & EXPLOSIVE & PCS \\
\hline num pieces & WPS & OUTSIZE & PCS \\
\hline num pieces & WPS & SHIPMENT & PCS \\
\hline num pieces discharged & WPS & SHIPMENT & DISCHARGED PIECES \\
\hline num rail transit days & IBS & INTRANS & RAIL_D \\
\hline num shipment units & IBS & CMR RU & NO_SU \\
\hline num_standard Inading_minutes & UDM & $\mathrm{ST}$ & ST.LOAD.STANDARD.DAYS \\
\hline
\end{tabular}




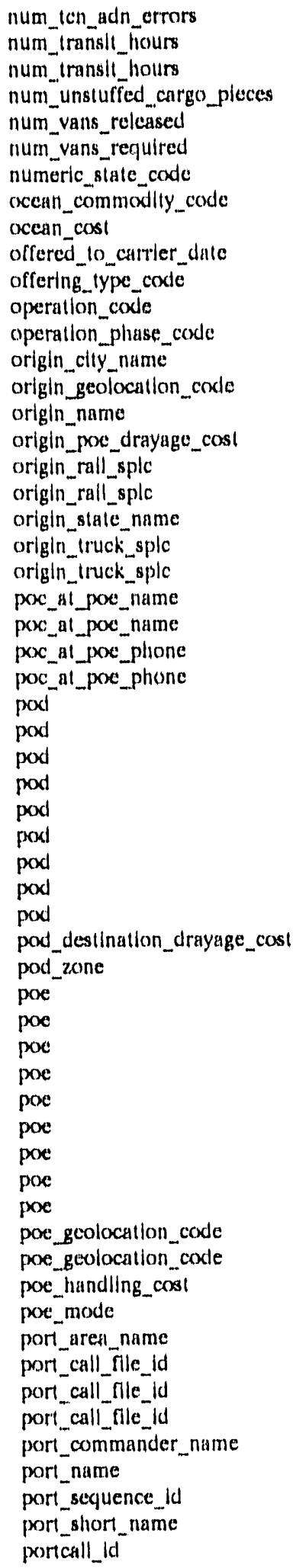

\begin{tabular}{|c|c|c|}
\hline TDR & $?$ & NO, 'TCN/ADN LIRROKSS \\
\hline IBS & OCNTIME & DAYS \\
\hline IBS & OCNTIME & HOURS \\
\hline WI'S & SHIPMEN'T & UNSTUHT_PIECES \\
\hline IBS & CMR_RU & VAN-RISSD \\
\hline IBS & $\mathrm{CMR}_{-1} \mathrm{RU}$ & VAN_REQD \\
\hline IBS & MADİ & $N\left(U M_{-} S^{\prime} T C D\right)$ \\
\hline IBS & CMR_RU & $O C N$ COMM \\
\hline IBS & CMR_RU & OCEANN_COST' \\
\hline IBS & CMR_RU & OFIERED \\
\hline IBS & CMR_RU & TYPE_OFFER \\
\hline WPS & SHIPMEN'I' & OPCODE \\
\hline UDM & $5 \mathrm{~T}$ & STIPHIASE \\
\hline IBS & CONUSDR & ORIOINC \\
\hline IBS & MSTRHIDR & ORIOIN.G \\
\hline IBS & INTRANS & ORIOIN \\
\hline IIBS & CMR_RU & CONUS_COS'I \\
\hline IBS & HEADEER & O_R_SPLC \\
\hline IHS & MSTTRHDR & O_R_SPLC \\
\hline IBS & CONUSDK & OR̈IÖINS \\
\hline IBS & HEADER & O_TSSPLC \\
\hline IBS & MSTRIIDR & $O_{-}^{-T S S P L C}$ \\
\hline IIBS & CHNLEUCR & POEPOC \\
\hline IBS & EUCR & POEPOC \\
\hline IBS & CHNLEUCR & POEFONE \\
\hline IBS & EUCR & POEIIONE \\
\hline IBS & CHANNELS & POD \\
\hline IBS & CMR_RU & POD \\
\hline IBS & $\mathrm{CMR}_{-} \mathrm{SU}$ & POD \\
\hline IBS & JOPESE3 & POD \\
\hline IBS & MADD & POD \\
\hline WPS & SHIPMEN'T' & POD \\
\hline wrs & SUPPLEMENT & POD \\
\hline WPS & VOYDOC & POD \\
\hline WPS & XVOYDOC & POD \\
\hline IBS & CMR_RU & OCONS_COST \\
\hline IBS & CON'TRATTE & PODZONE \\
\hline IBS & CHANNELS & POE \\
\hline IBS & CMR_RU & POE \\
\hline IBS & INTKANANS & POE \\
\hline IBS & JOPESE3 & POE \\
\hline IBS & PCALLMSO & POE \\
\hline WPS & SHIPMEN'T & POE \\
\hline WPS & SUPPLEMEN'T & POE \\
\hline WPS & VOYDOC & POE \\
\hline WPS & XVOYDOC & POE \\
\hline IBS & INTRANS & $\mathrm{POE}-\mathrm{G}$ \\
\hline IBS & PORTTHIRU & POE_G \\
\hline IBS & CMR_RU & POE_COST \\
\hline IBS & PORTTT-IRU & POE MOD \\
\hline IBS & PORTS & HORTAREA \\
\hline IBS & CMR_OUT & PCIN \\
\hline IBS & CMR_RU & PCFN \\
\hline IBS & CMR_SU & PCFN \\
\hline UDM & $S^{\prime} \Gamma$ & STIPORTICMDRSANAMI: \\
\hline IBS & PORTS & POIRTNAME \\
\hline UDM & $\mathrm{S}^{\prime} \mathrm{T}$ & STIPOR'T.SEQ \\
\hline IBSS & POR'IS & SHORTPORT \\
\hline WPS & SHIPMENT' & POR'TCALL_NUMBER \\
\hline
\end{tabular}




\begin{tabular}{|c|c|c|c|}
\hline por _ecolor cende & WPS & SHII'MEN'I' & POVCOLOR \\
\hline pov_llconse_lag & Wis & SHIPMENT & POVLICLNSI! \\
\hline por Illcenso lag nlale ceode & WPS & SHIIPME'N'T' & POVSTATIE: \\
\hline prov_mako_model_codo & WPS & SHIIPMEN'1' & POVMAKI! \\
\hline pKov_manufacture year & WPS & SHIII'MEN'T' & PCIVYR \\
\hline primary_destination_rall_scac & IBS & HEADER & P_D_R_SCAC \\
\hline primary_destination_rnil_scac & IBS & MSTTRHDR & P_D_R_SCAC \\
\hline primary_orlgln_rall_scac & IIIS & HIEADER & PO_K_SCAC \\
\hline primary_origln_rall_scac & IBS & MS'TRHIDR & $\mathrm{POO} \mathrm{O}_{-} \mathrm{SCAC}$ \\
\hline prime_gerolocalion code & IBS & OLOFILE & $\mathrm{P} \mathrm{CHOO}^{\circ}$ \\
\hline private_siddag_flag & IBSS & HEADER & P'si \\
\hline privato_sidlng_.llag & IBSS & MS'TRHDR & PSI \\
\hline projected_roleaso_date & IBS & CMR_RU & PRI'KEL, D \\
\hline providence_cosde & IBS & OEOFIILE & PKOV_CD \\
\hline providence...namo & IIIS & OEOTILE & PKOV_N \\
\hline record_Id & WPS & EXPLOSIVE & RECNO \\
\hline record Id & WPS & OUTSIZE & RLCNO \\
\hline record_Id & WPS & REMARKS & RECNO \\
\hline record_id & WPS & SHIIPMENT & RECNO \\
\hline record_type_code & TDR & $?$ & RECORY TYYPE \\
\hline reglon_..codio & IAS & ACHAROE & RESO_CODL? \\
\hline release_ld & IBS & CHNLEUCR & RELEASE \\
\hline release $1 d$ & IBS & EUCR & RELEASE \\
\hline release_id & IBS & EUCR4 & RELLEASE \\
\hline release_|d & IBS & HEADER & RELEASE \\
\hline releasc_id & IBS & MSTRHDR & RELEASE \\
\hline release_routing id & IBS & CMR_RU & REL_ROU'IID \\
\hline reoffer_poc & IBS & CMR_KU & REOFFR_POE \\
\hline reoffer_posted_dato & IBS & CMR_RU & REOFIR_D \\
\hline repalr.jport_ctä & UDM & $S T-$ & STTREPAIR,PORT.ETA \\
\hline repalt_replacement_cost & TDR & 7 & REPAIR COST \\
\hline reponsible_org_code & TDR & $?$ & RESPONSIBILIT'Y CODE \\
\hline reporting_... & TDR & 7 & AREA OF OPERAIIION \\
\hline requesior_dodaac & IBS & CMR_RU & R_DODAAC \\
\hline requestor_dodanc & IBS & EUCR & R_DODAAC \\
\hline requestor_dodaac & IIBS & HEADER & R_DODAAC \\
\hline requestor_dodaac & IBS & MSTRHDR & R_DODAAC \\
\hline requestor_id & IBS & CMR_RU & R_ID \\
\hline requestor_ld & IBS & EUCR & $R_{\text {IID }}$ \\
\hline requestorid & IBS & HEADER & $R_{-1 D}$ \\
\hline requestor_id & IBS & MSTRHDR & $R_{\text {mID }}$ \\
\hline requestor name & IBS & HEADER & REQNAME \\
\hline requestor_name & IBS & MSTRHIDR & REQNAME \\
\hline requestor_phono & IBS & HEADER & REQPHONE \\
\hline requestor_phone & IBS & MSTRHDR & REQPHONE \\
\hline requestor_routing id & IBS & CMR_RU & REQ_ROUTII \\
\hline required_delivery_date & IBS & CMR_RU & $\mathrm{RDD}^{-}$ \\
\hline required_delivery_dato & IBS & CMR_SU & RDD \\
\hline requlred_delivery_date & IBS & HEADERR & RDD \\
\hline required_dellvery_date & IBS & MSTRHDR & RDD \\
\hline required_delivery_date & WPS & SHIPMENT & RDD \\
\hline reserve_unli _code & UDM & sT & S'T.PORT,'TTYS \\
\hline responsible_ulc & IBS & GEOFILE & UIC_RESP \\
\hline sail_dale & IBS & AL.LOCATE & SAIL_D \\
\hline sall_date & IBS & VESSCHED & SAIL_D \\
\hline second_destinatlon_rall_scac & IBS & HEADER & $S_{-} D_{-} \bar{R}_{-} S C A C$ \\
\hline recond_destination_rali_scac & IBS & MSTRHDR & S_D_R_SCAC \\
\hline second_origin_rail__scac & IBSS & HEADER & S_O_R_SCAC \\
\hline second_origin_rail_scac & IAS & MSTRRHDR & S_O_R_SCAC \\
\hline
\end{tabular}




\begin{tabular}{|c|c|c|c|}
\hline solf_sustalning..llag & IIIS & SHIIPCHAR & SS \\
\hline servite _lypo_code & IBS & ACHARGE & TYPE_SLRY \\
\hline ship_..agent_exde & WI'S & VSNIR & SHII'.ABCIEN' \\
\hline ship_agent_code & W'S & XVSNR & SHIP_AGENT \\
\hline Whip_bargo_capaclly & UDM & $S^{\prime} T$ & S'I'STIIIPS,BAROE,CAP' \\
\hline shlp_call_sign & IBS & VESSIEL & CALLSIGN \\
\hline ship_cosde & WPS & SHIPMEN'T' & SHIP_COLE \\
\hline $\operatorname{shl}\left|p_{-}\right| d \mid$ & IBS & PCALLMSG & SHIIPNUMMBR \\
\hline $\sin 12 \operatorname{sed}$ & WPS & SHIPMEN'T & VSNR \\
\hline ship.id & WPS & SUPPLEMEN'T & VSNR \\
\hline $\operatorname{sh}|p| p_{m} \mid d$ & WPS & VOYDOC & VSNIR \\
\hline ship_. & WP'S & VSNR & VSNR \\
\hline ship_inactive date & WPS & VSNR & DATE INACI \\
\hline shlp_inaotive_dato & WPS & XVSNR & DATE_INACT \\
\hline ship_loading percont & UDM & ST & STIPERCENTILOADED \\
\hline shlip_name & IBS & ALLOCATE & SHIIPNAME \\
\hline ship name & IBS & CHINLEUCR & VESSELNAME \\
\hline ship name & IBS & EUCR & VESSELNAME \\
\hline ship_name & IBS & VESSEL & SHIIPNAME \\
\hline ship_narno & IBS & VOYACE & SHIIPNAME \\
\hline ship_natlonality_code & IBS & VESSEL & FLAG \\
\hline ship_speed_knots & IBS & OCNTIME & SPEED \\
\hline ship_spreed_knots & IBS & SHIPCHAR & SPEED \\
\hline ship_status_code & UDM & $\mathbf{S T}^{\prime}$ & ST,SHIP,S'ATUS \\
\hline ship_status_codo & WI'S & SHIPMENT' & VSTAT \\
\hline ship_status_code & WPS & SUPPLEMENT & VSI'A'T \\
\hline shlp_status_code & WPS & VOYDOC & VS'TAT' \\
\hline ship_status_rode & WPS & XVOYDOC & VS'TAT' \\
\hline ship_subtype_code & IBS & LOADTIME & SUBTYPE \\
\hline ship_subtype_code & IBS & SHIPCHLAR & SUBTYPE \\
\hline shlp_type_codo & IBS & LOADTIME & SHIPTYPE \\
\hline ship_type_code & IBS & SHIPCHLAR & SHIPTYPE \\
\hline ship_type_codo & IBS & STOWFACT & SHIPTYPE \\
\hline ship_type_code & IBS & VESSEL & SHIP'TYPE \\
\hline ship_type_code & IBS & VOYAGE & SHIP'TYPE \\
\hline ship_type_code & UDM & ST & ST,IYPE.VESSEL \\
\hline shipment_correction_date & WPS & SHIPMENT & CORRECTION DATE \\
\hline shipment_correction_user_id & WPS & SHIPMENT & CORRECTION USER ID \\
\hline shipment_method_cude & T'DR & $?$ & METHOD SHIPMENT \\
\hline shlpper_dodanc & IBS & CMR_RU & S DODAAC \\
\hline shilpper_dodaac & IBS & HEADEER & SDODAAC \\
\hline shipper_dodaac & IBS & MSTRHDR & S_DODAAC \\
\hline shipping_.document_id & TDR & $?$ & SHIPPING DOC, NO. \\
\hline shipping_documeni_type_code & TDR & $?$ & TYPE CODE \\
\hline shipplng_name & IBS & DETAIL. & SHPGNAME \\
\hline shlpplng_numo & IBS & MS'TRDET & SHPGNAME \\
\hline sitrep_listing_tlag & UDM & ST & ST'SITREP.FLAG \\
\hline soco_carriage_lerrns & IBS & CMR_RU & SOCO_TERM \\
\hline soco_routing_index & IBS & CMR_RU & SOCOR NDX \\
\hline soco_vessol_id & IBS & CMR_RU & SOCO_VES \\
\hline splc & IBS & $M A D D$ & SPLC \\
\hline spod_actual_arrival_date & UDM & $\mathrm{ST}$ & ST.MNFST'ARIV,SPOD.DNII: \\
\hline spoe_name & IBS & PCALLMSG & SPOENAME \\
\hline spol_date & IBS & CMR_RU & SPOT D \\
\hline sro_dut_al_.pod_date & IBS & CMRRU & SRO_DUED \\
\hline sro_id & IBS & CMR_RU & SRO ID \\
\hline sro poe & IBS & CMR RU & SRO POE \\
\hline sro... Iransportation_mode_code & IBS & CMR RU & SRO MODE \\
\hline station_narne & IBS & HEAD̄ER & STATION \\
\hline
\end{tabular}




\begin{tabular}{|c|c|c|c|}
\hline station_name & Il1s & MSTRHDR & STATIION \\
\hline slow_factor & WPS & SHIPMENT & STOW \\
\hline stowago_capacity & IBS & VESSEL & STOW_CAP \\
\hline stuffing_activity_code & WPS & SHIPMENT & STUFFINC_AC'IV_CD \\
\hline sluffing_user_ld & WISS & SHIPMENT' & STUFTING_USER_ID \\
\hline supplement_dale & WI'S & SUPPLEMENT' & SUP.DATE \\
\hline supplement dato & WIS & XVOYDOC & SUP_DATE \\
\hline supplament_td & WHS & SHII'MEN'I' & SUPÑO \\
\hline supplement_ld & WPS & SUPPLEMEN'T & SUPNO \\
\hline supplemeni_ld & WPS & XVOYDOC & SUPNO \\
\hline lactical_zone & IBS & GEOFILE & TAC_ZONE \\
\hline lemd_preparation_date & WHS & VOYDOC & TCMD_PREP_DA'TE \\
\hline Ian & IBS & CMR_OUT & $\mathrm{TCN}$ \\
\hline Ion & IBS & $\mathrm{CMR}_{-} \mathrm{SU}$ & $\mathrm{TCN}$ \\
\hline Ient & IBS & DETĀIL & TCN \\
\hline $\tan$ & IBS & EUCRA & TCN \\
\hline Ion & IBS & MSTRRE'T & TCN \\
\hline $\operatorname{lon}$ & WPS & SHIIPMENT & $\mathrm{TCN}$ \\
\hline leu & IBS & SHIIPCHAR & TEU \\
\hline lotal_cargo_movement_cost & IBS & CMR_RU & TO'TAL_COS'T \\
\hline lotal_cargo_stons & IBS & CHAÑNELS & WaT - \\
\hline total_cargo_stons & IBS & CMR_OUT & WGT \\
\hline total_cargo_stons & IBS & CMR_RU & WGT \\
\hline total_cargo_stons & IBS & CMR_SU & WGI' \\
\hline total_cargo_stons & IBS & DETÄIL & Wa'T \\
\hline tolal_cargo_stons & IBS & MS'TRDET & WGT \\
\hline total_num_barges_londed & UDM & ST & ST.SHIP,TOTALBAROESLOADIBD \\
\hline tractor & IBS & MSITRHDR & TRACTOR \\
\hline transaction_coxde & IBS & DETAIL & ACTION \\
\hline Iransaction_..code & IBS & HEADER & ACTION \\
\hline transaction_code & IBS & MSTRDET & ACTION \\
\hline transaction_code & IBS & MSTRHDR & ACTION \\
\hline transniltied_date & IBS & HEADER & TRANSMTD \\
\hline transmitted_._date & IBS & MSTRHDR & TRANSMTD \\
\hline transportation_mode & IBS & PORTTHRU & MODE_C \\
\hline Iranaportation_priority_codo & WPS & SHIPMENT & TPRI \\
\hline transportation_priority_code & IBS & CMR_RU & PRIORITY \\
\hline transpottation__priority_code & IBS & CMR_SU & PRIORITY \\
\hline transportalion_priority_code & IBS & HEAD̈ER & PRIORITY \\
\hline transportation_priority_code & IBS & MSTRHDR & PRIORITY \\
\hline type_packlng_code & WPS & SHIPMENT & PKG \\
\hline Uic & IBS & ALLOCATE & UIC \\
\hline uic & IBS & CHANNELS & UiC \\
\hline ule & IBS & DETAIL. & UIC \\
\hline ulc & IBS & EUCR & UIC \\
\hline ulc & IBS & HEADER & UIC \\
\hline uic & IBS & JOPESE3 & UIC \\
\hline ulc & IBS & MSTRDET & UIC \\
\hline ulc & IBS & MSTRHDR & UIC \\
\hline ulc & IBS & SHORTFAL & UIC \\
\hline uln & IBS & ALLOCATE & ULN \\
\hline uln & IBS & CHANNELS & ULN \\
\hline uln & IBS & DETAIL & ULN \\
\hline uln & IBS & EUCR & ULN \\
\hline uln & IBS & HEADER & ULN \\
\hline uln & IBS & JOPESE3 & ULN \\
\hline uln & IBS & MSTRDET & ULN \\
\hline uln & IBS & MSTRHDR & ULN \\
\hline uln & IBS & SHORTTAL & ULN \\
\hline
\end{tabular}




\begin{tabular}{|c|c|c|c|}
\hline uln & WPS & SHIPMENT & ULN \\
\hline un_class_division_code & IBS & DETAIL & UN_CLASS \\
\hline un_olass_divislon_code & IBS & MS'TRDET' & UN_CLASS \\
\hline un_class_divislon_coxde & WPS & SHIPMENT & UN_CLASS \\
\hline un_na_cocode & IBS & DETAIL & UNNA_IND \\
\hline un_ma_code & IBS & MSTRDET & UNNA_IND \\
\hline utI_na_mld & IBSS & DETAII, & UNNA_NO \\
\hline Un_tna_Id & IBS & MS'TRDET & UNNA_NO \\
\hline unit_move_flag & IBS & VOYAGE & UNITMOVE \\
\hline unit_name- & IBS & HEADER & UNI'INAME \\
\hline unit_name & IBS & MSTRHDR & UNITNAME \\
\hline unload_minutes & IBS & LOADTIME & UNLOAD \\
\hline unstuffed_aclivity_code & WPS & SHIIPMENT' & UNSTUFF_ACIV_CD \\
\hline ursistuffed_cargo_cube & WPS & SHIIPMEN'T' & UNSTUFF CUBE \\
\hline unstuffed_cargo_stons & WPS & SHIPMENT & UNSTUFF_WEIGHT \\
\hline unsluffed_user_id & WPS & SHIPMEN'T' & UNSTUFF_USER_ID \\
\hline van_Id & WPS & SHIPMENT & VAN_NO \\
\hline van_owner_code & WPS & SHIPMENT' & VAN_OWNER \\
\hline Van_size & WPS & SHIIPMEN'l' & VAN_SIZE \\
\hline van_type_code & IBS & MT_FACT & VAN_TYPE \\
\hline vehlcle_mion_factor & IBS & MT_EACT & VFAC̈TOR \\
\hline voyage_document_|d & WPS & SHIPMENT & VOYDOC \\
\hline voyage_documen!_id & WPS & SUPPLEMENT & VOYDOC \\
\hline voyage_ducument_id & WPS & VOYDOC & VOYDOC \\
\hline voyage_document_Id & WPS & XVOYDOC & VOYDOC \\
\hline voyage_document_ld & WPS & XVSNR & VOYDOC \\
\hline water_commodity_code & IBS & CMR_RU & COMMODITY \\
\hline water_comtnodity_code & IBS & CMR_SU & COMMODITY \\
\hline water_commodity_code & IBS & DETAIL & COMMODITY \\
\hline water_commodity_code & IBS & MSTRDET & COMMODITY \\
\hline water_commodity_code & WPS & SHIPMENT & COMMODITY \\
\hline zip_code & IBS & DODAACS & ZIP \\
\hline zlp_code & IBS & MADD & ZIP \\
\hline
\end{tabular}




\section{Appendix E. SYSTEM FIELD CROSS REFERENCE}

The following report contains fieids in the participating systems (IBS, WPS, TDR, and UDM, in that order) cross referenced to SDE fields.

\begin{tabular}{|c|c|c|}
\hline table_name & field_name & sde_field_name \\
\hline CMR_RU & ACISTAT & aci_status \\
\hline DETÄIL & ACTION & transaction_code \\
\hline HEADER & ACTION & Iransaction_code \\
\hline MSTRDET & ACTION & transaction_code \\
\hline MSTRHDR & ACTION & transaction_code \\
\hline CHANNELS & Al.D & ald \\
\hline JOPESE3 & $A L D$ & ald \\
\hline CHANNELS & ALLOCATED & cargo_allocated_flag \\
\hline SHORTFAL & ALLLOCATED & cargo_allocated_flag \\
\hline PORTTHRU & AMMO_F & ammo_facility_flag \\
\hline GEOFILE & $\mathrm{ARMY}^{-}$ & army_location_code \\
\hline VESSCHED & ARRIVE_D & arrival_date \\
\hline VESSCHED & ARRIVE_T & atrival_code \\
\hline DETAIL & AWT & air_wheeled_track_code \\
\hline MSTRDET & AWI & air_wheeled_track_code \\
\hline MADD & BBULKCD & breakbulk_code \\
\hline CMR RU & BOOKED & carrier_booked date \\
\hline CMR_RU & BOOK_REM & booking_remarks \\
\hline CMR_RU & BOOKRSN & booking reason_code \\
\hline MSTREHDR & BUS & commercial bus \\
\hline JOPESE3 & CALD & ald_cday \\
\hline VESSEL & CALLSIGN & ship_call_sign \\
\hline GEOFILE & CANCELLED & cancellationn_date \\
\hline CMR_RU & CANCEL_C & cancellation_code \\
\hline CMR_RU & $\mathrm{CANC}_{-} \mathrm{D}^{-}$ & cancellation_code_posted_date \\
\hline CMR_RU & CANC_RSN & cancellation_reason \\
\hline STOW̄'FACT & CARG_TYPE & cargo_type \\
\hline ACHARGE & CARR_ID & carrier_id \\
\hline CMR_RU & CARR_ID & carrier_id \\
\hline CONTRATE & CARR_ID & carrier_id \\
\hline CONUSDR & CARR_ID & carrier_id \\
\hline MT_FACT & CARR_ID & carrier_id \\
\hline OCÖNUSDR & CARR_ID & carrier_id \\
\hline VESSEL, & CARR_ID & carrier id \\
\hline ACHARGE & CAS CODE & cas code \\
\hline DETAIL & $\mathrm{CCC}^{-2}$ & cargo_classification_code \\
\hline MSTRDET & $\mathrm{CCC}$ & cargo_classification_code \\
\hline JOPESE3 & CEAD & ead_cday \\
\hline ALLOCATE & CHANNEL & channel_name \\
\hline CHANNELS & CHANNEL & channel_name \\
\hline CHNLEUCR & CHANNEL & channel name \\
\hline SHORTFAL & CHANNEL & channel name \\
\hline DODAACS & CITY & city name \\
\hline MADD & CITY & city_name \\
\hline JOPESE3 & CLAD & lad cday \\
\hline CMR_RU & COMMODITY & water commodity code \\
\hline CMR SU & COMMODITY & water commodity code \\
\hline DETAIL & COMMODITY & water commodity code \\
\hline MSTRDET & COMMODITY & water commodity code \\
\hline VESSCHED & COMVOYNO & commercial voyage id \\
\hline HEADER & CONSIGNEE & consignee name \\
\hline
\end{tabular}




\begin{tabular}{|c|c|}
\hline MSTRHDR & CONSIGNEE \\
\hline CMR_RU & CONUS_COST \\
\hline GEOF̄ILE & CREATEDD \\
\hline GEOFILE & $C S_{-} L N$ \\
\hline PORTS & $\mathrm{CS}_{-}^{-} \mathrm{LN}$ \\
\hline CHANNELS & CUBBE \\
\hline CMR_OUT & CUBE \\
\hline CMR RU & CUBE \\
\hline CMR_SU & CUBE \\
\hline DETĀIL & CUBE \\
\hline MSTRDET & CUBE \\
\hline VESSCHED & CUTOFF_D \\
\hline CMR RU & C_DODAAC \\
\hline CMR_SU & C_DODAAC \\
\hline OCNTIME & $\overline{D A Y S}$ \\
\hline CMR_RU & DELAY_C \\
\hline CMR_RU & DELAY_D \\
\hline OCOÑUSDR & DESTCITY \\
\hline OCONUSDR & DESTCTRY \\
\hline DODAACS & DODAAC \\
\hline DETAIL & DODIC \\
\hline MSTRDET & DODIC \\
\hline MSTRHDR & DROP \\
\hline MSTRHDR & DUCR \\
\hline CMR RU & D DUE POE \\
\hline HEAD̄ER & D_R_SPLC \\
\hline MSTRHDR & D_R_SPLC \\
\hline HEADER & D_T_SPLC \\
\hline MSTRHDR & $\mathrm{D}_{-}^{-T_{-}}$SPLC \\
\hline CHANNELS & $\mathrm{EAD}$ \\
\hline JOPESE3 & EAD \\
\hline MADD & EFFECTIVE \\
\hline VESSCHED & ENTRY_D \\
\hline VESSEL & ENTRY_D \\
\hline ACHARGE & EQUIP_LEN \\
\hline HEADER & EUCR \\
\hline MSTRHDR & EUCR \\
\hline VESSEL & FLAG \\
\hline DETAIL & FLASHPT \\
\hline MSTRDET & FLASHPT \\
\hline CMR_RU & FL.OW_FCT \\
\hline DETÄlL & FRGTÑDX \\
\hline MSTRDET & FRGTNDX \\
\hline DETAIL & FRGTNO \\
\hline MSTRDET & FRGTNO \\
\hline CMR_RU & FUND_AG \\
\hline CMR_SU & FUND AG \\
\hline HEAD̄ER & GBLOC̄ \\
\hline MSTRHDR & GBL_OC \\
\hline GEOFILE & GEOCODE \\
\hline PORTS & GEOCODE \\
\hline DETAIL & GROUP \\
\hline MSTRDET & GROUP \\
\hline GEOFILE & GSACITY \\
\hline GEOFILE & GSACOUNTY \\
\hline GEOFILE & GSASTATE \\
\hline DETAIL & HAZARD \\
\hline MSTRDET & HAZARD \\
\hline DETAIL & HLDC \\
\hline
\end{tabular}

consignee_name

origin_pot_drayage_cost

created_date

country_state_long_name

couniry_state_long_name

cargo_cube

cargo_cube

cargo_cube

cargo_cube

cargo_cube

cargo_cube

cutoff_date

consignee_dodaac

consignee_dodaac

num_transit_hours

delay_code

delay_code_posted_date

destination_city_name

destination_country_name

dodaac

dodic

dodic

drop_frame

domestic_ucr

due_al_poe_date

destination_rail_splc

destination_rall_splc

destination_truck_splc

destination_truck_splc

ead

ead

effective_date

entry_date

entry_date

equipment_length_feet

export_ucr_flag

export_ucr_flag

ship nationality code

nash_point

nash_point

daily_now_factor

freight_classification_index freight_classification_index freight_classification_code freight_classification_code funding_agency_code funding_agency_code gbl_office_code gbl_office_code geolocation_code grolocation_code compatibility_group compatibility group gsa_city_code gsa_country_code gsa_state_code hazardous_cargo_flag hazardous_cargo_flag heavy_lifi_dimension_code 


\begin{tabular}{|c|c|c|}
\hline MSTRDET & HLDC & heavy_llift_dimension_code \\
\hline OCNTIME & HOURS & num_transil_hours \\
\hline GEOFILE & ICAO & lcao_code \\
\hline GEOFILE & ITC & installation_type_code \\
\hline CHANNELS & LAD & lad \\
\hline JOPESE3 & LAD & lad \\
\hline CMR_RU & LIFT_D & lift_date \\
\hline DETÄIL & LIN & line_item_id \\
\hline MSTRDET & LIN & line_item_id \\
\hline MSTRHDR & LOWBOY & lowboy \\
\hline GEOFILE & LPRC & logisties_planning_report_code \\
\hline CMR_RU & LTC & lading_lerm_code \\
\hline CMR RU & LTON & long tons \\
\hline PORTTHRU & MODE_C & transportation mode \\
\hline PCALLLMSG & MSGID & message id \\
\hline MT_FACT & MTFACTOR & mton_factor \\
\hline ALIOOCATE & MTON & cargo_mtons \\
\hline CHANNELS & MTON & cargo_mtons \\
\hline CMR_RU & MTON & cargo_mtons \\
\hline PORTTHRU & MTON & cargo_mtons \\
\hline SHIPCHAR & MTON & cargo mtons \\
\hline SHORTFAL & MTON & cargo mtons \\
\hline LOADTIME & MTON_AVG & average_cargo_mtons \\
\hline GEOFILE & NAVY & navy_ocean_area_code \\
\hline VESSEL & NO_CONT & num_containers \\
\hline CMR_RU & $\mathrm{NO}_{-}^{-} \mathrm{SU}$ & num_shipment units \\
\hline MADD̄ & NUM_STCD & numeric state code \\
\hline CMR_RU & OCEĀN_COST & ocean_cost \\
\hline CMR_RU & $\mathrm{OCN} \triangle \mathrm{COMM}$ & ocean commodity code \\
\hline CMR RU & OCONS_COST & pod destination drayage cost \\
\hline CMR RU & OFFERED & offered to carrier date \\
\hline INTRANA & ORIGIN & origin name \\
\hline MSTRHDR & ORIGIN-G & origin_geolocation_code \\
\hline CONUSDR & ORIGINC & origin city name \\
\hline CONUSDR & ORIGINS & origin_state_name \\
\hline HEADER & O_R_SPLC & origin_rail_splc. \\
\hline MSTRHDR & O_RSPLC & origin rail_splc \\
\hline HEADER & $\mathrm{O}_{-} \mathrm{T}$ SPLC & origin truck splc \\
\hline MSTRHDR & $\mathrm{O}^{-1} \mathrm{~T}$ SPLC & origin truck splc \\
\hline CMR_OUT & P $\bar{C} F \bar{N}$ & port_call_file id \\
\hline CMR RU & PCFN & port call file id \\
\hline CMR SU & PCFN & port call file id \\
\hline CMR_OUT & PCS & num pieces \\
\hline CMR RU & PCS & num pieces \\
\hline CMR_SU & PCS & num pieces \\
\hline CONTRATE & PERCENT & carrier usage rate percent \\
\hline CHANNELS & POD & pod \\
\hline CMR_RU & POD & pod \\
\hline CMR_SU & POD & pod \\
\hline JOPESE3 & POD & pod \\
\hline MADD & POD & pod \\
\hline CONTRATE & PODZONE & pod zone \\
\hline CHANNELS & POE & poe \\
\hline CMR_RU & POE & poe \\
\hline INTRANS & POE & poe \\
\hline JOPESE3 & $\mathrm{POE}$ & poe \\
\hline PCALLMSG & POE & poe \\
\hline CHNLEUCR & POEFONE & poc at poe phone \\
\hline EUCR & POEFONE & poc at poe phone \\
\hline
\end{tabular}




\begin{tabular}{|c|c|}
\hline CHNLEUCR & POEPOC \\
\hline EUCR & POEPOC \\
\hline CMR_RU & POE_COST \\
\hline INTRĀANS & POE_G \\
\hline PORTTHRU & $\mathrm{POE}_{-}^{-} \mathrm{G}$ \\
\hline PORTTHRU & POEMOD \\
\hline PORTS & PORTAREA \\
\hline PORTS & PORTNAME \\
\hline CMR_RU & PR.IORITY \\
\hline CMR_SU & PRIORITY \\
\hline HEAD̄ER & PRIORITY \\
\hline MSTRHDR & PRIORITY \\
\hline GEOFILE & PROV_CD \\
\hline GEOFILE & PROV N \\
\hline CMR_RU & PRP_REL_D \\
\hline HEADER & PSI \\
\hline MSTRHDR & PSI \\
\hline HEADER & P_D_R_SCAC \\
\hline MSTRHDR & P_D_R_SCAC \\
\hline GEOFILE & P_GEO \\
\hline HEADER & P_O_R_SCAC \\
\hline MSTRHDR & P_O_R_SCAC \\
\hline INTRANS & RAIIL_E \\
\hline CMR_RU & $\mathrm{RDD}$ \\
\hline CMR_SU & RDD \\
\hline HEAD̄ER & RDD \\
\hline MSTRHDR & RDD \\
\hline CMR_RU & RECD_D \\
\hline ACHĀRGE & REG_CODE \\
\hline CHNLEUCR & RELEASE \\
\hline EUCR & RELEASE \\
\hline EUCR4 & RELEASE \\
\hline HEADER & RELEASE \\
\hline MSTRHDR & RELEASE \\
\hline CMR_RU & REL_D \\
\hline CMR_RU & REL_POE \\
\hline CMR_RU & REL_ROUTID \\
\hline CMR_RU & REOFFFR_D \\
\hline CMR_RU & REOFFR_POE \\
\hline HEADER & REQNAMĒE \\
\hline MSTRHDR & REQNAME \\
\hline HEADER & REQPHONE \\
\hline MSTRHDR & REQPHONE \\
\hline CMR_RU & REQ ROUTID \\
\hline CMR_RU & R_DÖDAAC \\
\hline EUCR & R"DODAAC \\
\hline HEADER & R_DODAAC \\
\hline MSTRHDR & R_DODAAC \\
\hline CMR_RU & R_ID \\
\hline EUCR & R_ID \\
\hline HEADER & $R_{-I D}$ \\
\hline MSTRHDR & $R_{-1}^{-1}$ \\
\hline ALLOCATE & SAIL_D \\
\hline VESSCHED & SAIL_D \\
\hline ALLOCATE & SHIPNAME \\
\hline VESSEL & SHIPNAME \\
\hline VDYAGE & SHIPNAME \\
\hline PCALLMSG & SHIPNUMBR \\
\hline LOADTIME & SHIPTYPE \\
\hline
\end{tabular}

poc_at_poe_name

poc_al pox_name

poe_handlling_cost

poe_geolocalion_code

poe_geolocation_code

poe mode

port area name

port_name

transportation priority code

transportation_priority_code

transportation_priority_cove

transportation_priority_code

providence_codo

providence_name

projected_release_date

private_siding_flag

private_siding_nag

primary_destination_rail_scac

primary_desilnation_rail_scac

prime_geolocation_code

primary_origin_rall_scac

primary_origin_rall_scac

num_rall_transit_days

required delivery date

required_delivery_date

required_delivery_date

required_dellvery_date

etrr received date

region_code

release_id

release_id

release_id

release id

release_id

etr_release_date

etr_release poe

release routing id

reoffer_posted_dale

reoffer poe

requestor name

requestor name

requestor_phone

requestor phone

requestor_routing_id

requestor_dodaac

requestor_dodaac

requestor_dodaac

requestor_dodaac

requestor_id

requestor_id

requestor_ld

requestor id

sail_date

sail_date

ship_name

ship_name

ship_name

ship_id

ship_type_code 


\begin{tabular}{|c|c|}
\hline SHIPCHAR & SHIP'TYPE \\
\hline STOWFACI & SHIPTYPE \\
\hline VESSEL & SHIPTYPE \\
\hline VOYAGE & SHIPTYPE \\
\hline PORTS & SHOR'TPORT' \\
\hline DETAIL & SIHPGNAME \\
\hline MSTRDET & SHPGNAME \\
\hline CMR_RU & SOCO_R_NDX \\
\hline CMR_RU & SOCO IERM \\
\hline CMR_RU & SOCO_VES \\
\hline OCNTIME & SPEED \\
\hline SHIPCHAR & SPEED \\
\hline MADD & SPLC \\
\hline PCALLMSG & SPOENAME \\
\hline CMR_RU & SPOT_D \\
\hline CMR_RU & SRO_DUE_D \\
\hline CMR_RU & SRO_ID \\
\hline CMR_RU & SRO_MODE \\
\hline CMR_RU & SRO POE \\
\hline SHIP'C & SS \\
\hline DODAACS & STA'TE \\
\hline HEADER & STATE \\
\hline MSTTRHDR & STATE \\
\hline HEADER & STATION \\
\hline MSTRHDR & STATION \\
\hline VESSEL & STOW_CAP \\
\hline LOADTIME & SUBTŸPE \\
\hline SHIPCHAR & SUBTYPE \\
\hline CMR_RU & S_DODAAC \\
\hline HEAD̄ER & S_DODAAC \\
\hline MSTRHIDR & S_DODAAC \\
\hline HEADER & S_D_R_SCAC \\
\hline MSTRHDR & $S \_D \_S C A C$ \\
\hline HEADER & S_O_R_SCAC \\
\hline MSTRHDR & $\mathrm{S}_{-} \mathrm{O}_{-} \mathrm{R}$ _SCAC \\
\hline GEOFILE & TAC_ZONE \\
\hline CMR_OUT & $\mathrm{TCN}$ \\
\hline CMR_SU & TCN \\
\hline DE'TĀIL & TCN \\
\hline EUCR4 & TCN \\
\hline MSTRDET & TCN \\
\hline SHIPCHAR & TEU \\
\hline CMR_RU & TOTAL_COST \\
\hline MSTRHDR & TRACTOR \\
\hline HEADER & TRANSMTD \\
\hline MSTRHDR & TRANSMTD \\
\hline CMR_RU & TYPE_OFFER \\
\hline ACHĀARGE & TYPE_SERV \\
\hline ALLOCATE & UIC \\
\hline CHANNELS & UIC \\
\hline DETAIL & UIC \\
\hline EUCR & UIC \\
\hline HEADER & UIC \\
\hline JOPESE3 & UIC \\
\hline MSTRDET & UIC \\
\hline MSTRHDR & UIC \\
\hline SHORTFAL & UIC \\
\hline GEOFILE & UIC_RESP \\
\hline ALLOCA'TE & ULN \\
\hline
\end{tabular}

ship_type_code ship_lype.... code shlp_type_code ship_type_code port_stort_name shipping_name shipping name soco_routing_index soco_carriage_terms soco_vessel_ld shlp_speed_knots ship_speed_knots splc spoe_name spol_date sro_due_at_pod_date sro_id sro_transportation_mods_colle sro_poe

self_sustaining_flag country_state_code country_state_code country_state_code station_name station_name stowage_capacity ship_subtype_code ship_subtype_code shipper..dodaac shipper_dodaac shipper_dodaac second_destination_rail_scac second_destination_rail_scac second_origin_rail_scac second_origin_rail_scac tactical_zone Icn

tcrl

ten

ton

ton

teu

total_cargo_movement_cost tractor transmitted_date transmitted_date offering_type_code service_type_code uic uic

uic

uic

uic

ulc

uic

uic

uic

responsible... uic uln 


$\begin{array}{ll}\text { CHANNELS } & \text { ULN } \\ \text { DETAIL } & \text { ULN } \\ \text { EUCR } & \text { ULN } \\ \text { HEADER } & \text { ULN } \\ \text { JOPESE3 } & \text { ULN } \\ \text { MSTRDET } & \text { ULN } \\ \text { MSTRHDR } & \text { ULN } \\ \text { SHORTFAL } & \text { ULN } \\ \text { VOYAGE } & \text { UNITMOVE } \\ \text { HEADER } & \text { UNIINAME } \\ \text { MSTRHDR } & \text { UNITNAME } \\ \text { LOADTIME } & \text { UNLOAD } \\ \text { DETAIL } & \text { UNNA_IND } \\ \text { MSTRDET } & \text { UNNA_IND } \\ \text { DETAIL } & \text { UNNA_NO } \\ \text { MSTRDET } & \text { UNNA_NO } \\ \text { DETAIL } & \text { UN_CLASS } \\ \text { MSTRDET } & \text { UN_CLASS } \\ \text { CMR_RU } & \text { VAN_RLSD } \\ \text { CMR_RU } & \text { VAN_REQD } \\ \text { MT_FACT } & \text { VAN_TYPE } \\ \text { CHNLEUCR } & \text { VESSELNAME } \\ \text { EUCR } & \text { VESSELNAME } \\ \text { MTFFACT } & \text { VFACTOR } \\ \text { CHANNELS } & \text { WGT } \\ \text { CMR_OUT } & \text { WGT } \\ \text { CMR_RU } & \text { WGT } \\ \text { CMR_SU } & \text { WGT } \\ \text { DETAIL } & \text { WGT } \\ \text { MSTRDET } & \text { WGT } \\ \text { DODAACS } & \text { ZIP } \\ \text { MADD } & \text { ZIP } \\ & \\ & \end{array}$

uln
uln
uln
uln
uln
uln
uln
uln
unit_move_flag
unit_name
unit_name
unload_minutes
un_na_code
un_na_code
un_na_id
un_na_id
un_class_diviston_code
un_class_division_code
num_vans_released
num_vans_requited
van_type_code
ship_name
ship_name
vehicle_mton_factor
total_cargo_stons
total_cargo_stons
total_cargo_stons
total_cargo_stons
total_cargo_stons
total_cargo_stons
zip_code
zip_code




\begin{tabular}{|c|c|}
\hline table_name & ficld_ name \\
\hline VSNR & ACTL__DATE_ARV \\
\hline XVSNR & ACIL_DATE_ARV \\
\hline SHIPMENT & ADJ_CODE \\
\hline SHIIPMEN'T & BARGE_ARRIVAL_DATE \\
\hline SHIPMENT & BARGE_NAME \\
\hline SHIPMENT & BAROE_NO \\
\hline SHIIPMENT & BOOKINTG_DESC \\
\hline SHIPMENT & BOOKING_NR \\
\hline SHIPMENT & CARGO_STATUS \\
\hline SHIPMENT & COMMODITY \\
\hline SHIPMENT' & CONSIGNEE \\
\hline SHIPMENT' & CONSIGNOR \\
\hline SHIPMENT & CONTAINER_RELEASE_UNITS \\
\hline SHIIPMENT & CORRECTION_DATE \\
\hline SHIPMENT & CORRECTION_USER_ID \\
\hline EXPLOSIVE & CUBE \\
\hline OUTSIZE & CUBE \\
\hline SHIPMENT & CUBE \\
\hline VSNR & DATE_INACT \\
\hline XVSNR & DATE_INACT \\
\hline SHIPMENT & DELETE_ACTV_.CD \\
\hline SHIIPMENT & DELETE_REASON \\
\hline SHIPMENT & DELETE_USER_ID \\
\hline VOYDOC & DELIVERED_CONTAINERS \\
\hline VOYDOC & DELIVERED_CUBE \\
\hline VOYDOC & DISCHARGED_CONT'AINERS \\
\hline SHIPMENT & DISCHARGED_CUBE \\
\hline VOYDOC & DISCHAROED_CUBE \\
\hline SHIPMENT & DISCHARGED_..PIECES \\
\hline SHIPMENT & DISCHARGED_WEIGHT \\
\hline SHIPMENT' & DISCHARGE_ACIV_CD \\
\hline SHIPMENT & DISCHARGE_POD \\
\hline SHIPMENT & DISCHARGE_USER_ID \\
\hline VOYDOC & DISCH_COMP_DATE \\
\hline VOYDOC & DISCH_STARTE_DATE \\
\hline VOYDOC & DIVERTED_CŌNTAINERS \\
\hline VOYDOC & DIVERTED_CUBE \\
\hline SHIPMENT & DIVERTED_POD \\
\hline SHIPMENT & DODIC \\
\hline VSNR & EST_COMP_DATE \\
\hline XVSNR & EST_COMP_DATE \\
\hline SHIPMENT & ETA \\
\hline VSNR & ETA \\
\hline XVSNR & ETA \\
\hline SHIPMENT & EXPORT_IMPORT_IND \\
\hline SUPPLEMENT & EXPORT_IMPORT_IND \\
\hline VOYDOC & EXPOR'TIMPOR'T_IND \\
\hline VSNR & EXPORT_IMPORT_IND \\
\hline XVOYDOC & EXPORT_IMPORT_IND \\
\hline XVSNR & EXPORT_IMPORT_IND \\
\hline SHIPMENT & GBL \\
\hline OUTSIZE & HEIGHT \\
\hline OUTSIZE & LENGTH \\
\hline SHIPMENT & LLFT_ACIV_CD \\
\hline SHIPMENT' & LIFT_USER_ID \\
\hline XVOYDOC & LOAD_COMP_DATE \\
\hline
\end{tabular}

\section{we rickd mamo}

actual_arrival pod_date actual_arrival_pod_dale adjustment_coxle barge_arrival_date barge name barge Id boxking_description booking_ld cargo_status_code waler_commodity_code consignee name consignor_name container_release unlts shipment_correction_date shipment_correctlon_user_id cargo_cube cargo_cube cargo_cube ship_inaclive_date ship_Inactive_date deletion_activity_code deletion_reason_code deletion_user_id num_contalners_delivered dellvered_cargo_culse num_containers_discharged discharged_cargo_cube discharged_cargo_cube num_pleces_discharged discharged_cargo_stons discharged_cargo_activity_code discharged_cargo_pod discharged_cargo_user_ld discharged_completion_dale discharged_start_date num_containers_diverted diverted_cargo_cube diverted_cargo_pod dodlc

estimated_completion_date estimated_completion_date

eta

eta

eta

export_import_flag export import_flag export_import_flag export_import_llag export_import_flag exportimport_lag gbl cargo_height_fee! cargo length_feet lifi_activity...code lifi_user_ld load_completion_date 


\begin{tabular}{|c|c|}
\hline XVSNR & LOAD_COMP_DATE \\
\hline EXPLOSIVE & LOT \\
\hline SHIPMENT & MANIFEST_CUBE \\
\hline SHIPMENT & MANIFEST_DA'TE \\
\hline SHIIPMENT & MANIFEST_IND \\
\hline SHIIPMENT & MANIFEST_PIECES \\
\hline SHIPMENT & MANIFEST_WEICHT \\
\hline VOYDOC & MNFST_LOADED_DATE \\
\hline XVOYDOC & MNFST_LOADED DATE \\
\hline X'VOYDOC & MNFST_LOADED SU \\
\hline EXPLOSIVE & NET_EXPLOSIVE_WT \\
\hline SHIPMENT & OPCODE \\
\hline EXPLOSIVE & PCS \\
\hline OUTSIZE & PCS \\
\hline SHIPMENT & PCS \\
\hline SHIPMENT & PKG \\
\hline SHIPMENT & POD \\
\hline SUPPLEMENT & POD \\
\hline VOYDOC & POD \\
\hline XVOYDOC & POD \\
\hline SHIPMENT & POE \\
\hline SUPPLEMENT & POE \\
\hline VOYDOC & POE \\
\hline XVOYDOC & POE \\
\hline SHIPMENT & PORTCALL NUMBER \\
\hline SHIPMENT & POVCOLOR \\
\hline SHIPMENT & POVLICENSE \\
\hline SHIPMENT & POVMAKE \\
\hline SHIPMENT & POVSTATE \\
\hline SHIPMENT & POVYR \\
\hline SHIPMENT' & PROJECT_CODE \\
\hline SHIPMENT & RDD \\
\hline EXPLOSIVE & RECNO \\
\hline OUTSIZE & RECNO \\
\hline REMARKS & RECNO \\
\hline SHIPMENT & RECNO \\
\hline SHIIPMENT & SEALNO \\
\hline VSNR & SHIP_AGENT \\
\hline XVSNR & SHIP_AGENT \\
\hline SHIPMENT & SHIP_CODE \\
\hline SHIPMENT & STOW \\
\hline SHIPMENT & STUFFING_ACTV_CD \\
\hline SHIPMENT & STUFFING_USER_ID \\
\hline SHIPMENT & SUPNO \\
\hline SUPPLEMENT & SUPNO \\
\hline XVOYDOC & SUPNO \\
\hline SUPPLEMENT & SUP DATE \\
\hline XVOYDOC & SUP DATE \\
\hline VOYDOC & TCMD_PREP_DATE \\
\hline SHIPMENT & TCN \\
\hline SHIPMENT & TPRI \\
\hline SHIPMENT & ULN \\
\hline SHIPMENT & UNSTUFF_ACTV_CD \\
\hline SHIPMENT & UNSTUFF_CUBE \\
\hline SHIPMENT & UNSTUFF_PIECES \\
\hline SHIPMENT & UNSTUFF_USER_ID \\
\hline SHIPMENT & UNSTUFF_WEIGHT \\
\hline SHIPMENT & UN_CLASS̄ \\
\hline SHIPMEN'T & VAN NO \\
\hline
\end{tabular}

lasd_complellon_date

lot_la

manifest_cargo_oubs

manifest_date

manifest_flag

num_manlfes! pleces

manifesl_cargo_stons

manlfest_loading_dale

manlest_louding_date

num_manilest_shipment_unlis

net_explosive_weight_stons

operation_codo

num_pleces

num_pleces

num_pieces

lype_packing_code

pod

pod

pod

pod

pCE:

por:

poe

poe

portcall_id

por_color_code

pov_license _tag

pov_make_model_code

por_license_tag_state_code

por_manufacture year

milstrip_project_code

required_delivery_date

record_id

record id

record_id

record_id

container_seal_id

ship_agent_code

ship_agent_code

ship...code

stow factor

stuffing_. activity... code

stuffing user id

supplement_id

supplemeni_id

supplemeni_ld

supplement_date

supplement_date

tcmi_prepuration_date

Icn

transportation_priority_code

uln

unstuffed_activity_code unstuffed_cargo_cube num_unstuffed_cargo_pieces unstüfied_user_id

unstuffed_cargo_stons un_class_division_code van_id 
SHIPMENT

SHII'MENT'

SHIPMEN'T

SUPPLEMEN'I

VOYIDOC

XVOYDOC

XVSNR

SHIPMENT

SUPPI,EMEN'I

VOYDOC

VSNR

SIIIPMEN'I

SUPPLLEMEN'I

VOYDOC

XVOYDOC
VAN_OWNER

VAN SIZE

VOYDOC

VOYDOC

VOYDOC

VOYDOC

VOYDOC

VSNR

VSNR

VSNR

VSNR

VSTA'T'

VS'A'A'

VSTAT

VSTAT van_owner_code

van_slzo

voyage_documon!_ld voyage_documoni_de vayage dectument ld voyage_decumen!.|a| voyage document |d slilp... Id

ship.ad

ship_lo

ship_la

ship_stitus coxlo ship_otatus codo ship_stutus_code shilp_status_code 
tabile_anme

'II)

TIDK

ITDR

'I'DR

TIDIR

TIDK

T'L.)

TTDK

TDTR

'ITSTR

TITR

TIDK

T"DTR

ITDK

TDR liceld namove

ARTIA OF OPEIRATTION

CAUSE OF DISCREDHANCY

CLAASS/PRO'T' CODES

COUN'TRYASIAATIS CODII

DA'TT:

DISCIXEP, PIIECES

DISCREP, WIZICHTI

DODAAC

MEITIOD SHIIIMENT

NO. T'CN/ADN ERRRORS

RECORD TYPE

REPAIR COST

RESPONSIBILITY CODI?

SHIIPIINO DOC NO.

'TYPI CODE wle_fichd naine

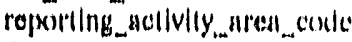
discropincy cosla

classified_protocted_coslo

country stale cexte

Jullan date

num_dinoropancy fyleces discrepancy canrgo alonsis

dextanc

shipment molliex. code

num_lon.adn_orrors

record_type_code

repair_roplacoment_cost

roponsilblo_org_codo

shipping documosi!_al

shipping...document_type.code 


\begin{tabular}{|c|c|}
\hline tablo nemo & fineld namo \\
\hline $\mathrm{SI}^{\prime \prime} \mathrm{C}^{-}$ & S'T,BERTTHED,DA'TE.ITIMI \\
\hline $\mathrm{s}^{\prime} \mathrm{T}$ & S'L'BEER'ITHEL,ES'IOR,ACI' \\
\hline $\mathrm{st}$ & S'I'HOURS,WORKEIS \\
\hline s'l' & S'T'LIFI'CAN'SO,NT \\
\hline $\mathrm{ST}$ & STILOADSSTANDARD,DAYS' \\
\hline $\mathrm{S}^{\prime} \mathrm{I}^{\prime}$ & S'IMAAJORITYYIUNITILOADED \\
\hline $\mathrm{st}^{\prime}$ & STIMNIS'I'ARIV,SHOD,DATEZ \\
\hline st & S'I'MNINS'ICCARRIEIK \\
\hline $\mathrm{SI}$ & STIMNIS'L'SENT'DATIE:IIML \\
\hline $\mathrm{sl}^{\prime}$ & S'IIMNISSTISHIIPMENTIID \\
\hline S'T & STIMNISTITYPE,CARCIO \\
\hline s'T & STIMTONS,LIFTED \\
\hline $\mathrm{ST}^{\prime}$ & ST,PEIRCENT,LOADED \\
\hline $\mathbf{S t}^{\prime}$ & S'THPHASE \\
\hline ST' & ST,PIECES,LIFTED \\
\hline$s T^{\prime}$ & ST.PORTIBAROES.LOADED \\
\hline ST & ST.PORT,BAROES,STUUFIED \\
\hline $3 y$ & ST,PORT'CMDRSINAME \\
\hline$S !$ & ST.POR'T.COMMAND \\
\hline S'T & S'T,PORT,SEQ \\
\hline $\mathrm{ST}$ & STPOORT.TOTALBAARGES \\
\hline ST' & SIIPORT,TIU \\
\hline ST' & ST'REPAIR,POR'T,ETA \\
\hline $\mathrm{S}^{\prime} \mathrm{I}^{\prime}$ & S'T.SHIP.STATUS \\
\hline $\mathrm{ST}$ & S'T,SHIP,'TO'TAL,BAROES,LOADEDD \\
\hline S'I' & ST'SHIPS,BARGE,CAP \\
\hline ST' & ST.SITREP.FLAO \\
\hline $\mathrm{ST}$ & STISQ,FT,LIFIED \\
\hline S'T & ST,SUPER,CARGO \\
\hline ST' & STITYPE.VESSEL \\
\hline
\end{tabular}

ndo_finekl_namo

bertli dalto

bertli_dinte ling

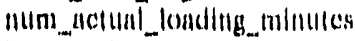

III_capubilly_sc a

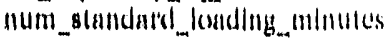

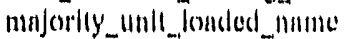
spoxl_actual_arrival_dinto manlies!_carrior" Inamo

manlfesi_son!_dälo

manlesi shipmon!..Id manlfesl_lypx:_ango_code carga_lified_mtons shilp_Ladding_percont operation_pliaso_... code actual_num_ nlfied_plocess num_barges_londed num_barges_stuffed port_commander_nume genorlo_port_location port_sequence_la num_barges_at_port reserve unli_code repalr_port_eta ship_status_codo lotal_num_barges_louded ship_barge_cupracliy sitrep_listing_flag llfi_cargo_selfi num_persons_shipped shlp_type_description 

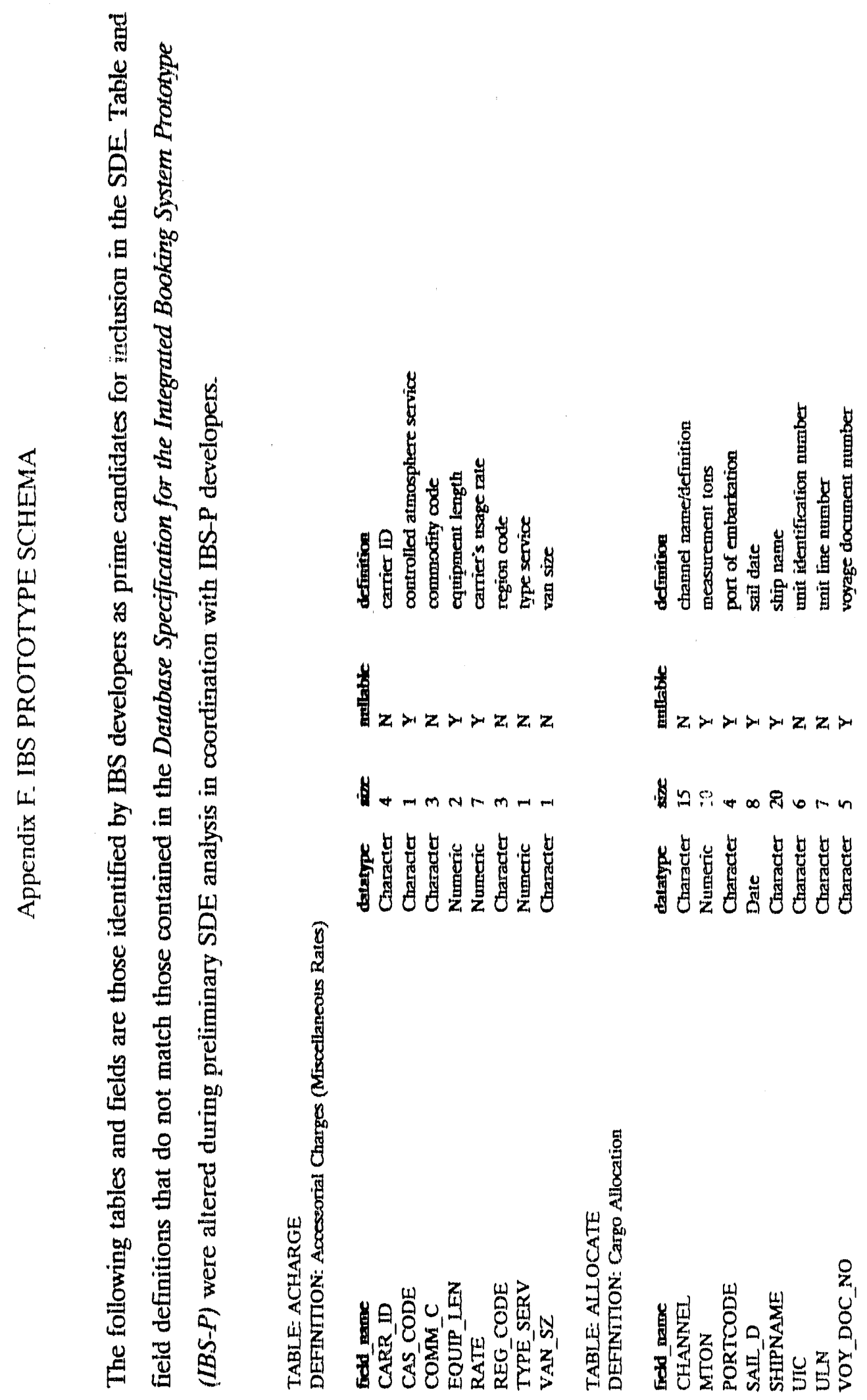

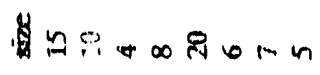

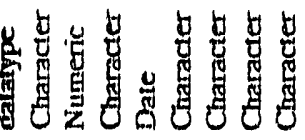
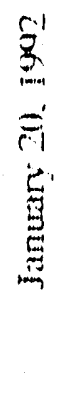

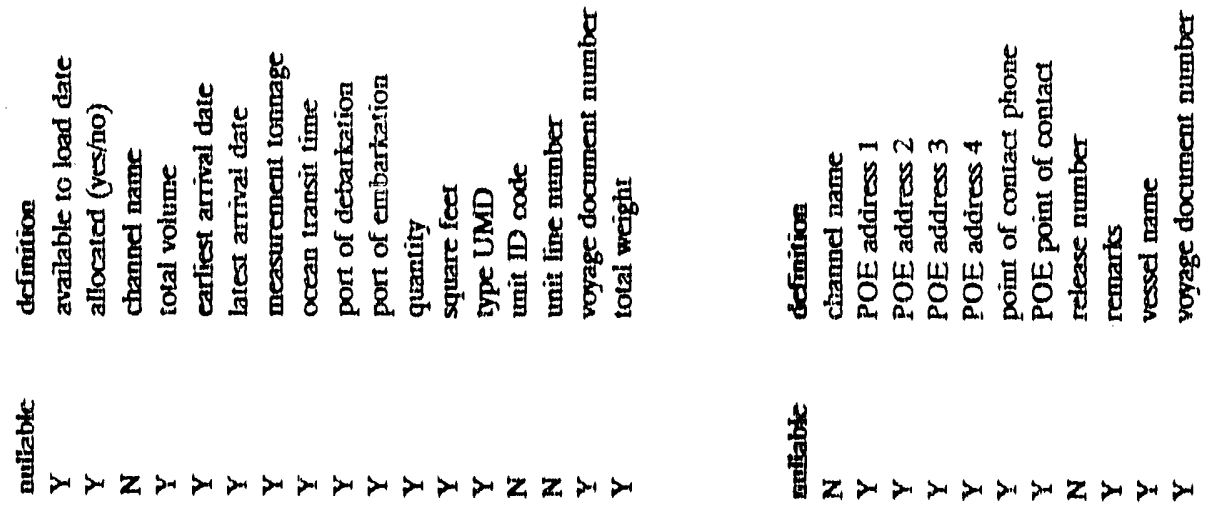

I

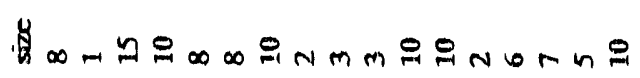

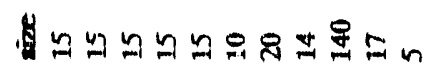

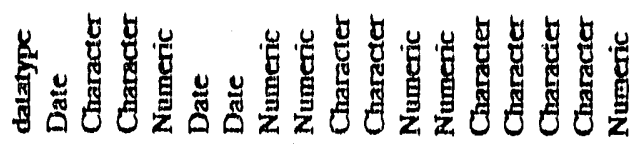

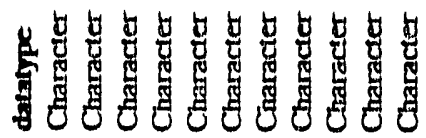



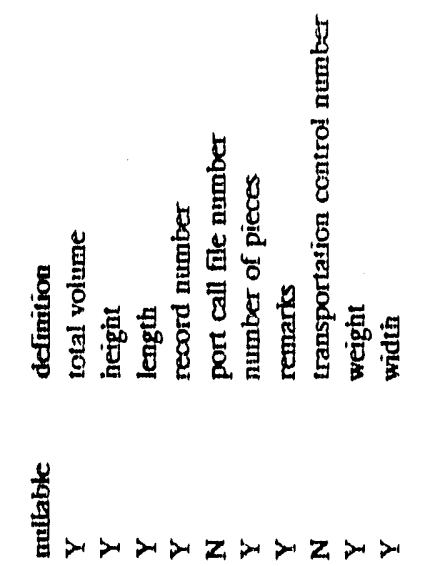

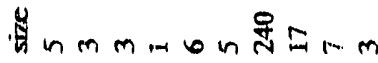

UIIIIIIIIII
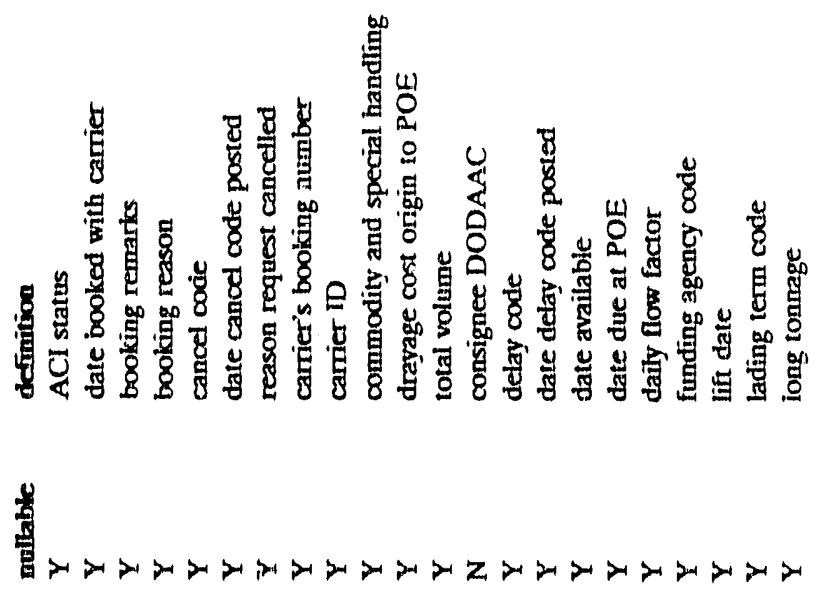

每-

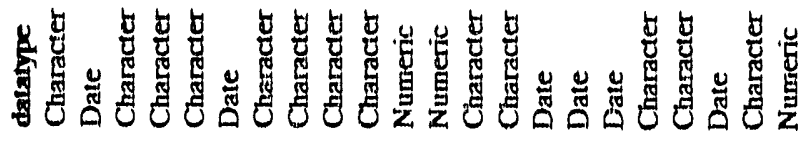




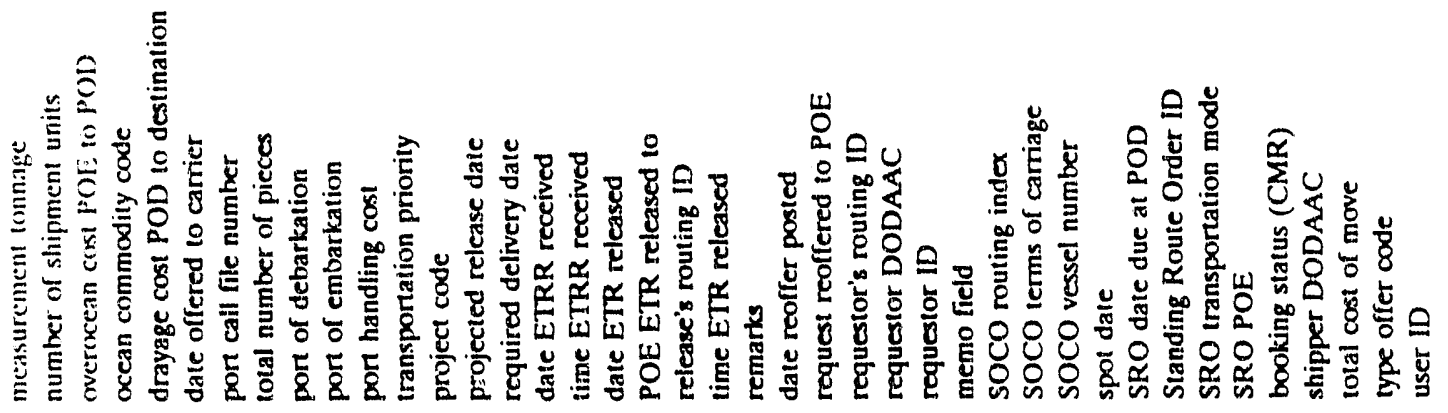

过

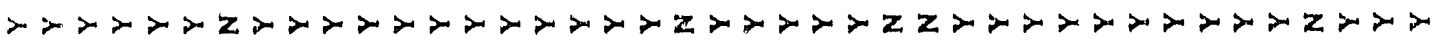

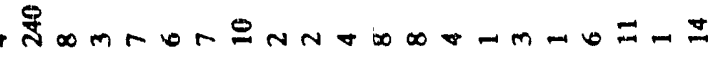

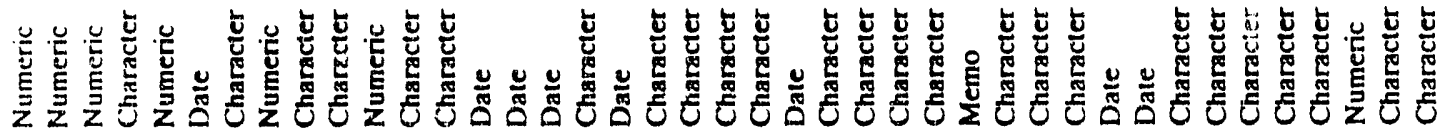

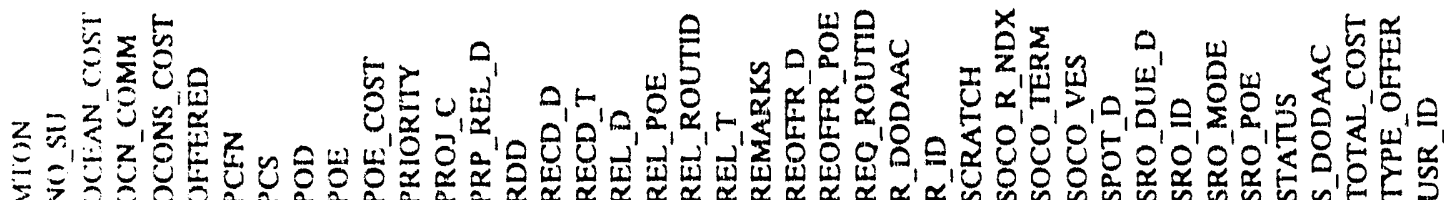




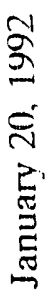
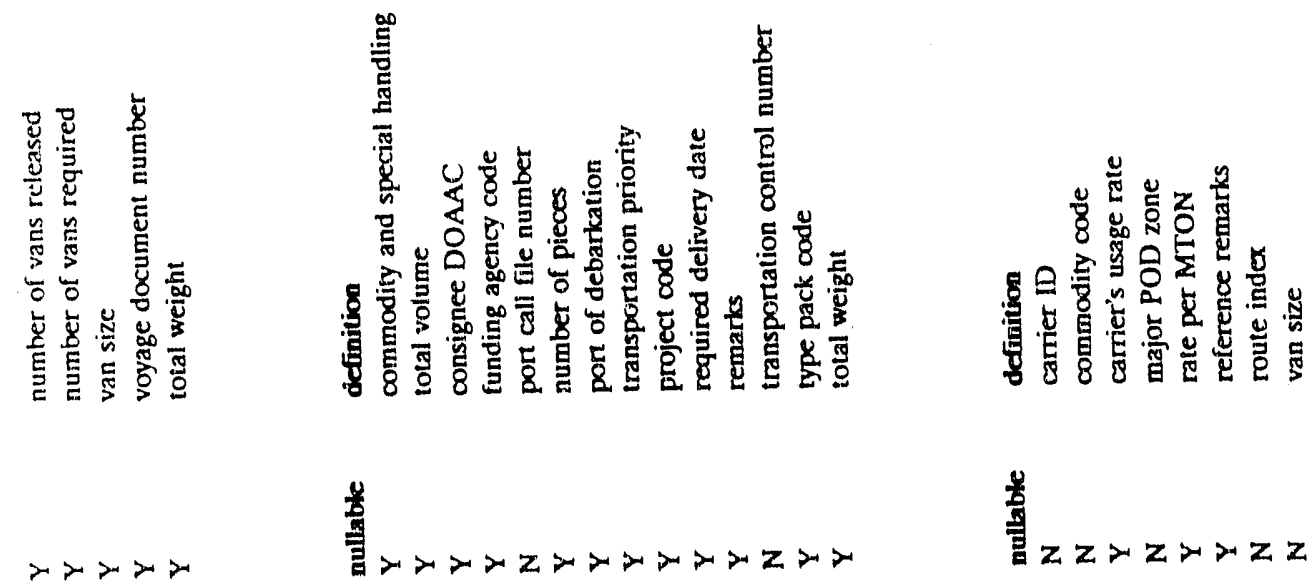

n
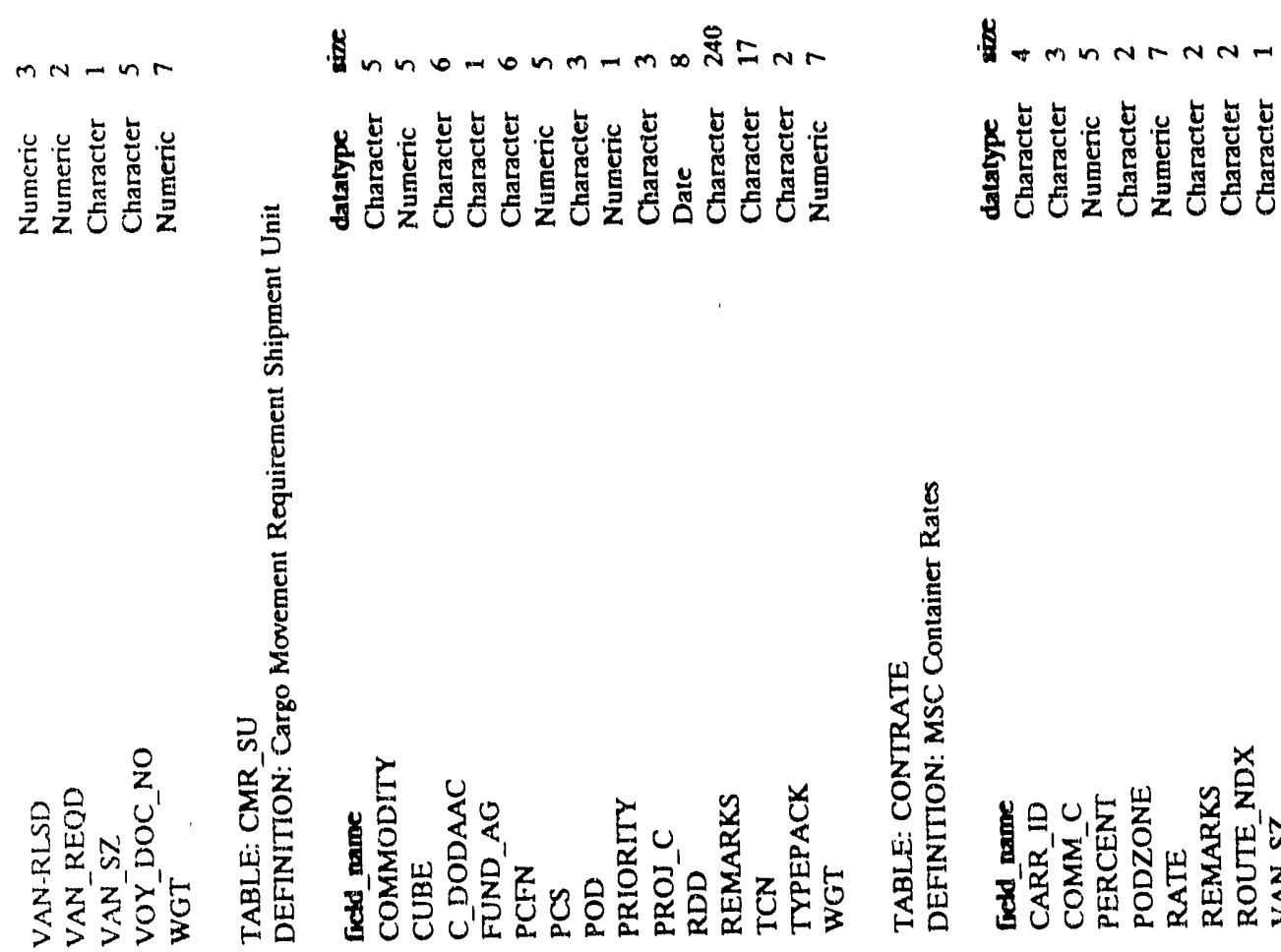

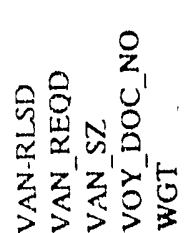

造望

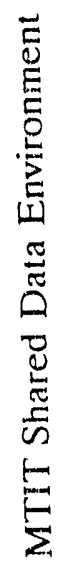



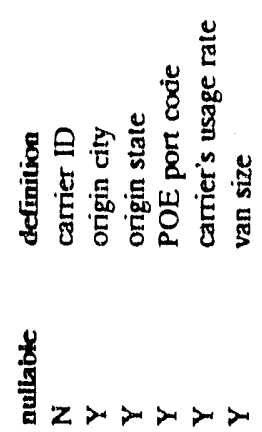

Band

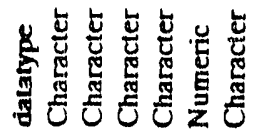
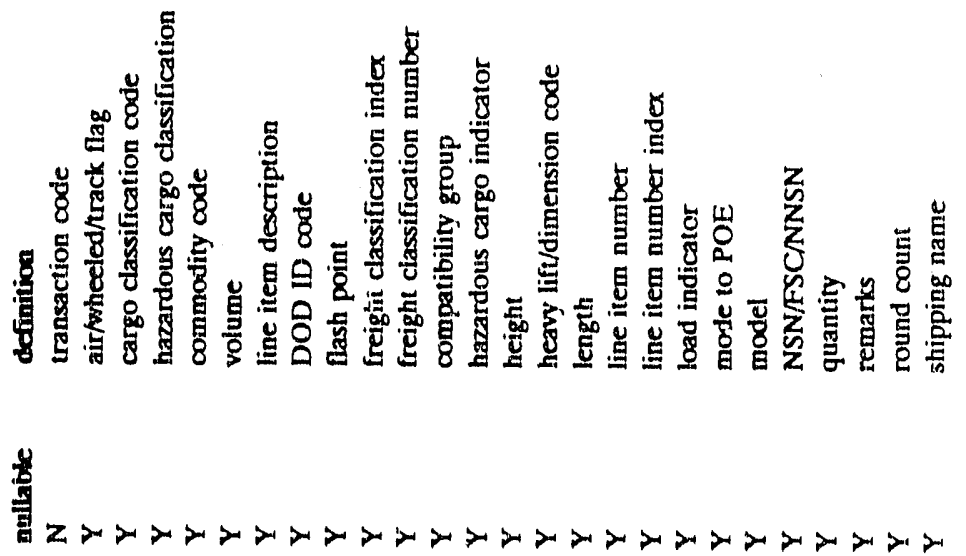

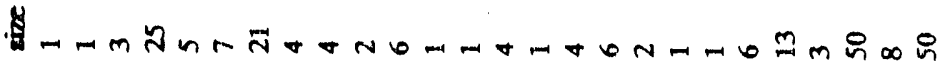

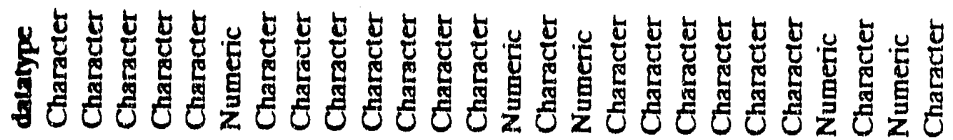

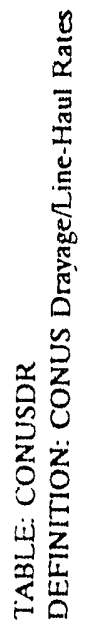
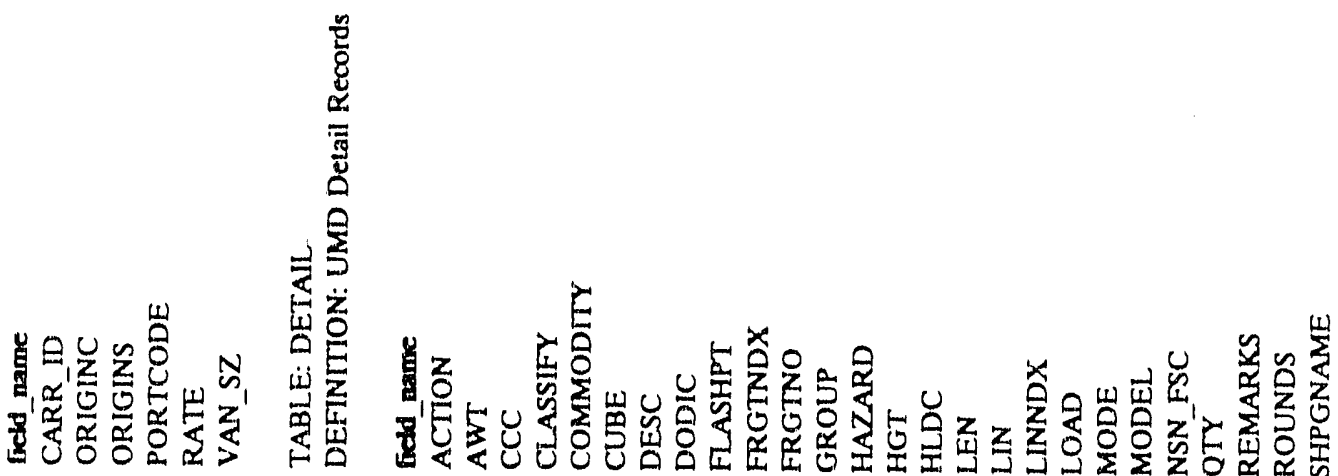

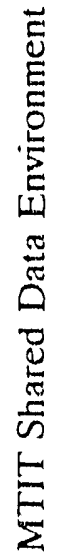



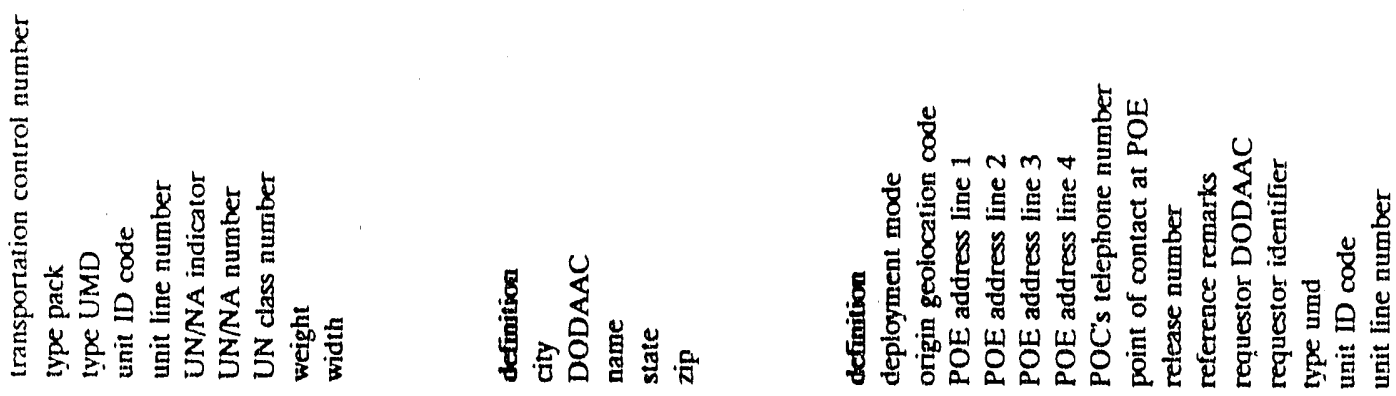

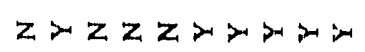
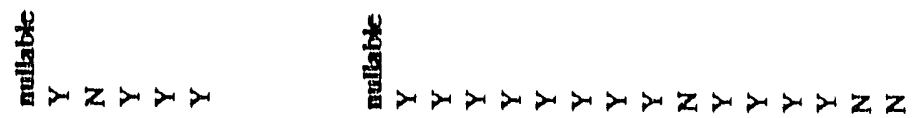

ii

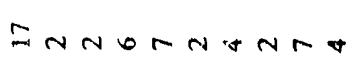

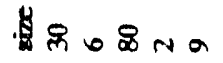

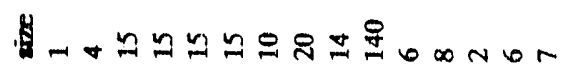

Wunewey

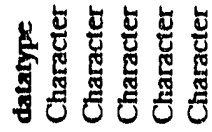

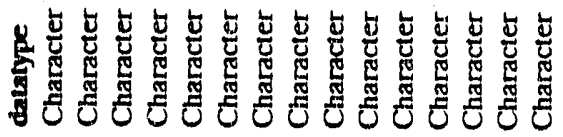
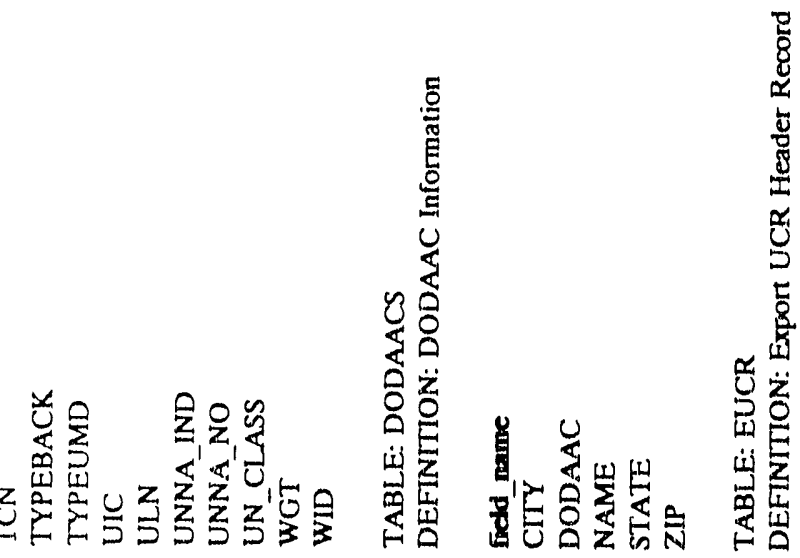

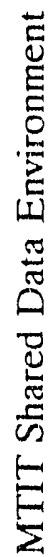




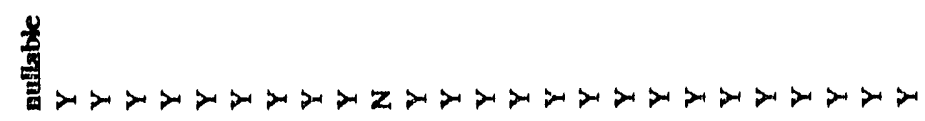

In

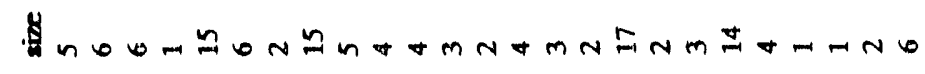

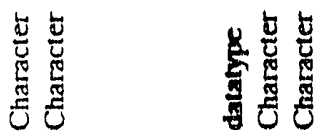

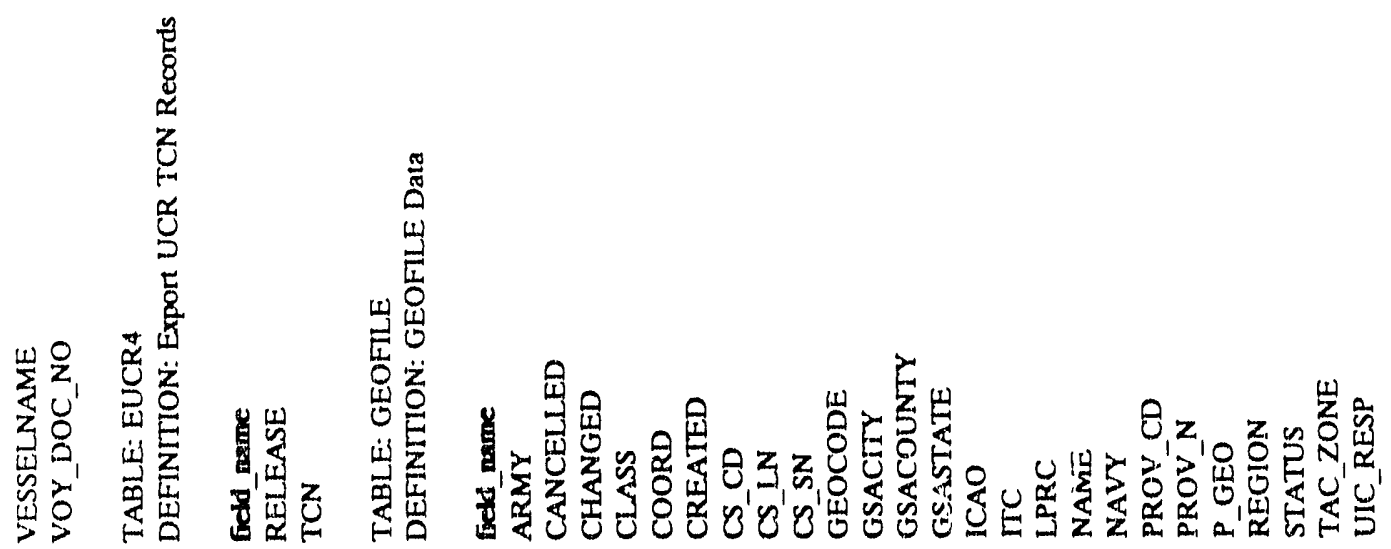



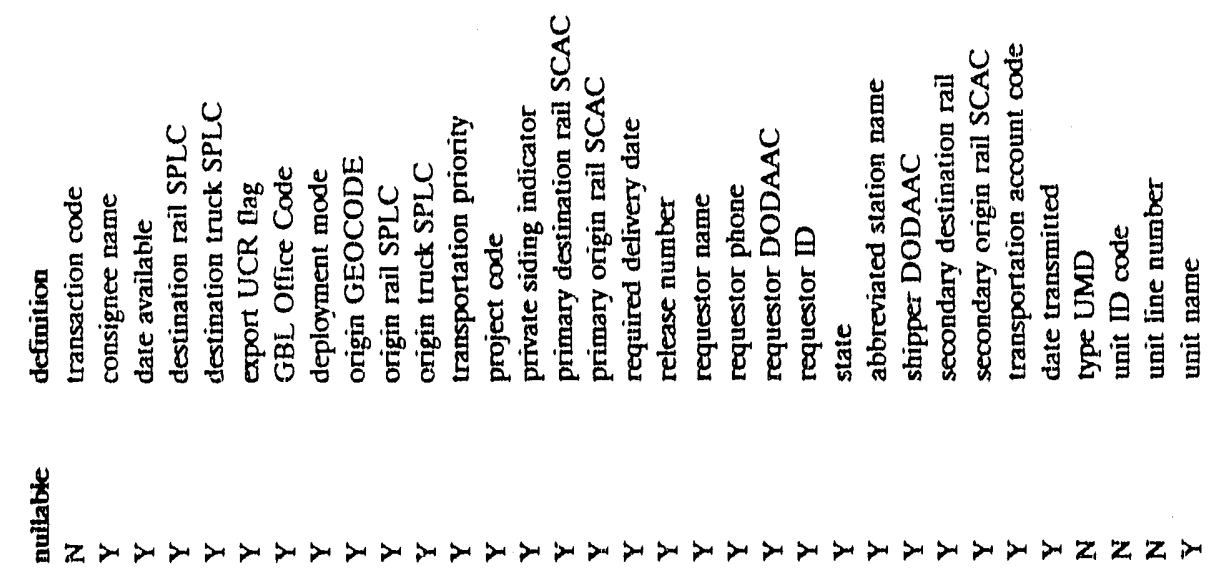

a

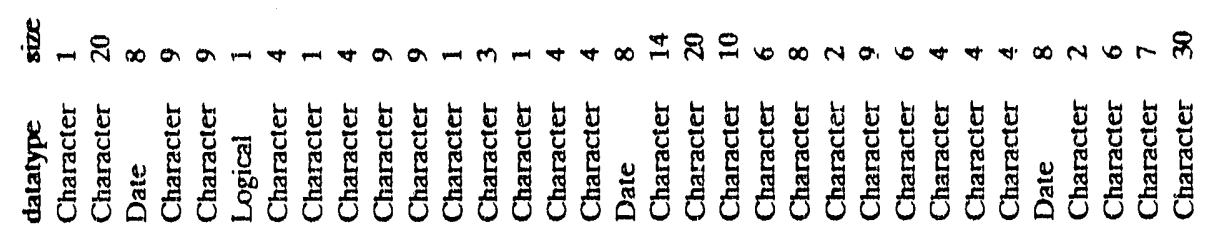



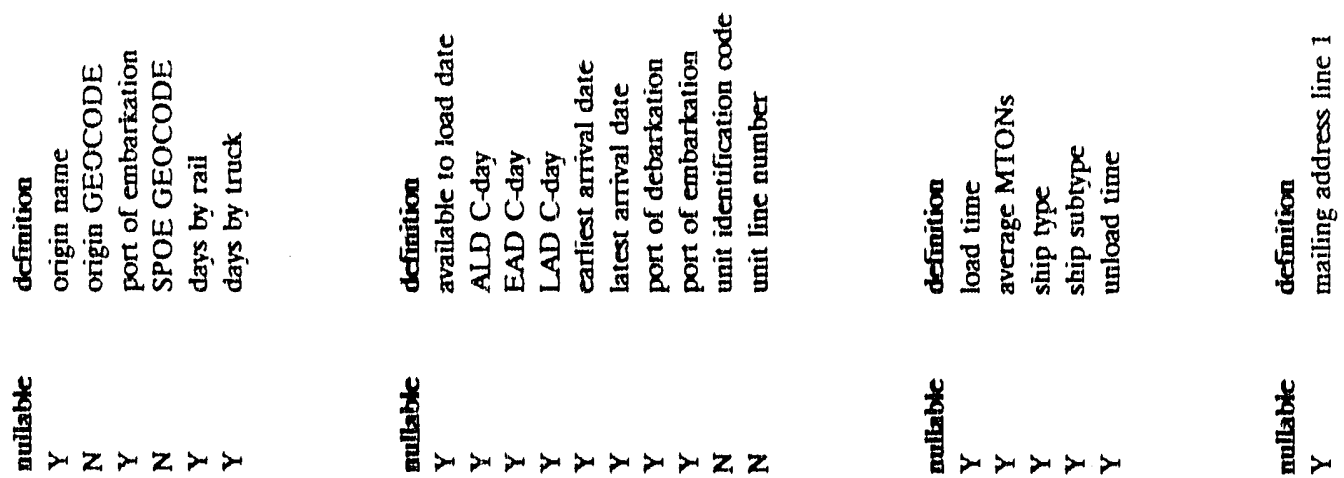

$\frac{0}{4}$

草

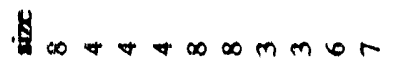

Hatom

盟品

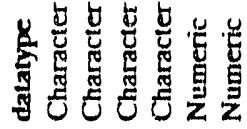
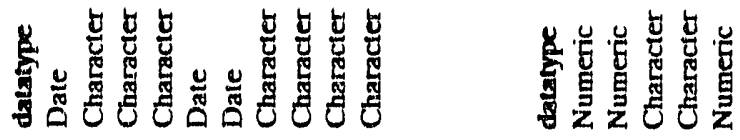

U⿺辶⿻日禸㇂
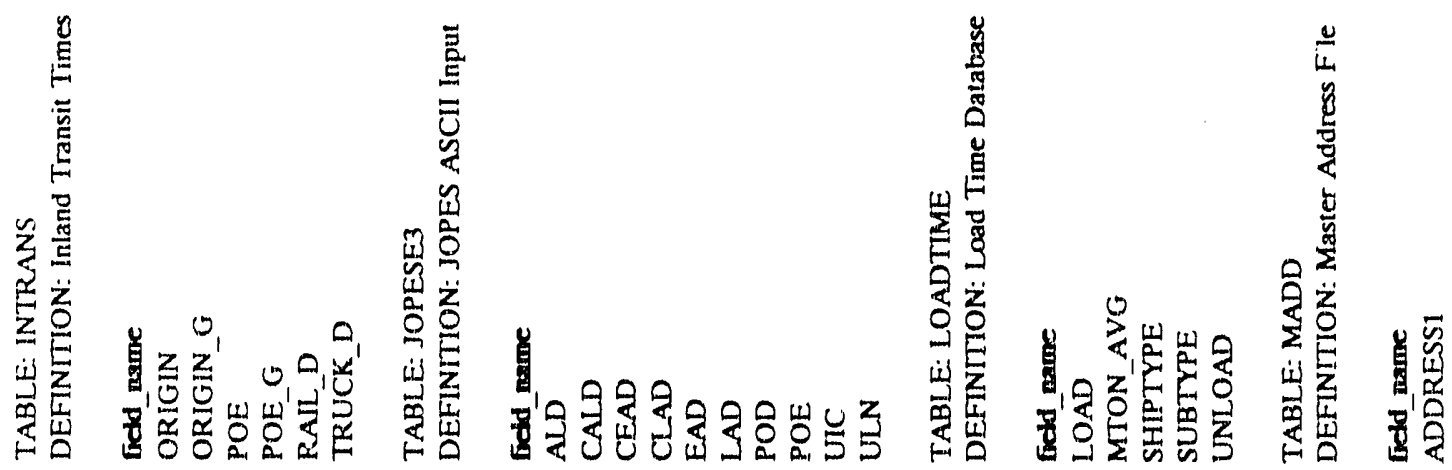

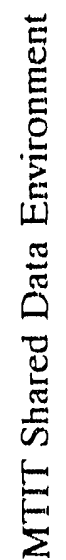




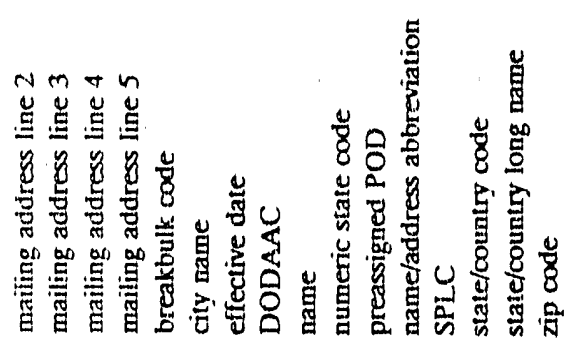

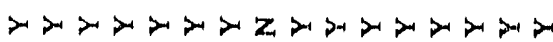

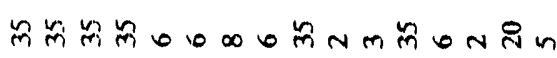

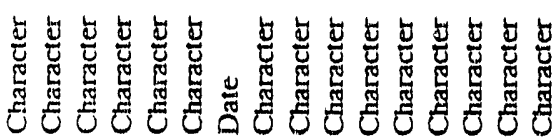
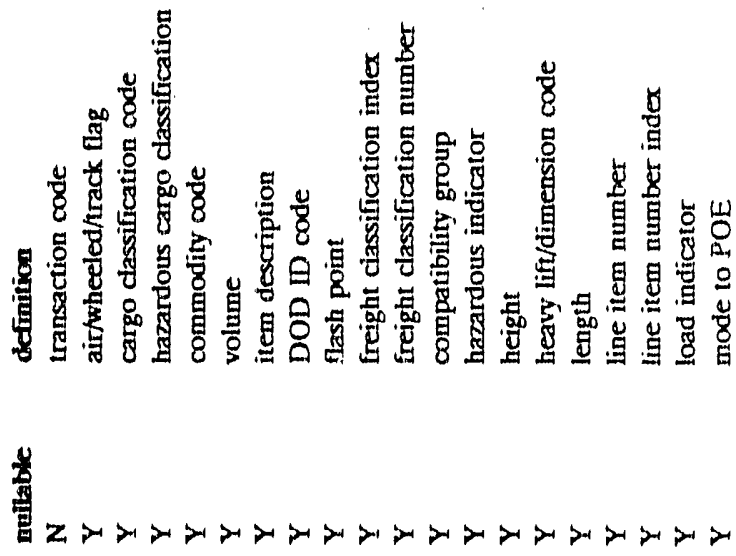

$m_{1}^{1}$
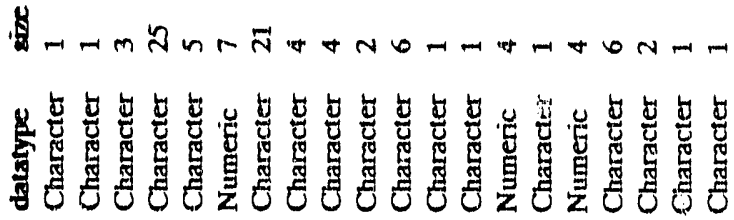

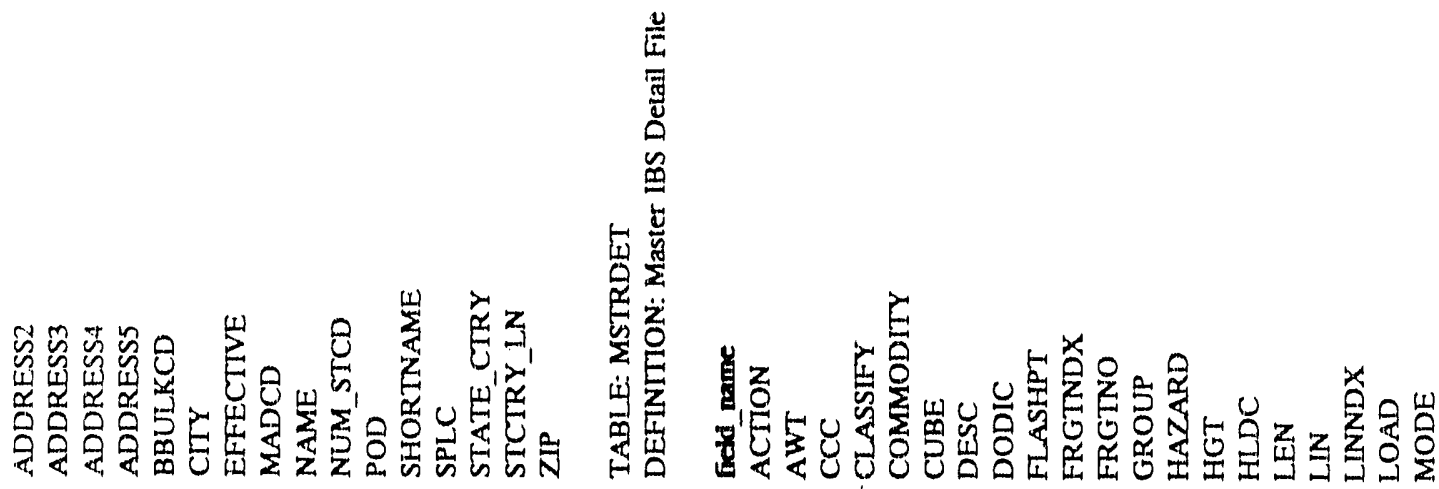

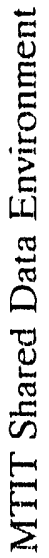



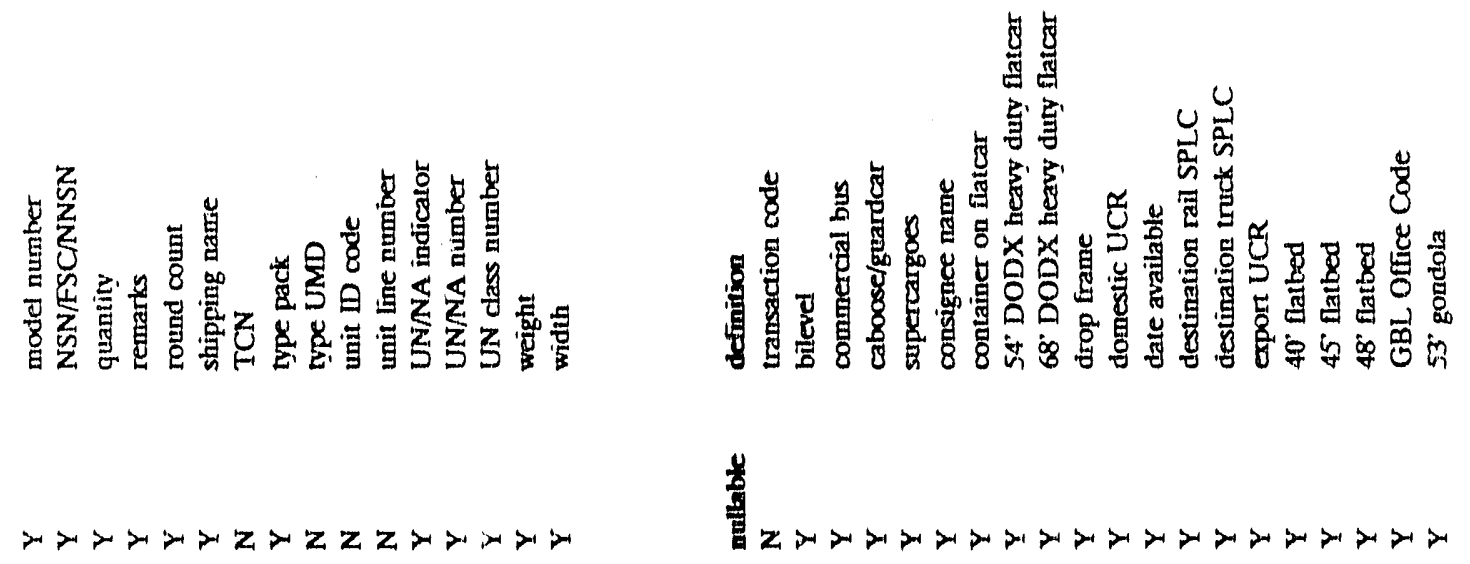

$\frac{5}{4}$

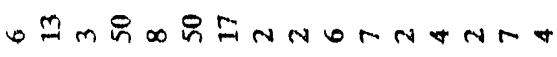

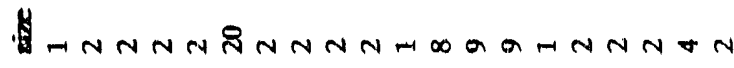

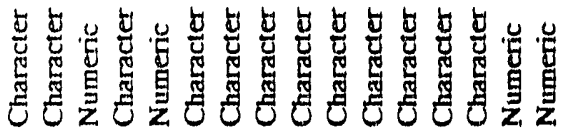
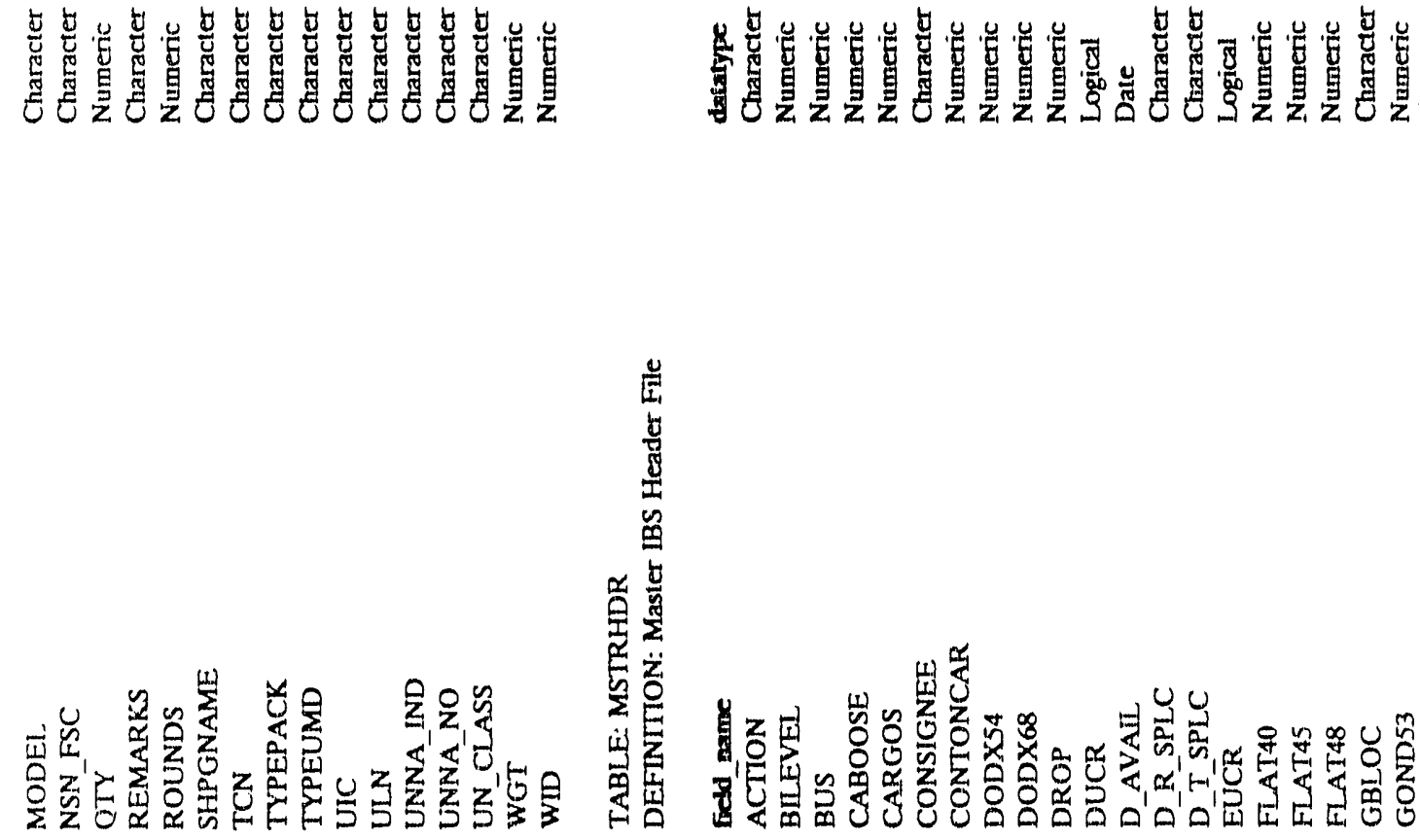

吾 


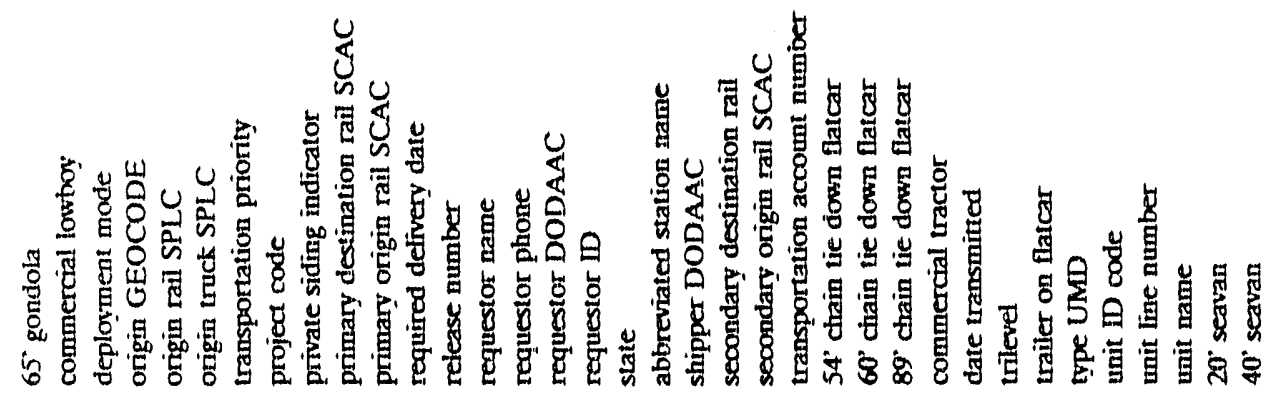

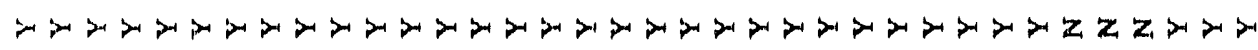

$\frac{m}{1}$

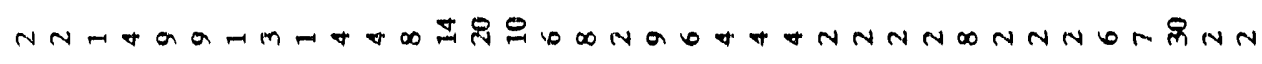

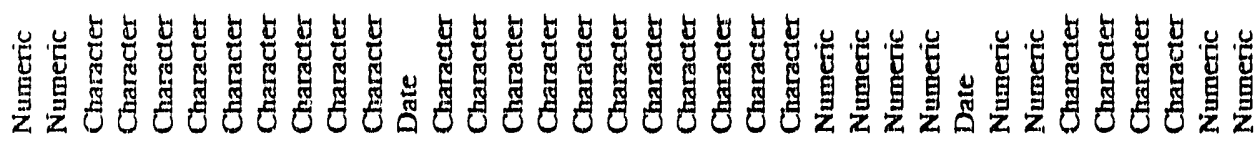

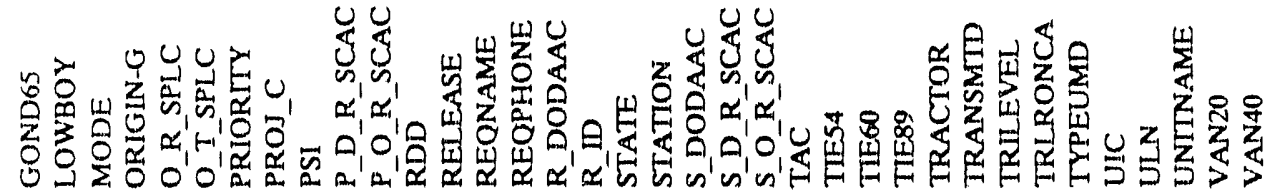


察

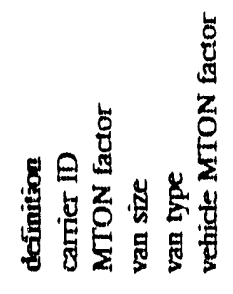
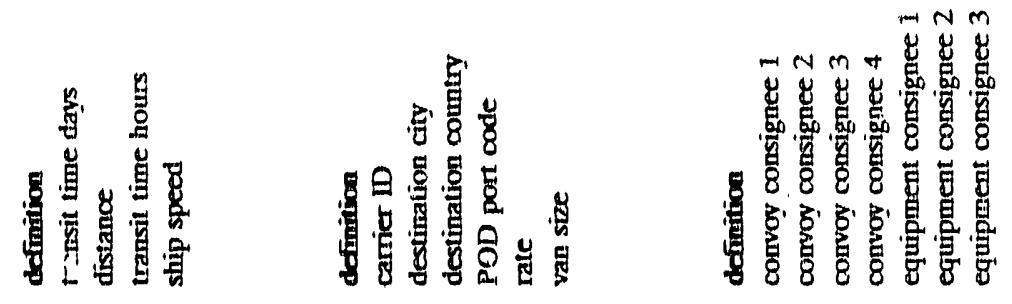

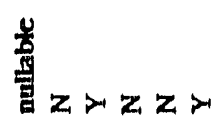
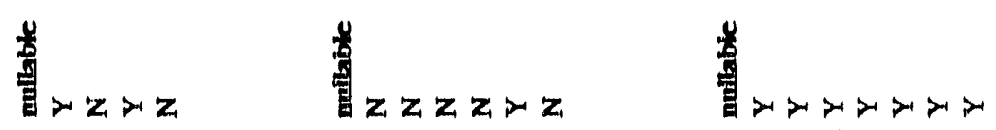

$\frac{⿱ 亠}{1}$

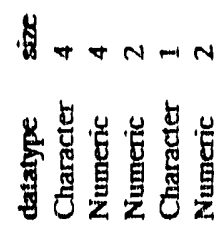

MnN

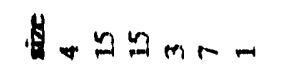

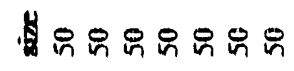
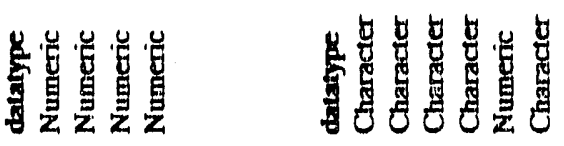

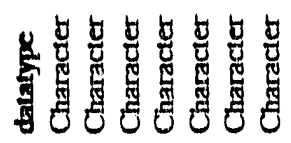
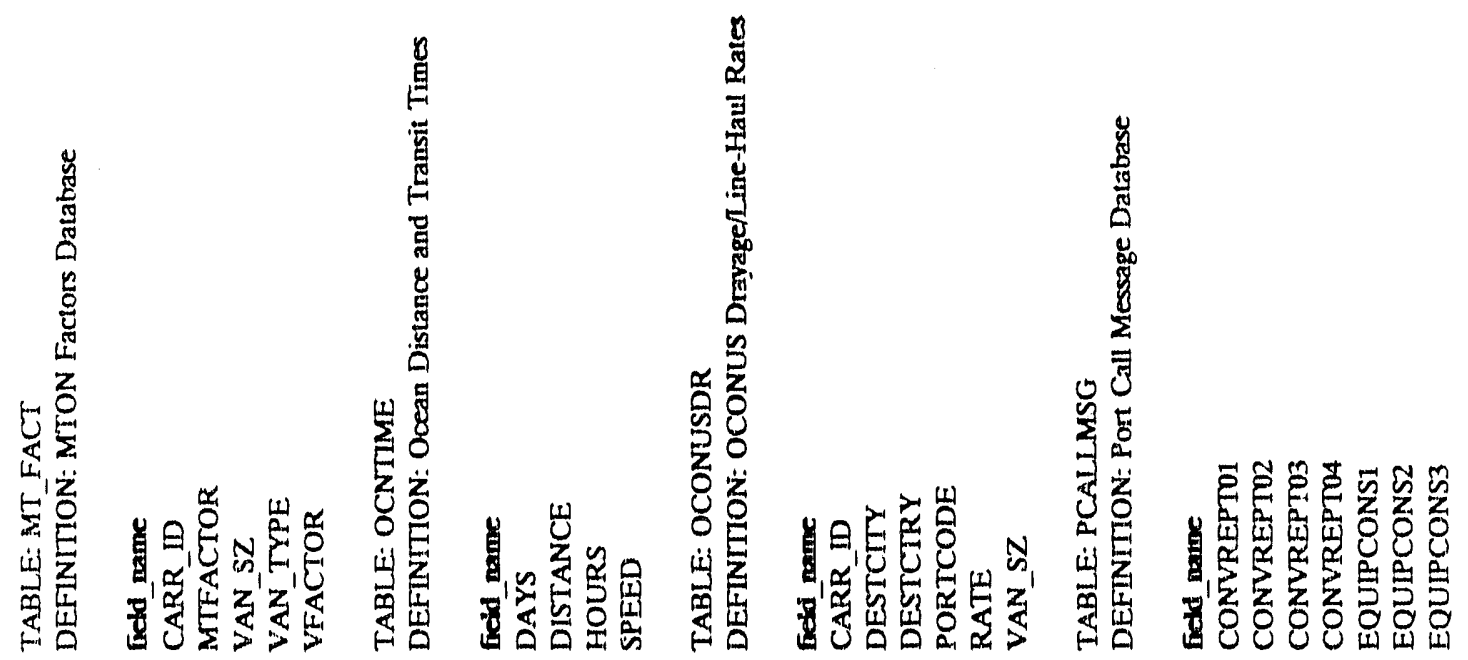

总 


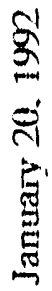
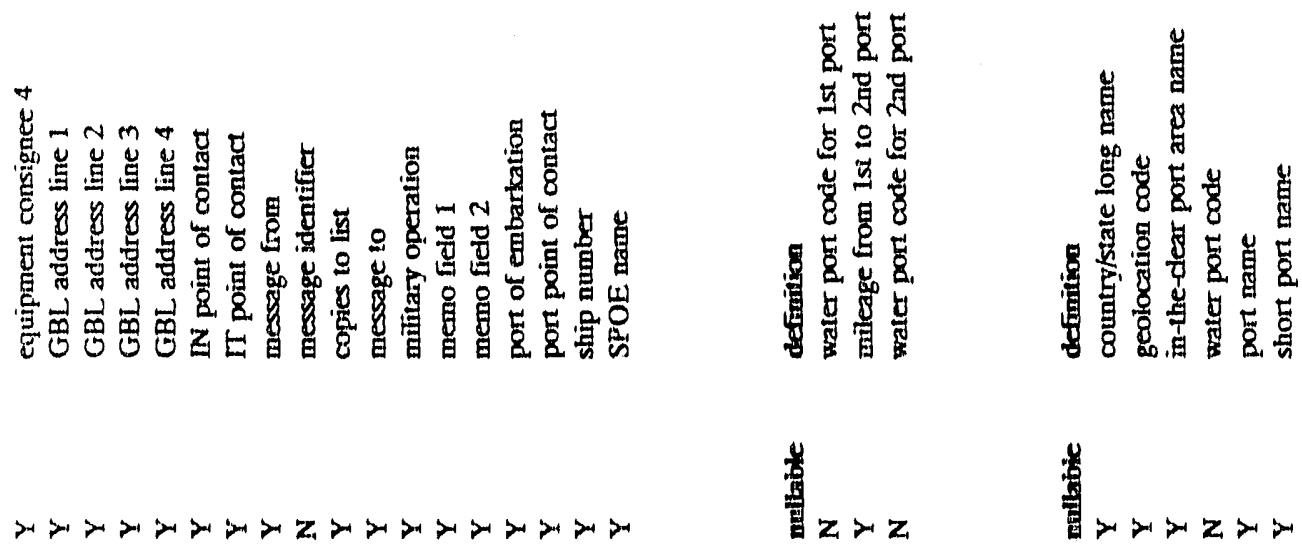

$\frac{n}{4}$

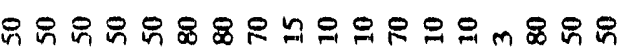

Hom

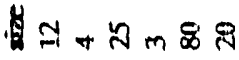

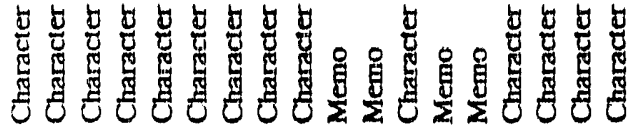

III

IIIney

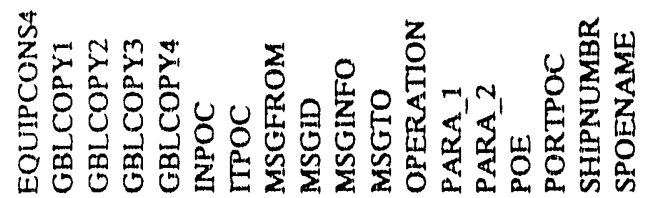

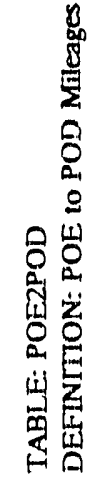

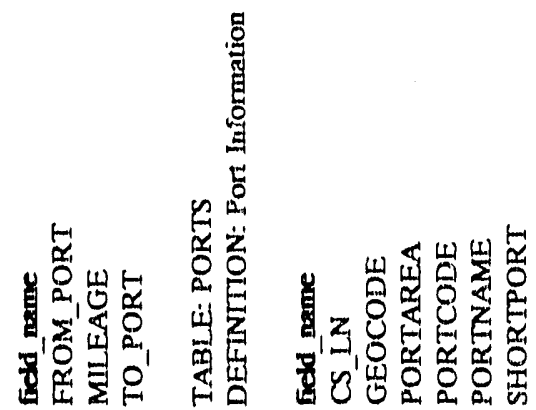

蕠 

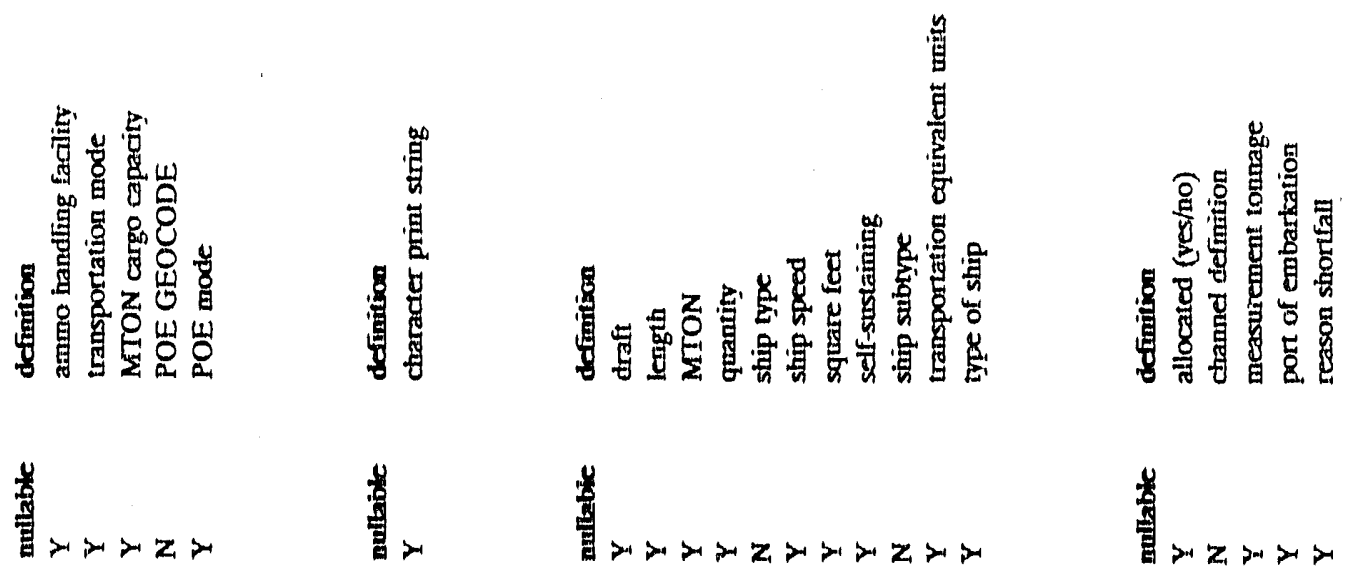

$\frac{0}{1}$

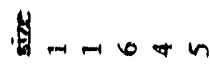

굼

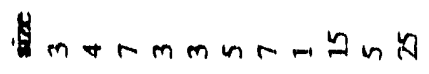

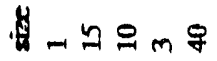

meneven

Il

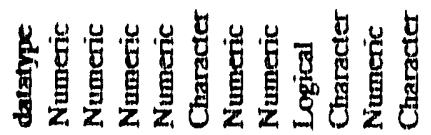

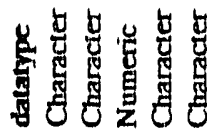
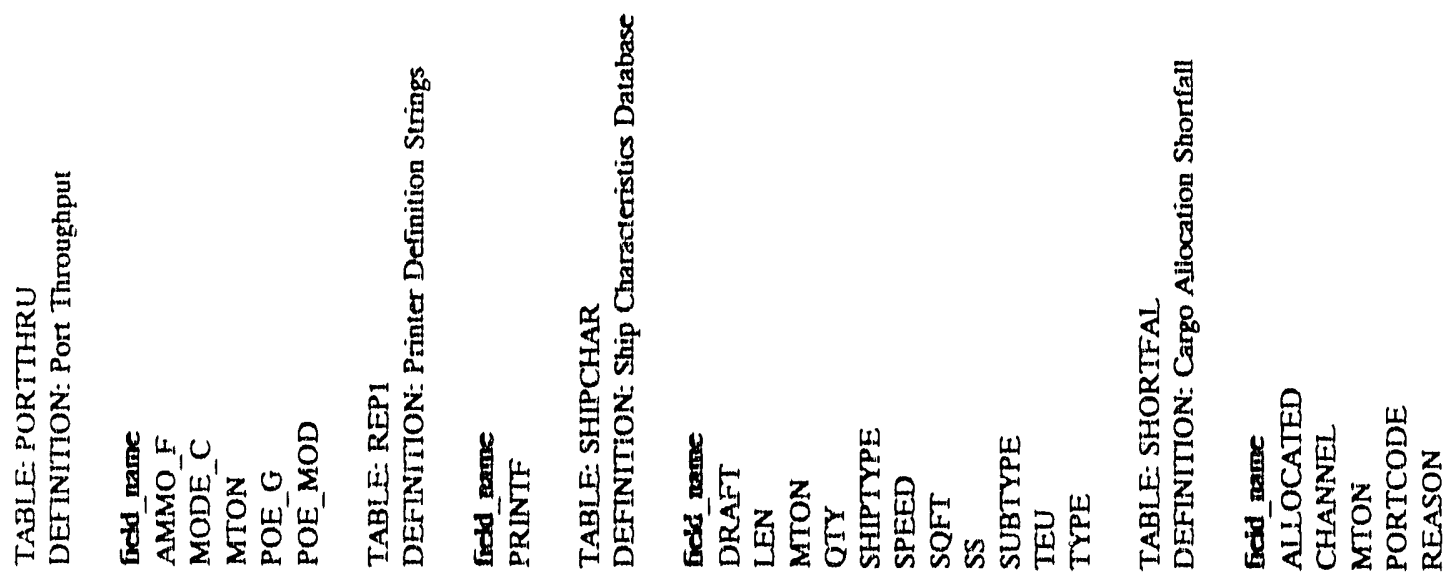

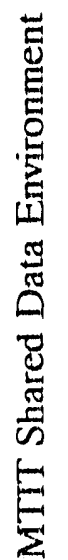



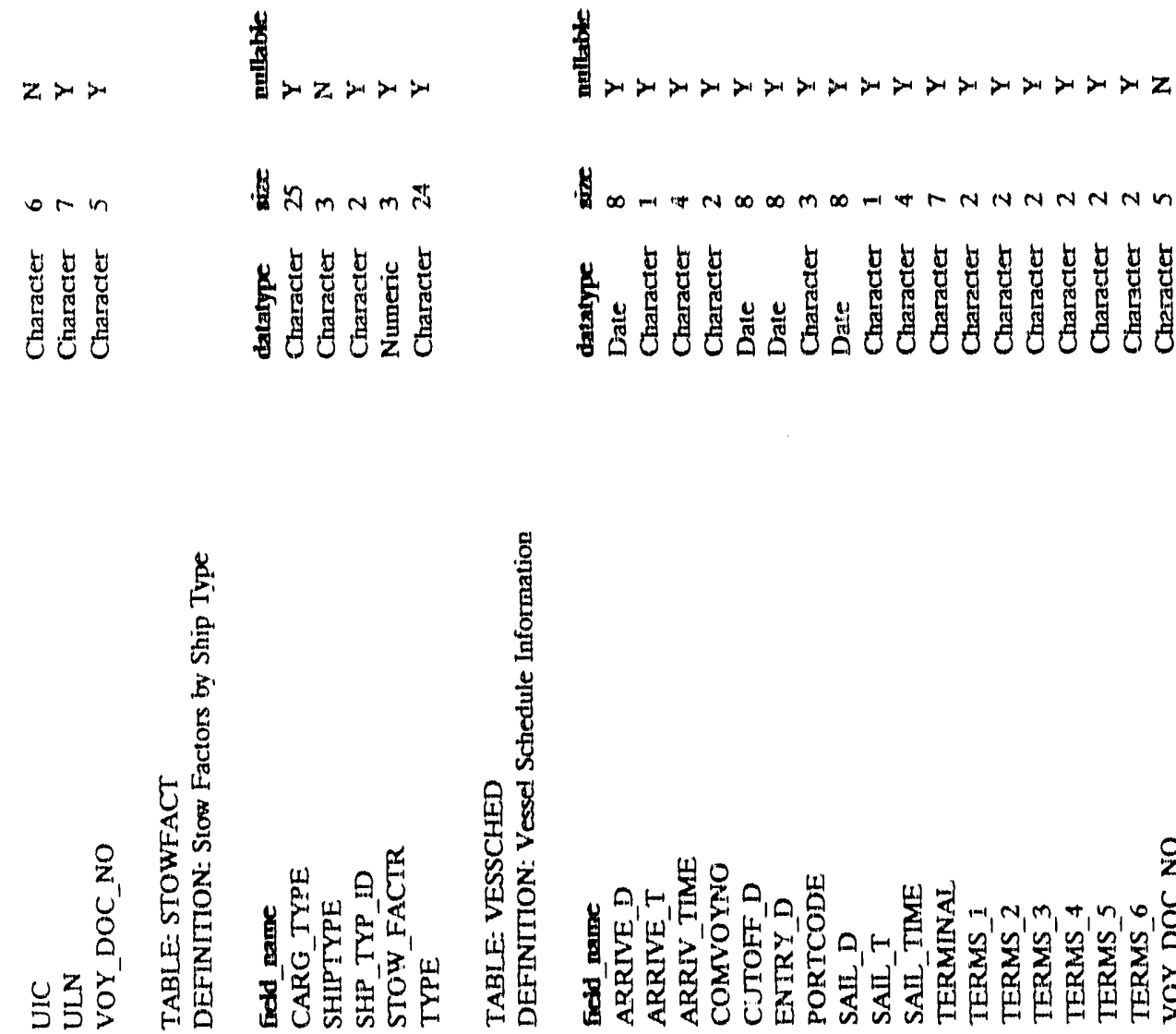

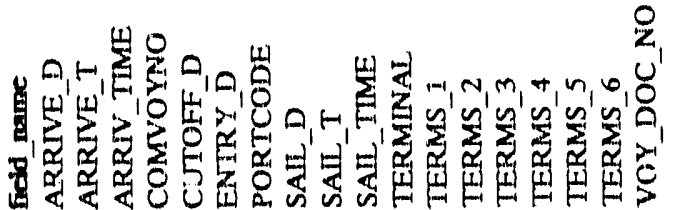

葛 

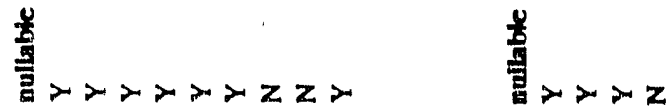

냅ㅇำ

ำ

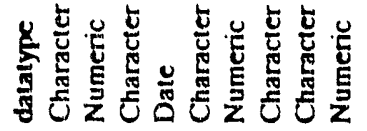

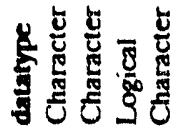

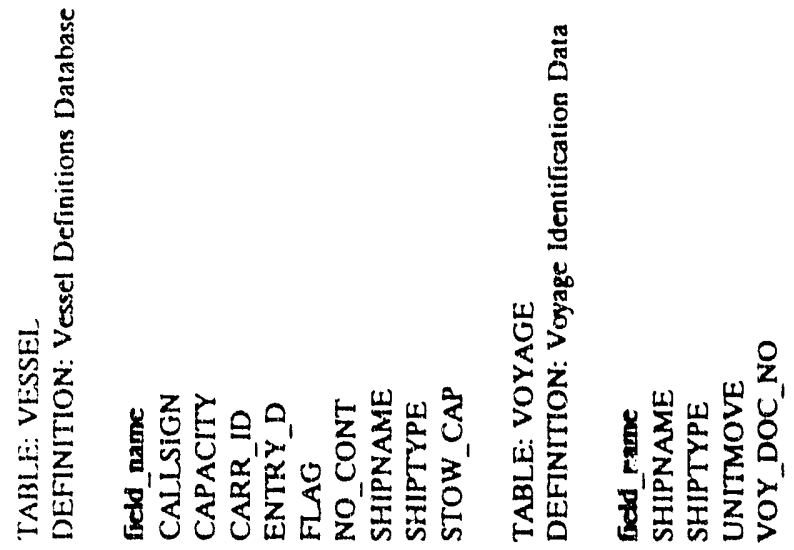

E⿱ 


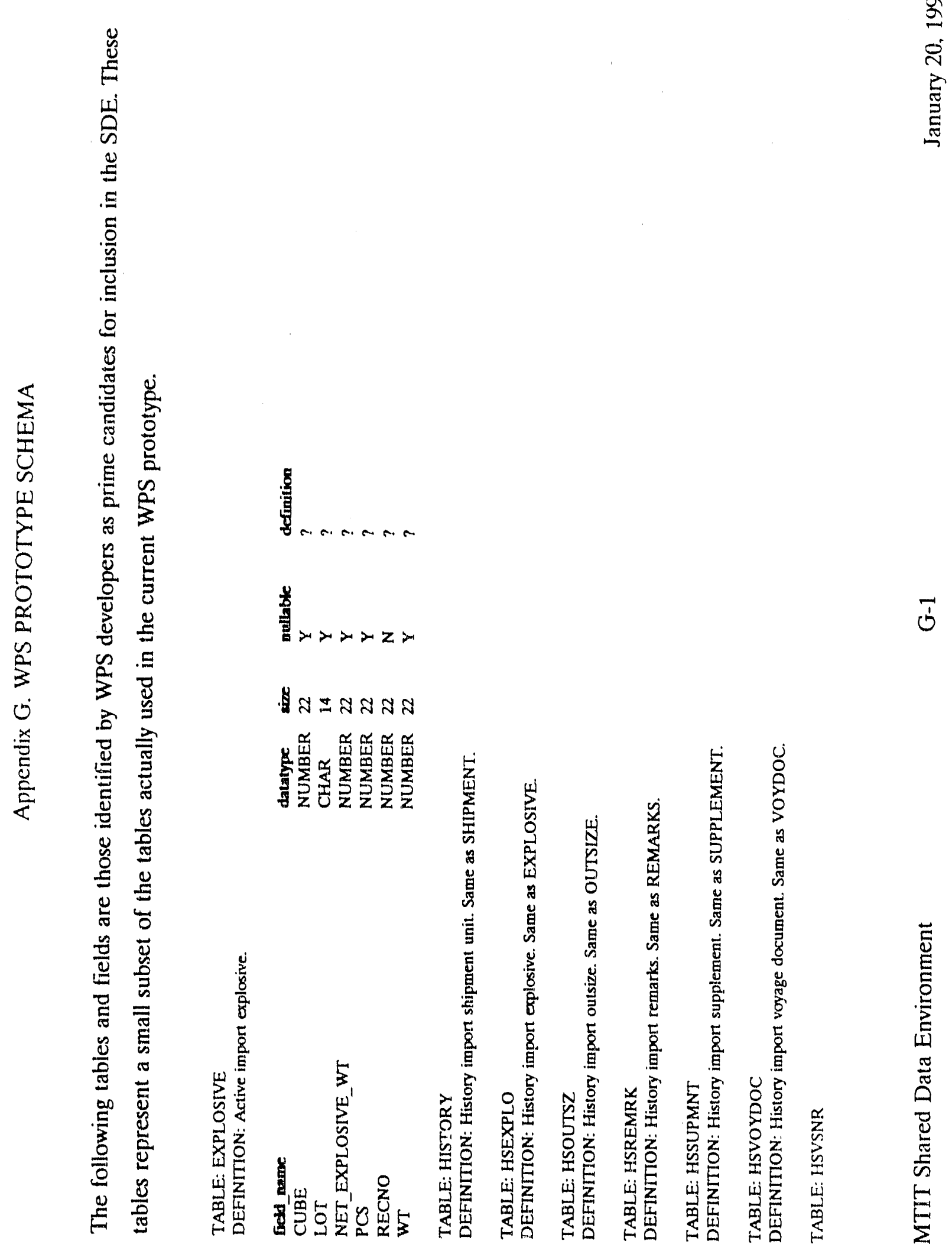



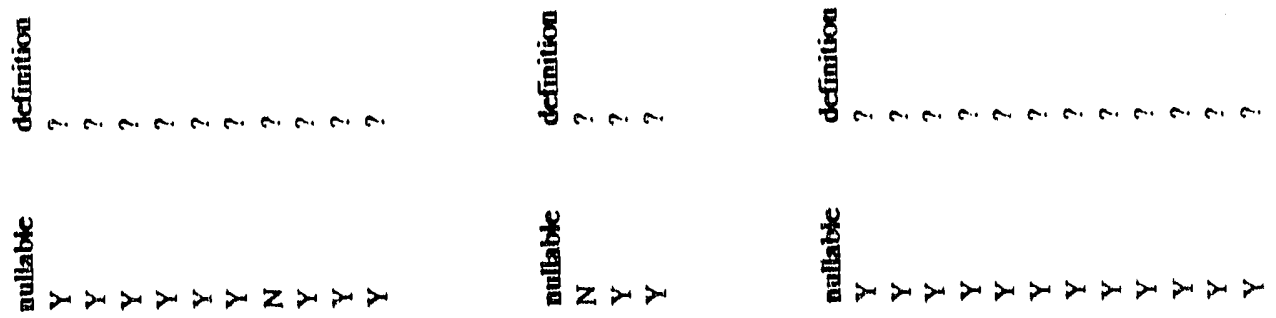

$\frac{1}{1}$

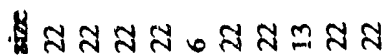

ำ

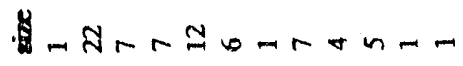

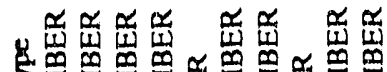

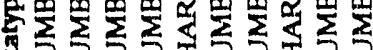

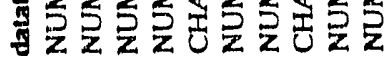

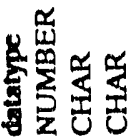

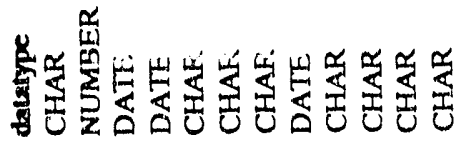

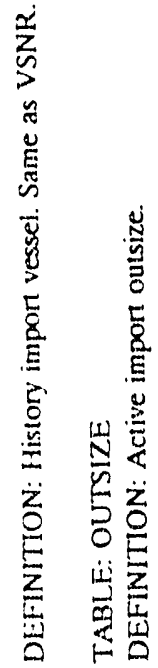

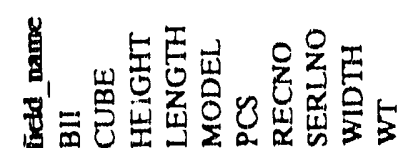

完

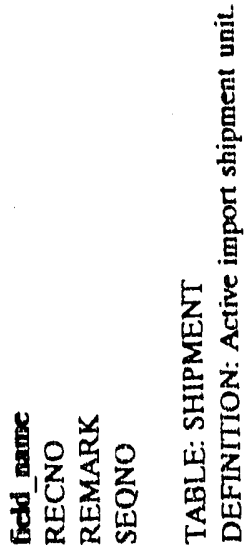

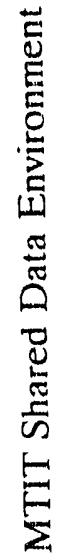




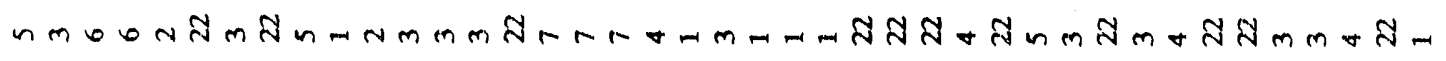

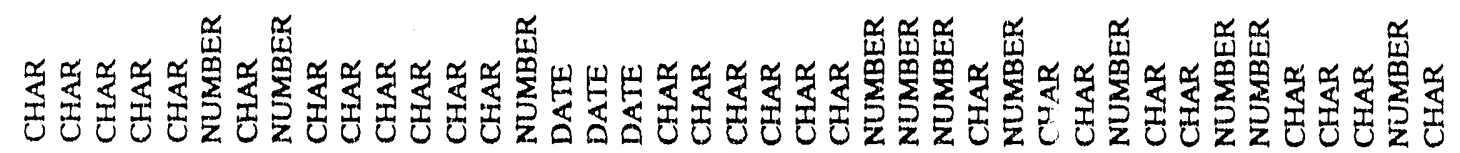

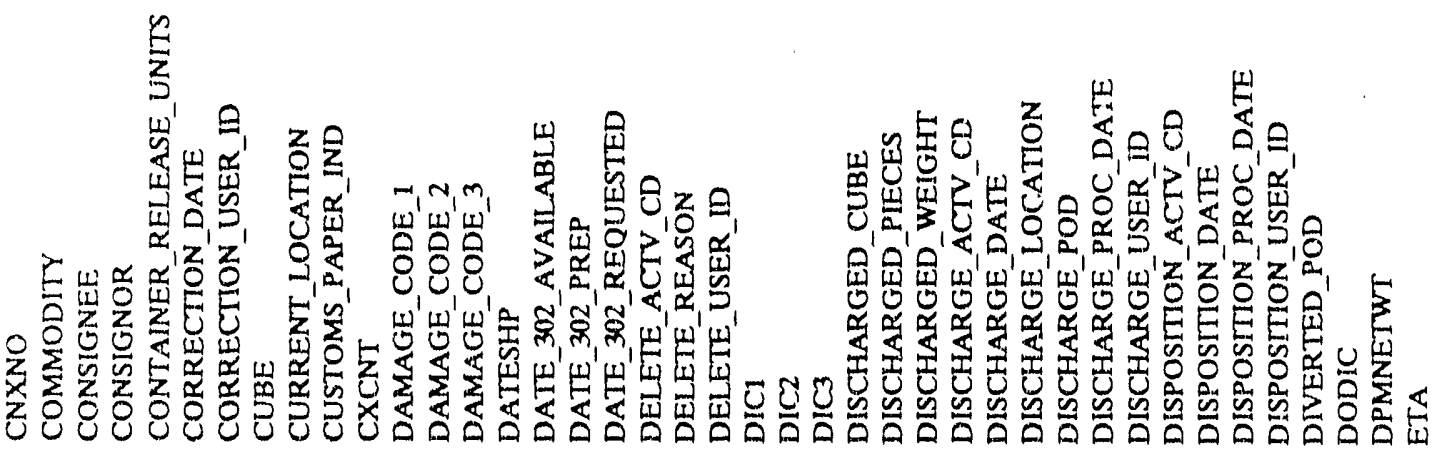




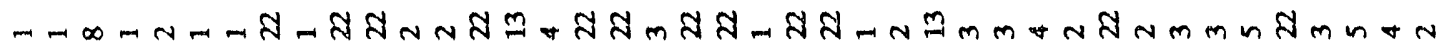

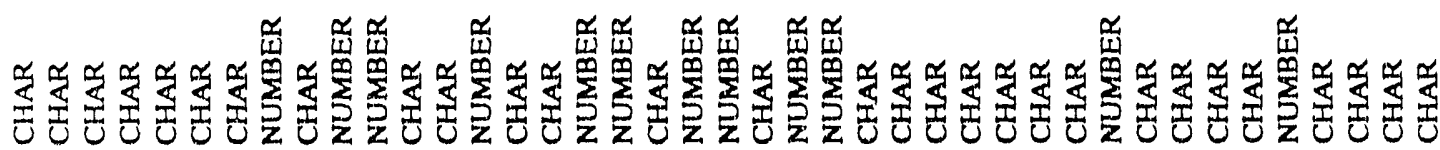

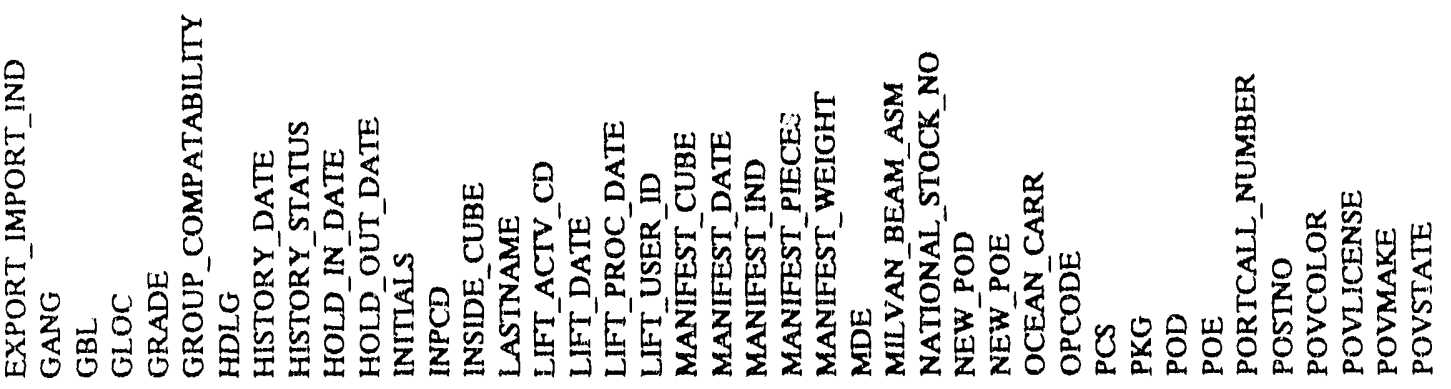




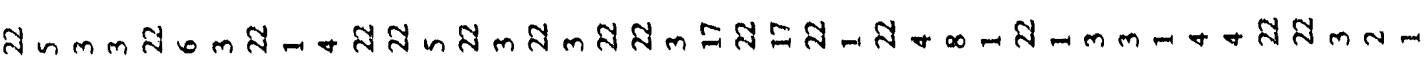

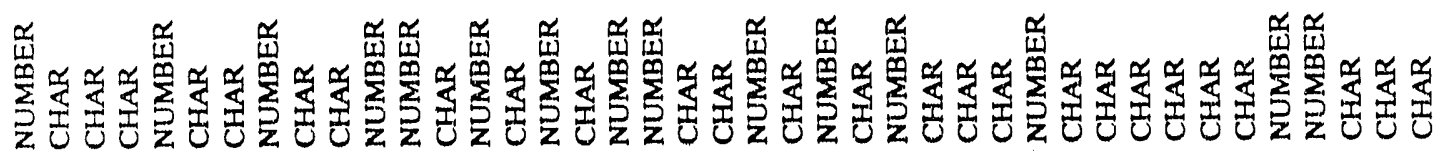

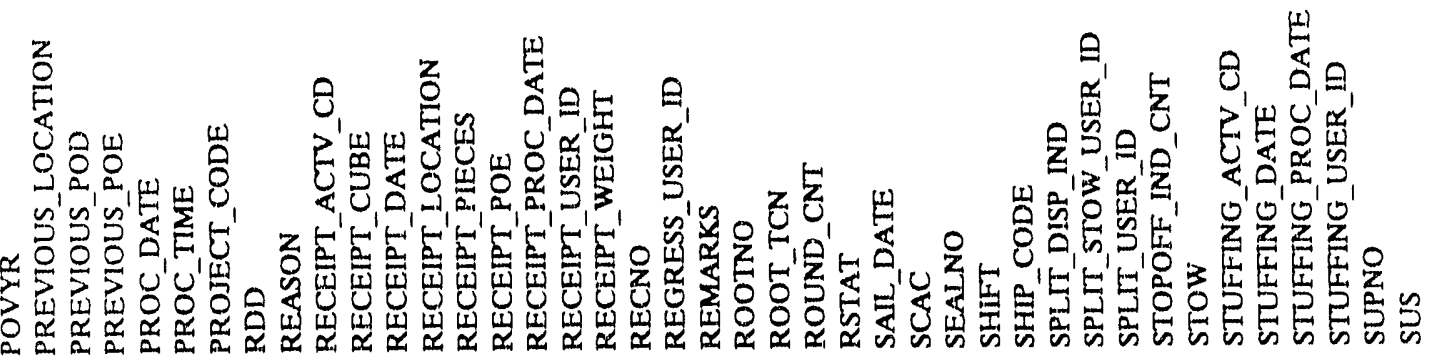




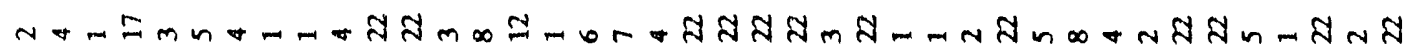

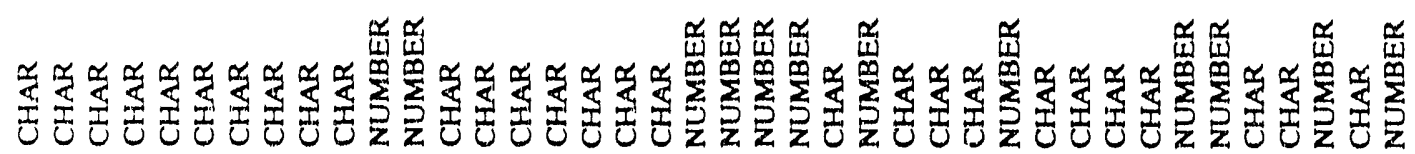

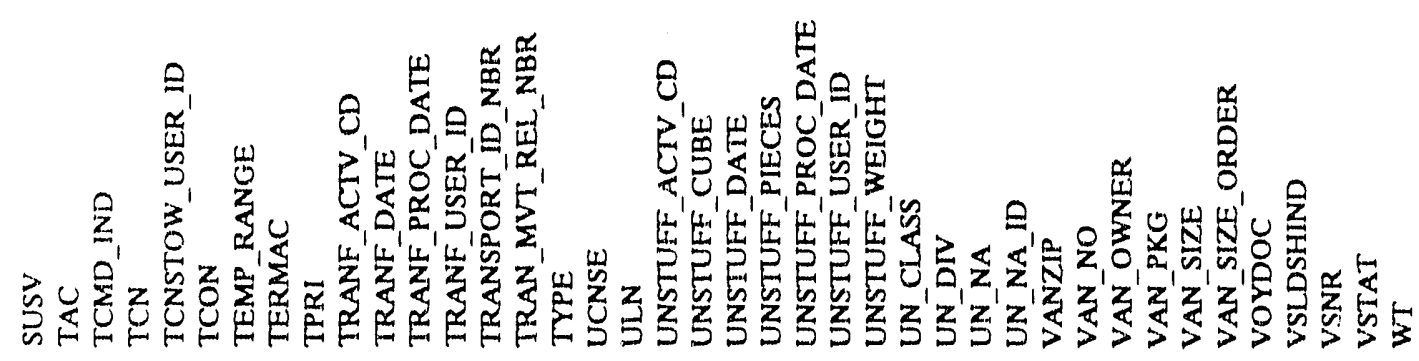



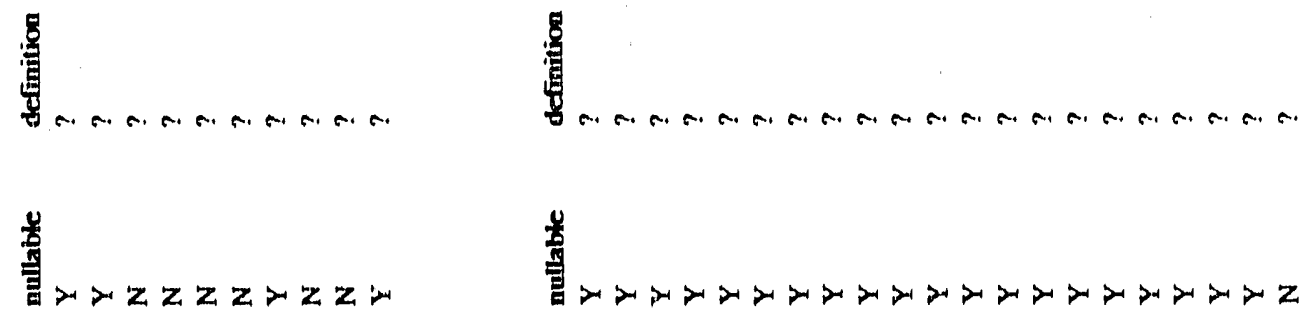

is

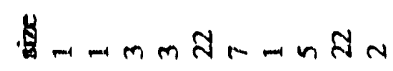

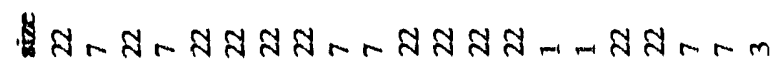

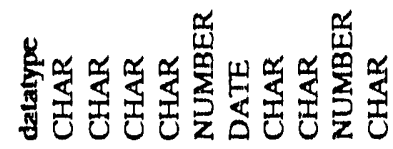

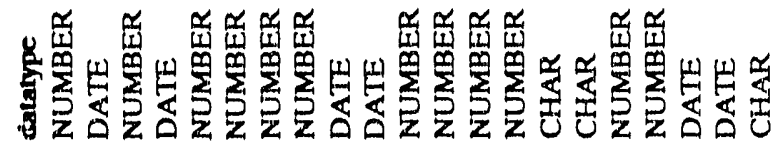
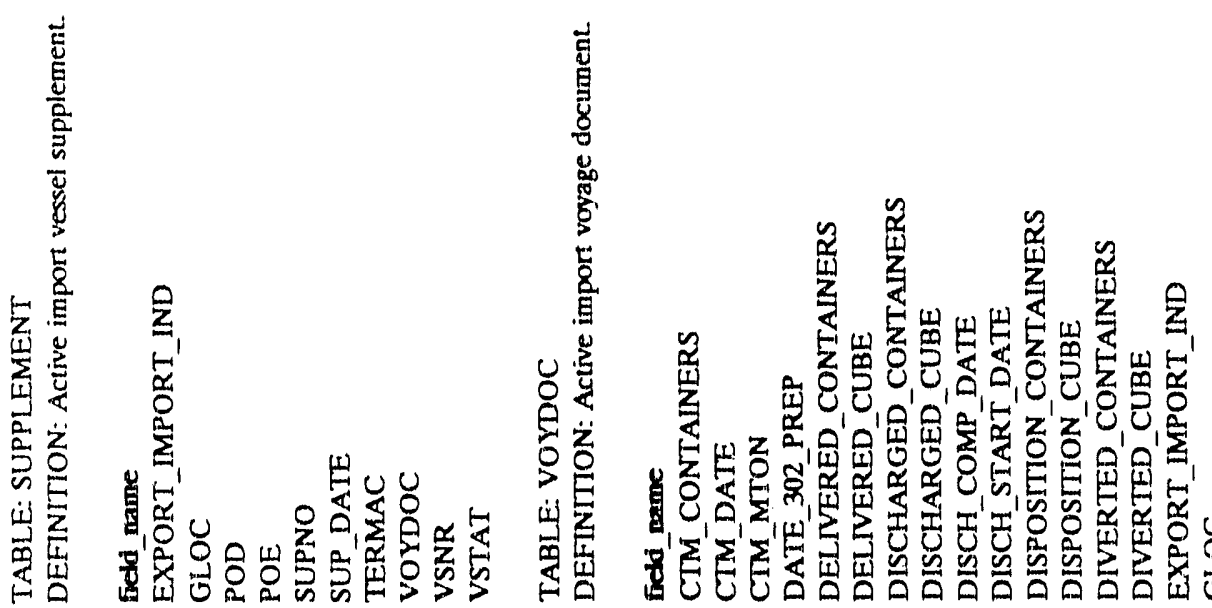

章 菂山

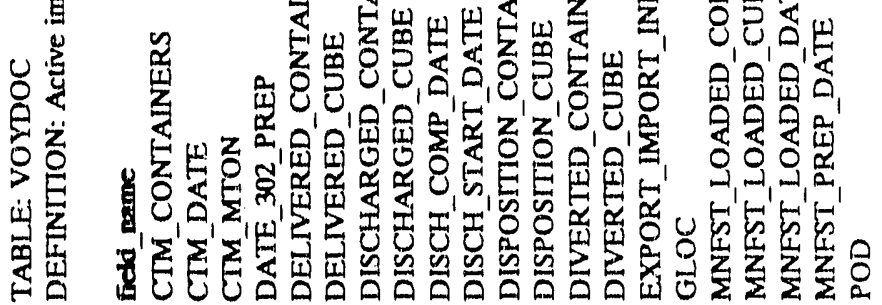

苞 
鄫。
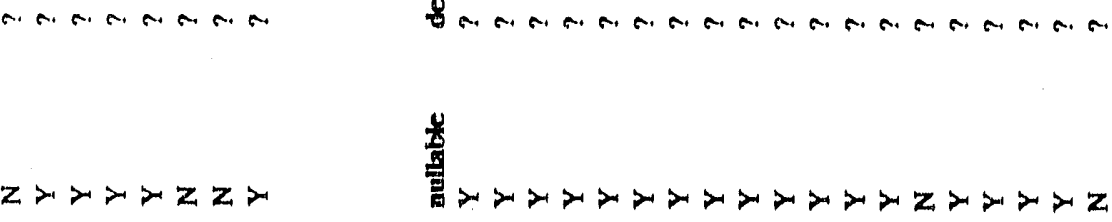

$\infty$

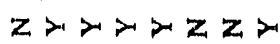

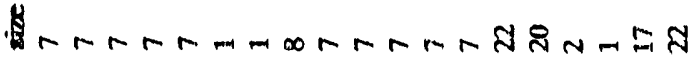

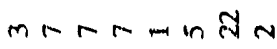

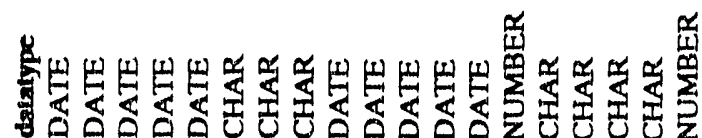

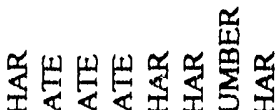

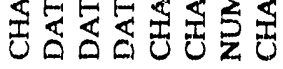

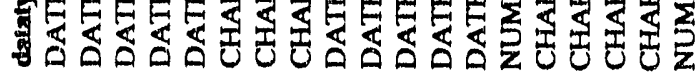
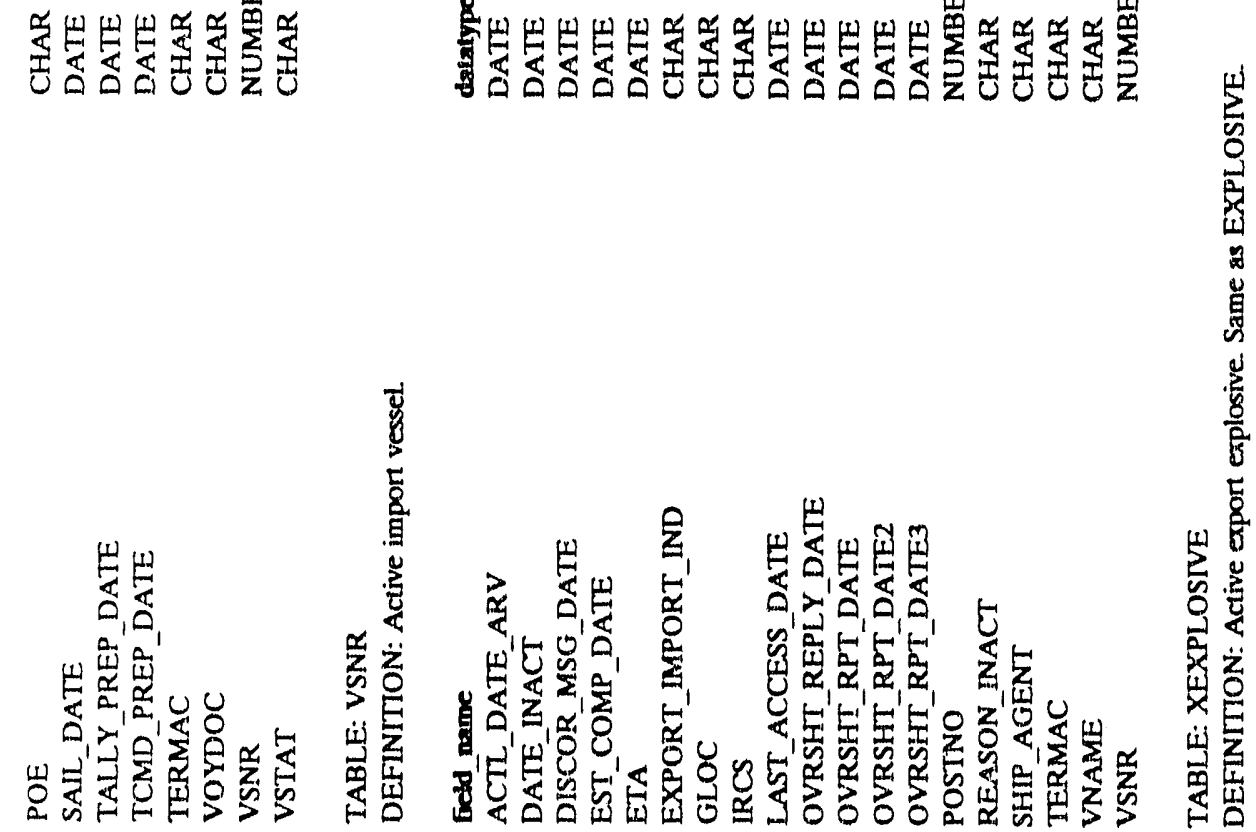

葛 

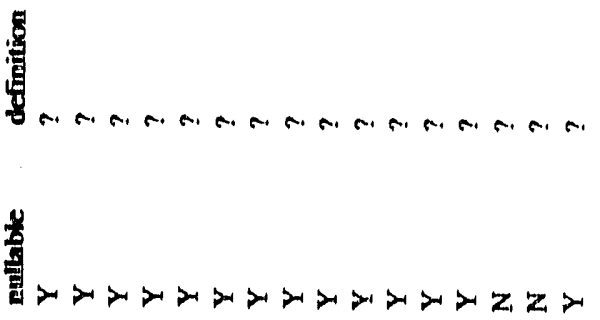

它

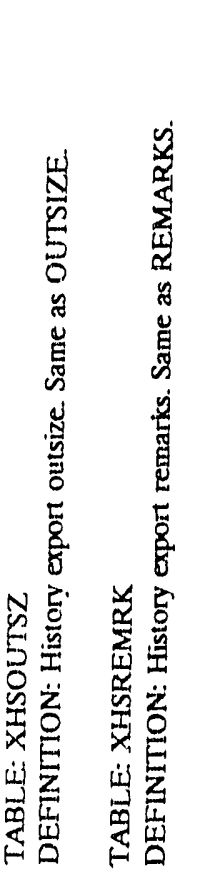

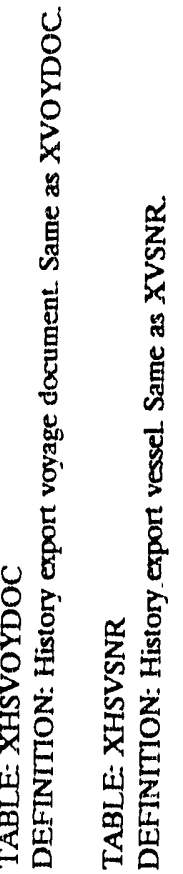

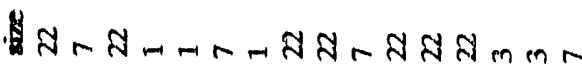

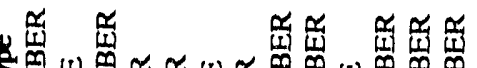

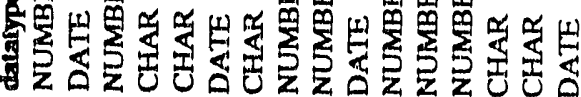

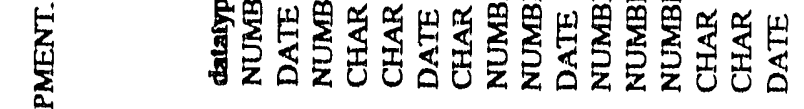

논

它

空

总总

节

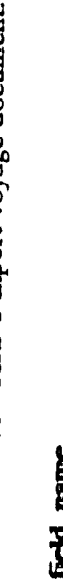

要密

竞苍

究家

远

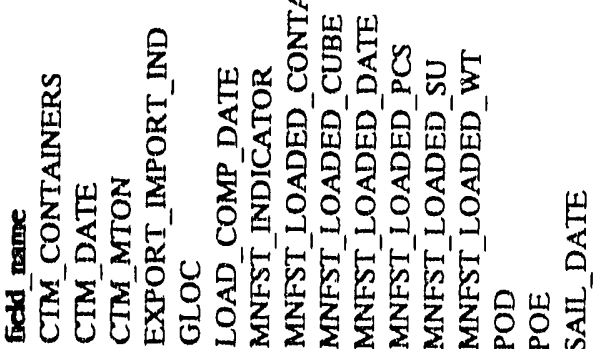

点

崖

总

苋

苞

$E$ 

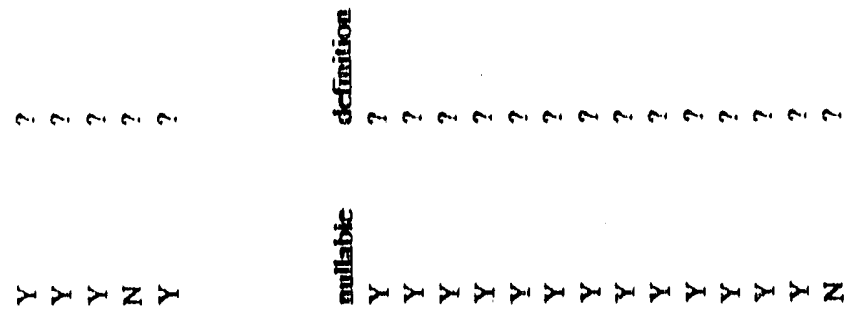

$\frac{0}{6}$

Antann

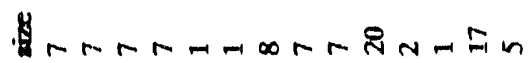

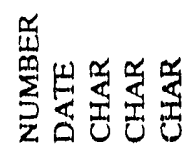

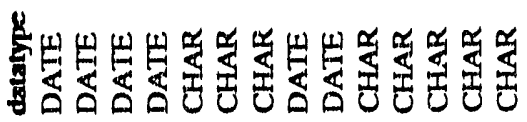

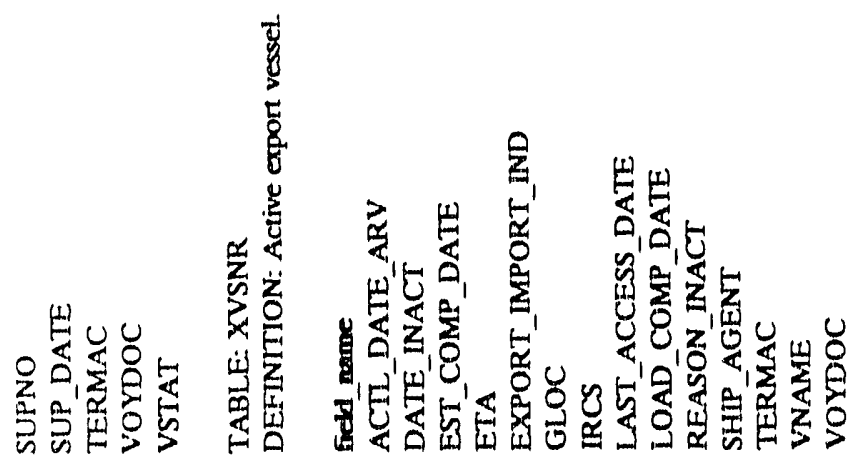

䓪 


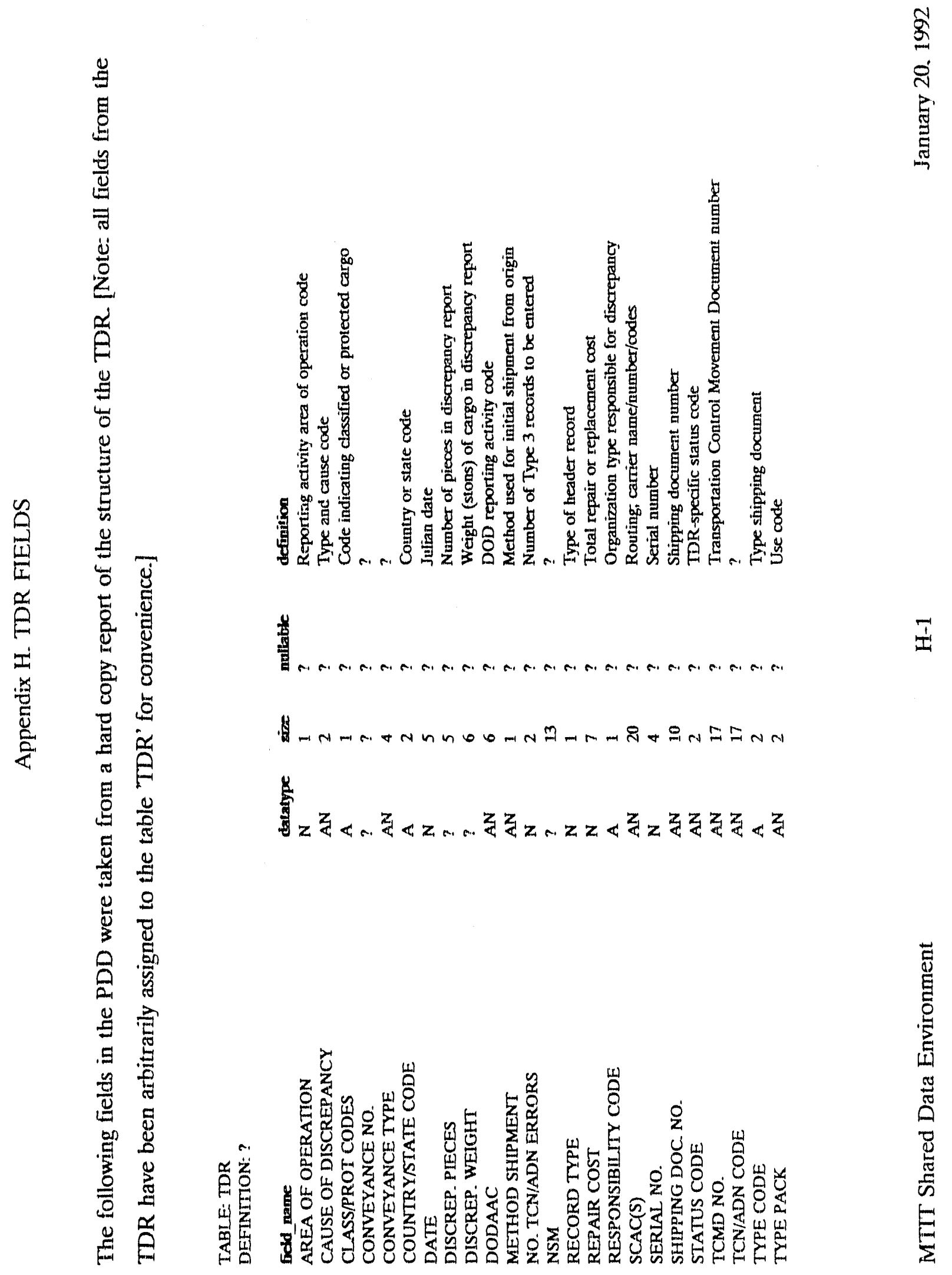




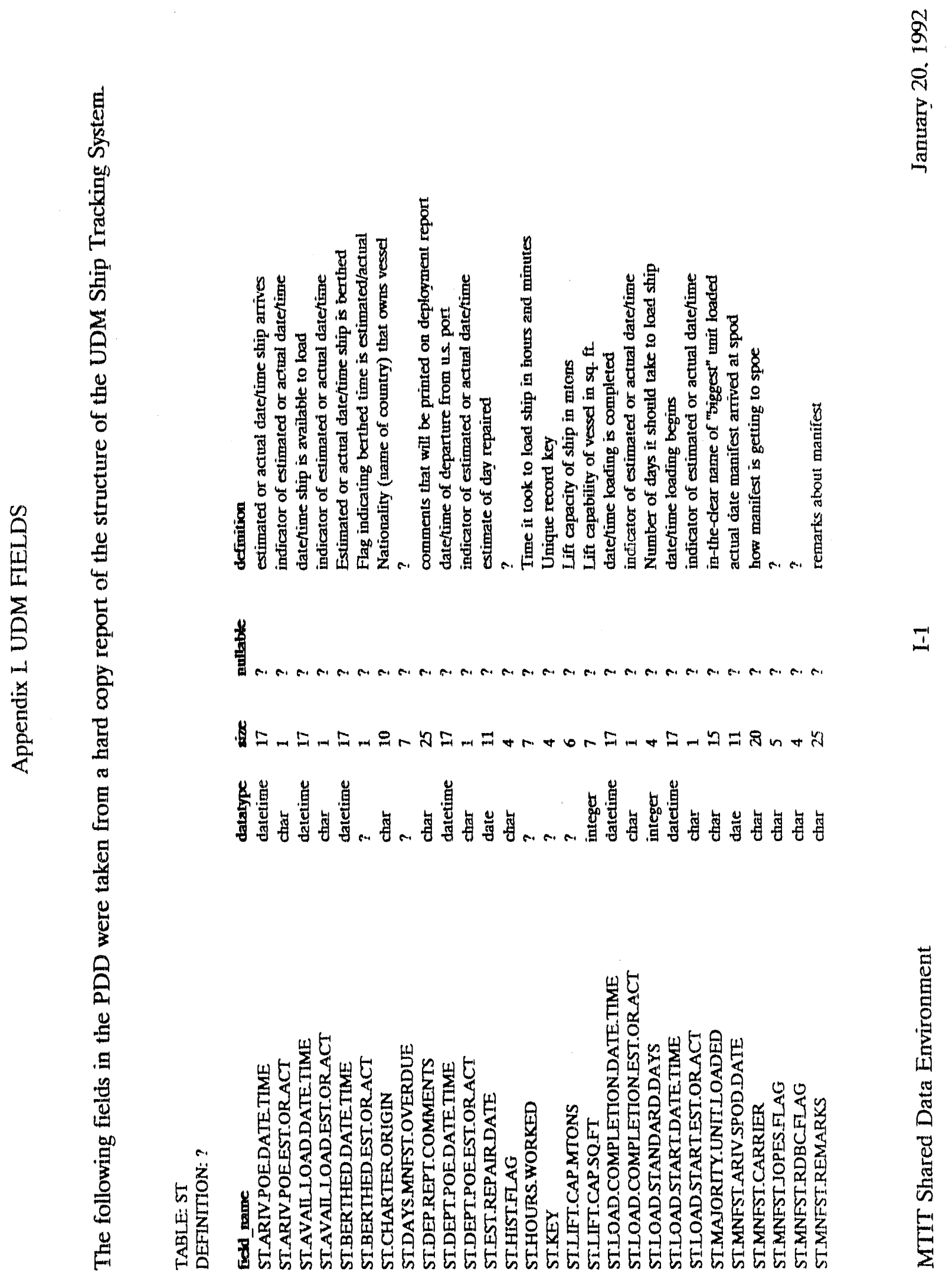




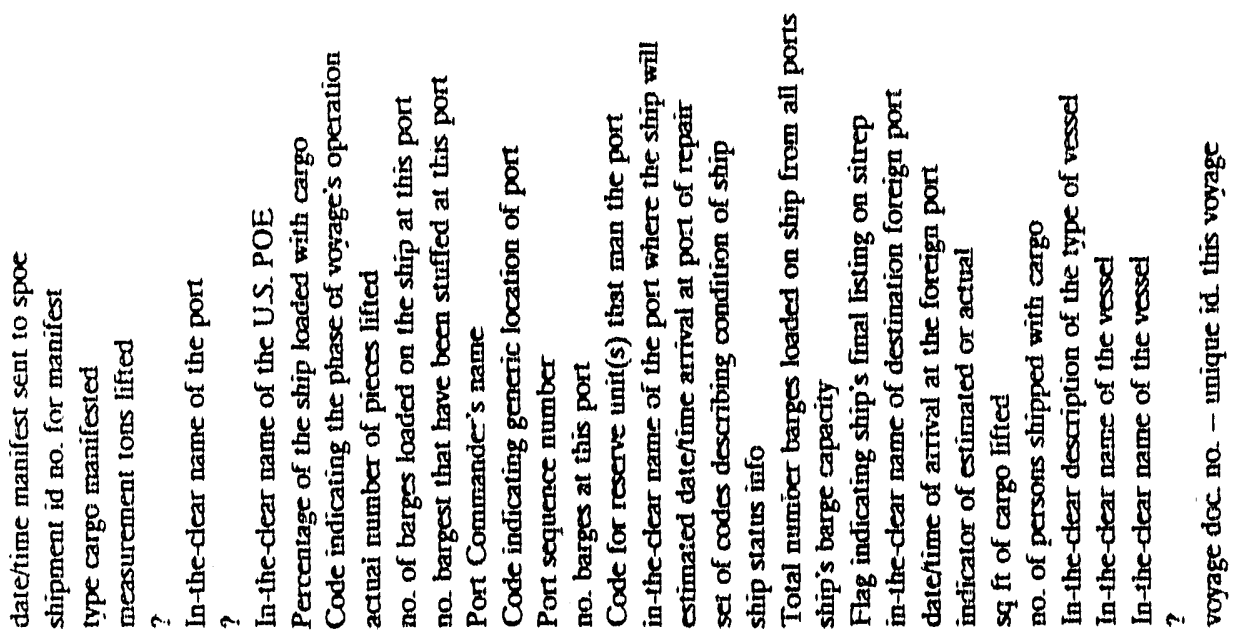

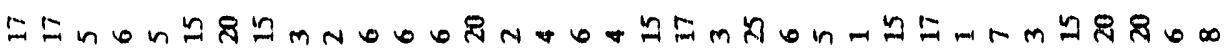

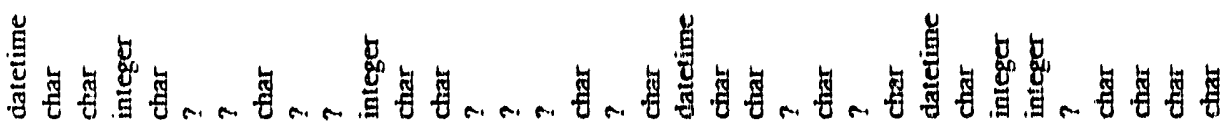

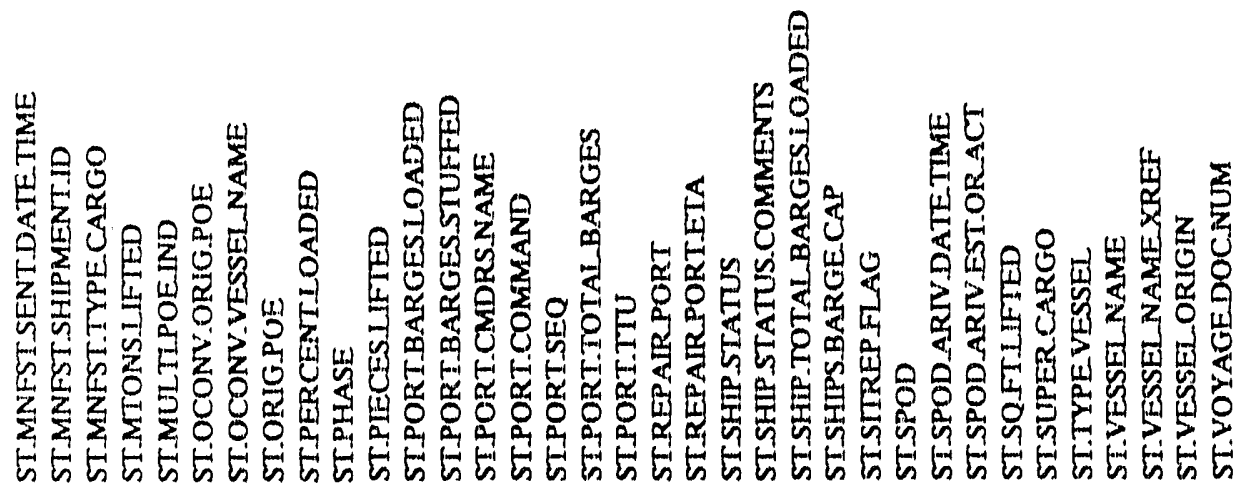

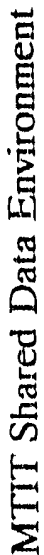




\section{Appendix J. PROTOTYPE DATA DICTIONARY SCHEMA}

$\begin{array}{ll}\text { Name: } & \text { fld_def } \\ \text { Owner: } & \text { ace } \\ \text { Created: } & 29-j u\}-1991 \quad 17: 19: 00 \\ \text { Type: } & \text { user table } \\ \text { Version: } & \text { ING6.0 }\end{array}$

Colum Information:

Column Name

system_acronym

table name

field_name

datatype

size

precision

nullable

definition

Name:

Owner:

Created:

Type:

Version:

Column infornition:

Column Name

sde_field_name

system_acronym

table name

field_name

Name:

Owner:

Created:

Type:

Version:

Column Information:

Column Name

field_name

datatype

size

precision

units

domain

definition

$\begin{array}{lrcc} & & & \text { Key } \\ \text { Type } & \text { Length } & \text { Nulls } & \text { Defaults Seq } \\ \text { char } & 3 & \text { yes } & \text { no } \\ \text { char } & 10 \text { yes } & \text { no } \\ \text { char } & 30 \text { yes } & \text { no } \\ \text { char } & 10 \text { yes } & \text { no } \\ \text { char } & 3 \text { yes } & \text { no } \\ \text { char } & 2 \text { yes } & \text { no } \\ \text { char } & 1 \text { yes } & \text { no } \\ \text { vehar } & 50 \text { yes } & \text { no }\end{array}$

fld_xref

ace

17-sep-1991 15:52:00

user table

ING6.0

$\begin{array}{lrlr} & & & \text { Key } \\ \text { Type } & \text { Length } & \text { Nulls } & \text { Defaults Seq } \\ \text { char } & 30 & \text { yes } & \text { no } \\ \text { char } & 3 & \text { yes } & \text { no } \\ \text { char } & 10 & \text { yes } & \text { no } \\ \text { char } & 30 \text { yes } & \text { no }\end{array}$

sde_fld_def

ace

17-sep-1991 16:07:00

user table

ING6.0 


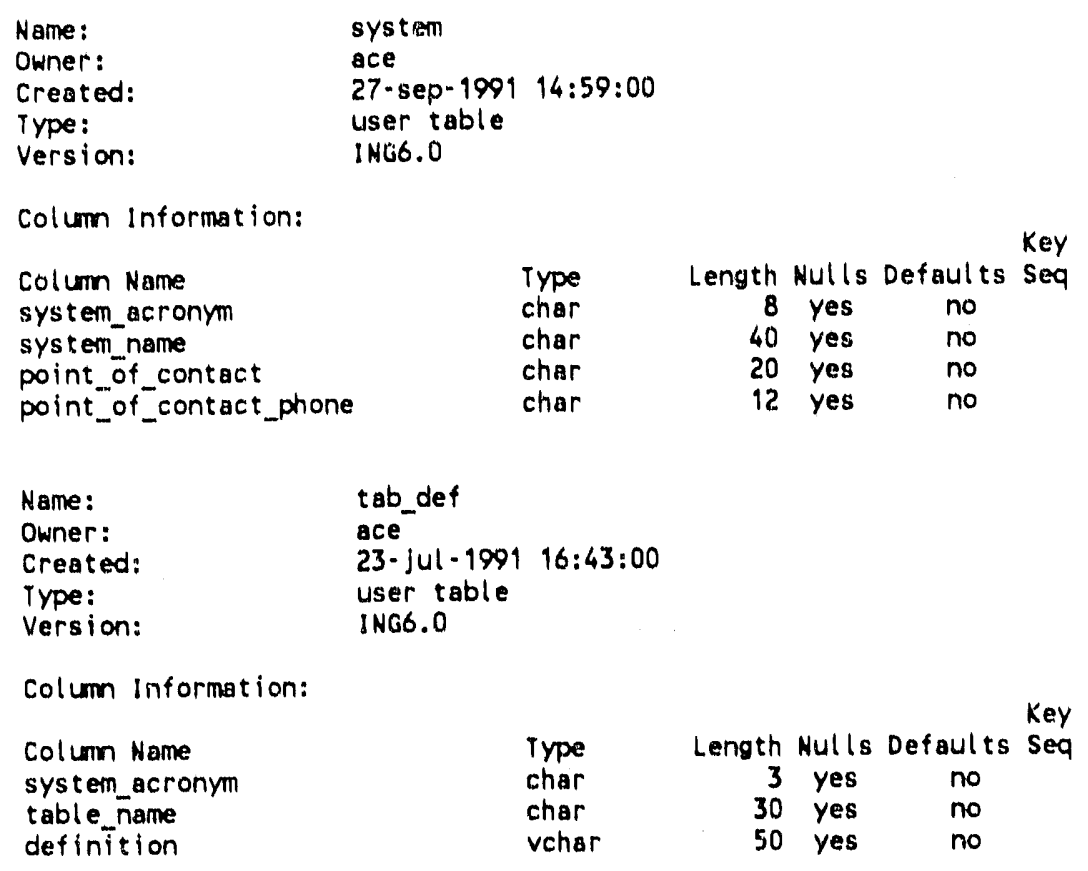




\section{Appendix K. PROTOTYPE DATA DICTIONARY SCRIPTS}

The following PDD scripts are available by executing a form of the command line as it appears after the word "usage:". For parameter choices enclosed by braces and separalled by a bar (e.g., \{sde_field_name|all\}), the user must choose one of the options presenled (i.e., either 'sde_field_name' or 'all' in the previous example).

sdeflddef

usage: sdeflddef \{sde_field_name $\mid$ all $\}$

Displays full field definition for sde_field_name.

If 'all' is specified, all SDE field names and full

definitions are displayed in alphabetiral order.

sdefldxref

usage: sdefldxref \{sde_field_name $\mid$ all $\}$

Displays full field definitions for all system fields that are cross referenced to sde_field_name. Results are sorted by system_acronym, table_name, field_name.

If 'all' is specified, all cross references to all SDE fields are displayed sorted by sde_field_name, system_acronym, table_name, field_name.

sdehelp

usage: sdehelp

Displays help for routines executable at the Unix prompt.

sdeinsertxref

usage: sdeinsertxref sde_field_name system_acronym table_name field_name

For an existing sde_field_name, adds a cross reference to the field_name contained in the specified system and table.

Enclose any parameters with embedded blanks (e.g., field_name) in double quotes. 
sdesysfldall

usage: sdesysfldall \{system_acronym|all\} string

Displays all ficlds with field_name equal to string.

Also displays containing system_acronym and table_name.

Wildcards (\% and ) may be used as part of string.

Run 'sdesystem list' for list of valid system_acronym values.

If 'all' is specified, fields from all systems are displayed, and

results are sorted by field_name, system_acronym, table_name.

sdesysflddef

usage: sdesysflddef \{system_acronym|all\} field_name

Displays full field definitions for field_name.

Run 'sdesystem list' for list of valid system_acronym values.

If 'all' is specified, all occurences of field_name in all systems are displayed with results sorted by system_acronym, table_name.

sdesysfldxref

usage: sdesysfldxref system_acronym \{field_rame $\mid$ all\}

Displays full field definitions for the sde field that

is cross referenced to field_name.

Run 'sdesystem list' for list of valid system_acronym values.

sdesystabdef

usage: sdesystabdef $\{$ system_acroniym|all\} \{table_name $\mid$ all $\}$

Displays table definitions for participating systems in SDE. Run 'sdesystem list' for list of valid system_acronym values. If 'all' is specified for both parameters, all table definitions for all systems are displayed, sorted by sj'stem_acronym.

sdesystabfld

usage: sdesystabfld system_acronym \{table_name|all\}

Displays table/field definitions for participating systems in SDE.

Run 'sdesystem list' for list of valid system_acronym values.

If 'all' is specified, table/field definitions for all tables

are displayed, sorted by table_name. 
sdesystem

usage: $\quad$ sdesystem $\{$ list $\mid$ full $\}$

Displays information on participating systems in the SDE.

If 'list' is specified, a list of system_acronym's is displayed.

If 'full' is specified, additional information (e.g., phone

number of the point of contact) is displayed.

sdetabfld

usage: sdetabfld \{table_name $\mid$ all $\}$

Displays structure of table(s) that comprise the SDE Prototype

Data Dictionary (PDD). Results are sorted by column sequence (as defined in create table statement).

sdeupdatename

usage: sdeupdatename old_name new_name

Updates old_name to new_name in both sde_fld_def and fld_xref. 


\section{Appendix L. EXAMPLES OF SCRIPT USAGE AND OUTPUT}

The following examples illustrate the usage of several PDD scripts. The full current sct of PDD information retrieval and maintenance scripts is described in Sect. 4.4, and the scripl documentation is listed in Appendix K. [Note PLiD scripts were used to produce the listings in Appendixes C-K.]

All examples of user input below are preceded by the number of the Unix job and the $\$$ prompt. The user types the input after the $\$$ prompt to produce the output that follows.

(1) In Job $\# 325$, the user types a script name without any parameters. The result is documentation on the usage of the script. [Note: for a complete list of the available scripts, type sdehelp.]

325 s sdesysfldall

Usage: sdesysfldall (system_acronym|all) string

Displays all fields with field_name equal to string.

Also displays containing system_acronym and table_name.

Wildcards ( $x$ and ) may be used as part of string.

Run 'sdesystem list' for list of valid system_acronym values.

If 'all' is specified, fields from all systems are displayed, and

results are sorted by field_name, system_acronym, table_name.

(2.) In job \$326, the user takes the recommendation above and finds out which systems are currently participating in the SDE.

326 sdesystem list

acronym

n.........

IBS

TDR

UDM

WPS

(n........

(4 rows)

(3) In job $\$ 327$, the user is interested in finding all fields in wPS that contain the string IPOD' anywhere in the string.

327 sdesysfldall WPS xpoo\%

system table_name field_name

.............................

WPS SHIPMENT

WPS SHIPMENT

WPS SHIPMENT

WPS SHIPMENT

WPS SUPPLEMENT

WPS VOYDOC

WPS XVOYDOC

WPS SHIPMENT

....... ...........

(8) rows)

DISCHARGE_POO

DIVERTED_POO

NEW POD

$P O D$

$P O O$

POD

POD

PREVIOUS POO 
(4) in Job $\$ 328$, a similar query returns all fields in all systems that contain the string IUN'.

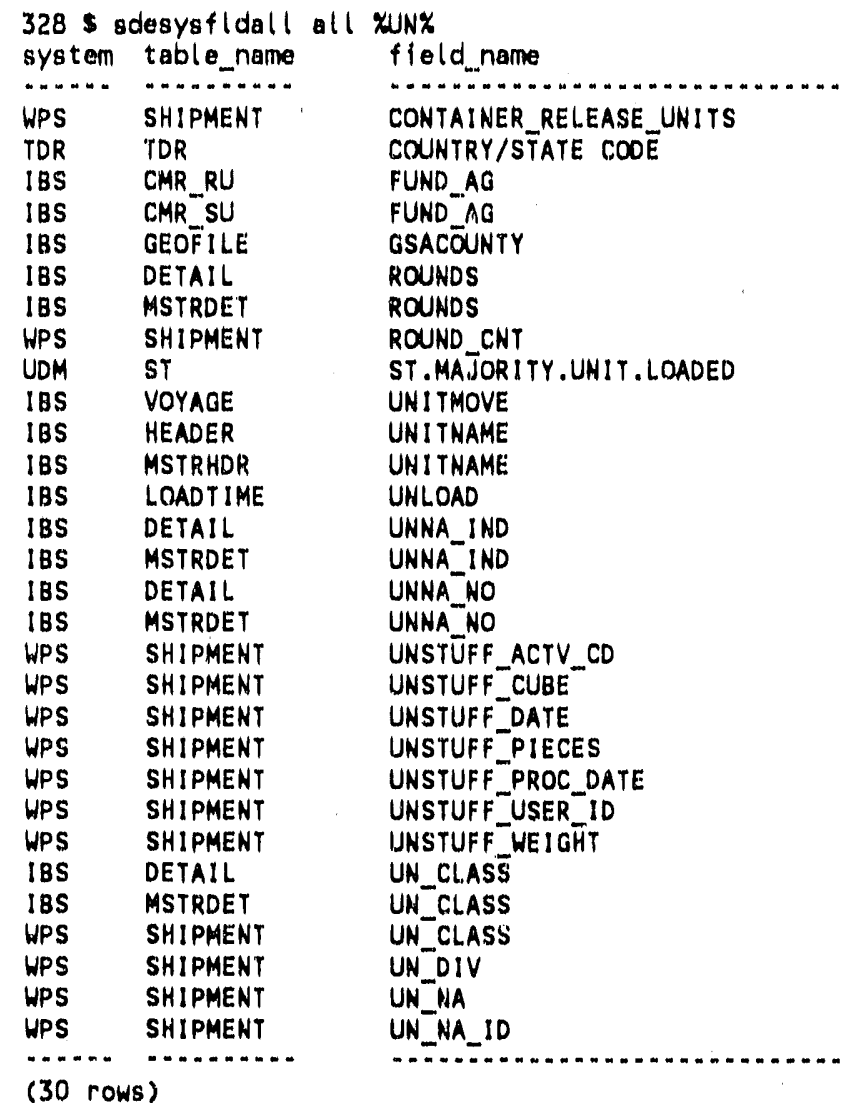

Notice in this output that two systems (IBS and UPS) have field named 'UN_CLASS'.

(5) In job $\$ 329$, the user wants to know more about how IBS and WPS each define the field IUN_CLASSI.

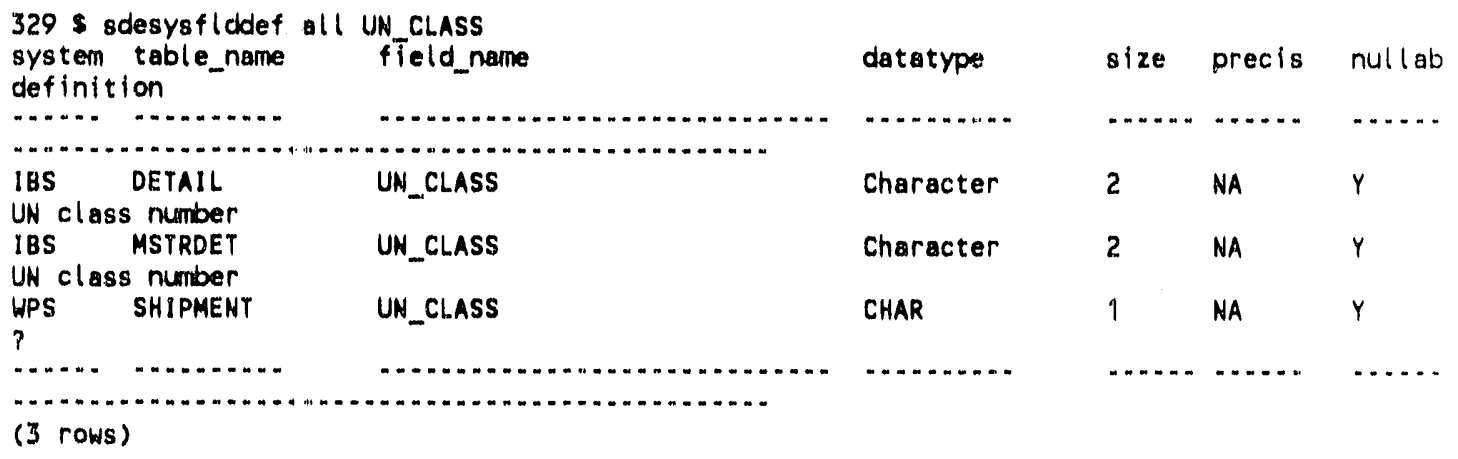


(6) In Job $\$ 330$, the definition of the proposed SDE field that relates to these system fields is displayed.

330 s sdeflddef un_class_division_code

SDE FIELD NAME: Un_class_division_code

DATA TYPE: ChaT LENGTH: $\overline{2}$

PRECISION: NA

UNITS: NA

DOMAIN: alphanumeric

DEFINITION: United Nations class and division numbers from the International Maritime Dangerous

Goods Code (IMDOC) 49 CFR 172.102. This code is part of the Unit Movement Data (UMD) detall from TC AIMS.

(7) In Job $\$ 331$, the user displays the definitions of all system flelds that are cross referenced to 'un_class_division_code'.

331 sodefldxref un_class_division_code

SDE FIELD NAME: Un_class_division_code

MAPS TO:

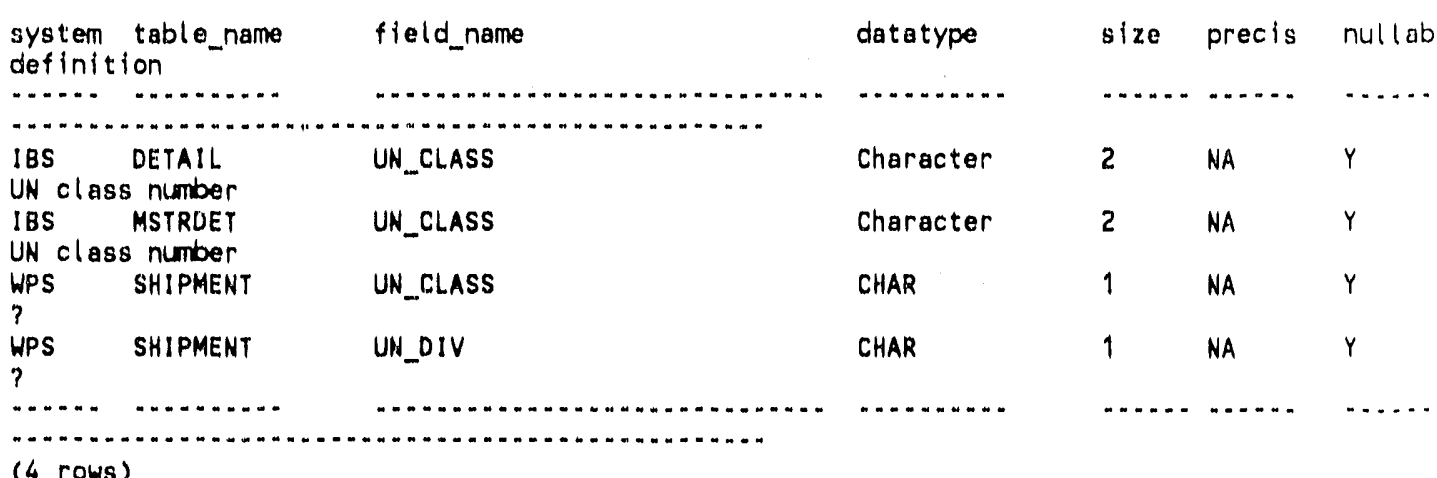

NOTE: In the mappings for the SDE field in the example above, IBS concatenates the codes for class and division into a single data element, whereas WPS splits these into two fields. Which design is "better" is debatable; since they enter the system (from the UMD) as one, and because there may be interrelated data quality issues (e.g., if CLASS $=x$, DIVISION can be $a, b$, or $c$, but not d), the SDE uses the composite form. Des/gners of the distributed database schema and/or interface messages will have to address this and similar discrepancies. 


\section{INTERNAL DISTRIBUTION}

$\begin{array}{ll}\text { 1. } & \text { H. G. Arnold } \\ \text { 2. } & \text { P. F. Daugherty } \\ \text { 3. } & \text { E. Z. Faby } \\ \text { 4. } & \text { P. S. Gillis } \\ \text { 5. } & \text { J. Hardee } \\ \text { 6. } & \text { R. D. Kraemer } \\ \text { 7. } & \text { M. A. Kuliasha } \\ \text { 8. } & \text { I. R. Moisson } \\ \text { 9. } & \text { D. E. Reichle } \\ \text { 10-14. } & \text { D. L. Russell }\end{array}$
15.
J. D. Shelton
16. R. B. Shelton
17. B. E. Tonn
18-20. L. F. Truett
21. T. G. Yow
22. Central Research Library
23. Document Reference Section
24-25. Laboratory Records
26. Laboratory Records - RC
27. ORNL Patent Office

\section{EXTERNAL DISTRIBUTYON}

28. Mr. Don Alvic, University of Tennessee, Transportation Center, 10512 Research Drive, Suite 200, Knoxville, TN 37932.

29. Dr. Bruce G. Buchanan, Department of Computer Science, University of Pittsburgh, 206 Mineral Industries Building, Pittsburgh, PA 15260.

30. Dr. Helen M. Ingram, Director, Udall Center for Studies in Public Policy, The University of Arizona, 803/811 East First Street, Tucson, Arizona 85719.

31. Mrs. Jean Heuer, MTWA-ITM, MTMC, Western Area, Division of International Traffic, Bldg. 1, Oakland Army Base, Oakland, CA 94626-5000.

32. Dr. Allan Hirsch, Vice President, Environmental Sciences and Director, Washington Operations, Midwest Research Institute, 5109 Leesburg Pike, Suite 414, Falls Church, VA 22041.

33. Mr. Kris Jerpe, MTE-ITM, MTMC, Eastern Area, Military Ocean Terminal, Bldg. 82, Rm. 249, Bayonne, NJ 07002.

34. Mr. Herb Kaskoff, MTITM, Headquarters, Military Traffic Management Command, 5611 Columbia Pike, Falls Church, VA 202241-5050.

35. Mr. Calvin D. MacCracken, President, Calmac Manufacturing Corporation, 101 West Sheffield Avenue, Englewood, NJ 07631.

36. Mr. Benjamin M. Plastina, MTMC, Eastern Area, Military Ocean Terminal, Bldg. 42, Fifth Floor, Bayonne, NJ 07002.

37. Mr. Bob Porter, MTITM, Headquarters, Military, Traffic Management Command, 5611 Columbia Pike, Falls Church, VA 202241-5050.

38. Ms. Jacqueline B. Shrago, Director, Office of Technology Transfer, 405 Kirkland Hall, Vanderbilt University, Nashville, TN 37240.

39. Ms. Vicki Wheeler, University of Tennessee, Transportation Center, 10512 Research Drive, Suite 200, Knoxville, TN 37932.

40. Dr. Martin Williams, Professor, Department of Economics, Northern Illinois University, DeKalb, IL 60115.

41. Office of Assist Manager for Energy Research and Development, DOE/ORO, P.O. Box 2001, Oak Ridge, TN 37831-8600.

42-43. Office of Scientific and Technical Information, U.S. Department of Energy, P.O. Box 62, Oak Ridge, TN 37831. 

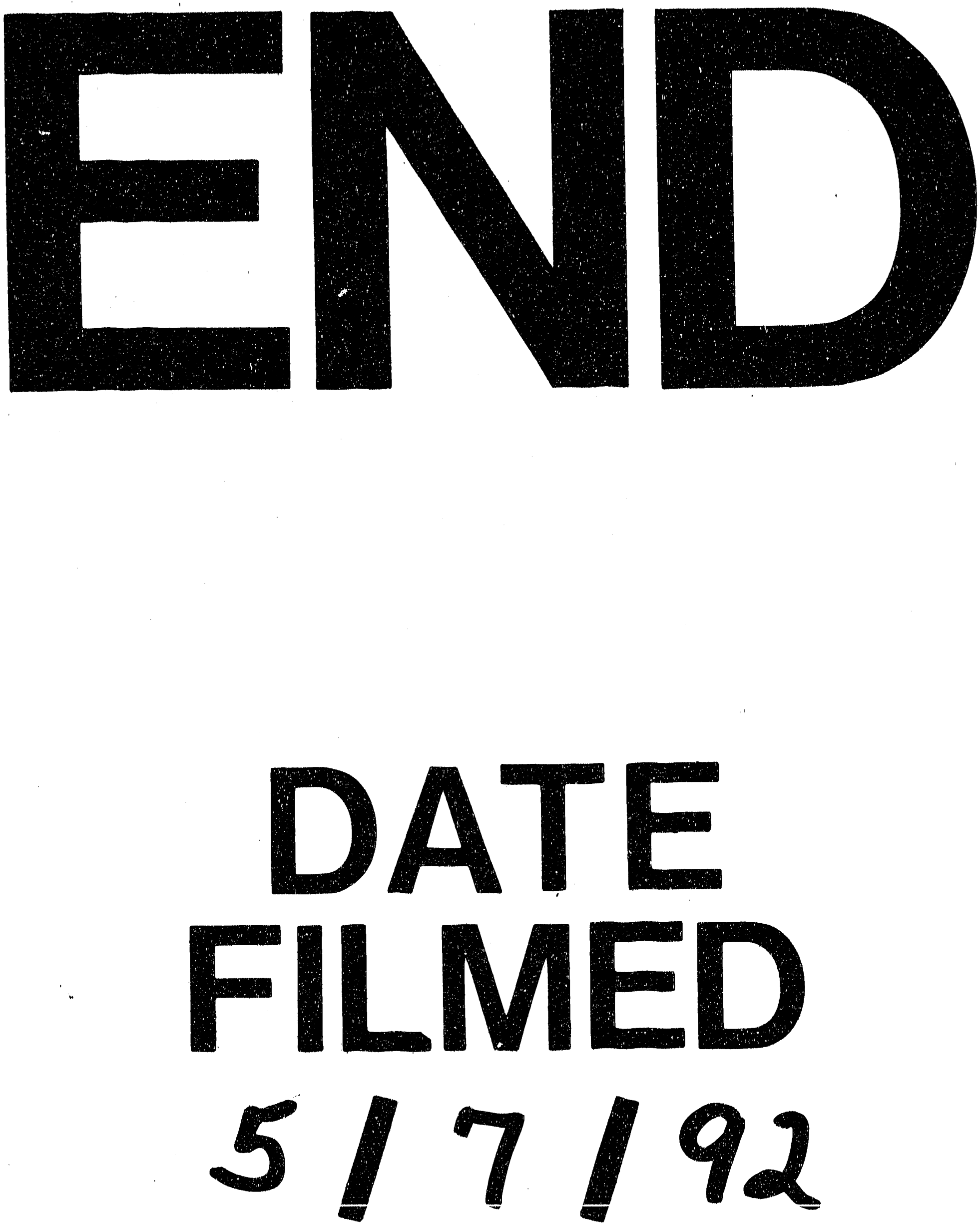
